\title{
Concentrations of organic contaminants in industrial and municipal bioresources recycled in agriculture in the UK
}

Article

Accepted Version

Creative Commons: Attribution-Noncommercial-No Derivative Works 4.0

Rigby, H., Dowding, A., Fernandes, A., Humphries, D., Jones, N. R., Lake, I., Petch, R. G., Reynolds, C. K. ORCID: https://orcid.org/0000-0002-4152-1190, Rose, M. and Smith, S. R. (2021) Concentrations of organic contaminants in industrial and municipal bioresources recycled in agriculture in the UK. Science of the Total Environment, 765. 142787. ISSN 0048-9697 doi: https://doi.org/10.1016/j.scitotenv.2020.142787 Available at https://centaur.reading.ac.uk/93962/

It is advisable to refer to the publisher's version if you intend to cite from the work. See Guidance on citing.

To link to this article DOI: http://dx.doi.org/10.1016/j.scitotenv.2020.142787

Publisher: Elsevier

All outputs in CentAUR are protected by Intellectual Property Rights law, including copyright law. Copyright and IPR is retained by the creators or other copyright holders. Terms and conditions for use of this material are defined in the End User Agreement. 


\section{CentAUR}

Central Archive at the University of Reading

Reading's research outputs online 


\section{Journal Pre-proof}

Concentrations of organic contaminants in industrial and municipal bioresources recycled in agriculture in the UK

Hannah Rigby, Alan Dowding, Alwyn Fernandes, David Humphries, Natalia R. Jones, Iain Lake, Rupert G. Petch, Christopher K. Reynolds, Martin Rose, Stephen R. Smith

Science of THE
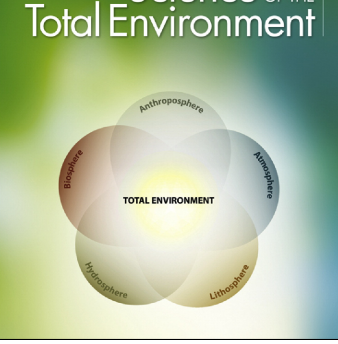

PII: $\quad$ S0048-9697(20)36316-6

DOI: $\quad$ https://doi.org/10.1016/j.scitotenv.2020.142787

Reference: $\quad$ STOTEN 142787

To appear in: $\quad$ Science of the Total Environment

Received date: $\quad 16$ October 2019

Revised date: $\quad 14$ August 2020

Accepted date: $\quad 30$ September 2020

Please cite this article as: H. Rigby, A. Dowding, A. Fernandes, et al., Concentrations of organic contaminants in industrial and municipal bioresources recycled in agriculture in the UK, Science of the Total Environment (2020), https://doi.org/10.1016/ j.scitotenv.2020.142787

This is a PDF file of an article that has undergone enhancements after acceptance, such as the addition of a cover page and metadata, and formatting for readability, but it is not yet the definitive version of record. This version will undergo additional copyediting, typesetting and review before it is published in its final form, but we are providing this version to give early visibility of the article. Please note that, during the production process, errors may be discovered which could affect the content, and all legal disclaimers that apply to the journal pertain.

(C) 2020 Published by Elsevier. 
Concentrations of organic contaminants in industrial and municipal bioresources recycled in agriculture in the UK

Hannah Rigby ${ }^{a}$, Alan Dowding ${ }^{b}$, Alwyn Fernandes ${ }^{c e}$, David Humphries ${ }^{d}$, Natalia R Jones ${ }^{e}$, lain Lake $^{\mathrm{e}}$, Rupert G. Petch ${ }^{\mathrm{c}}$, Christopher K. Reynolds ${ }^{d}$, Martin Rose ${ }^{c}$, Stephen R. Smith ${ }^{\mathrm{a} *}$

a Imperial College Consultants Ltd., 58 Prince's Gate, Exhibition Road, London SW7 2PG, UK

b Chemical Contaminants and Residues Branch, Food Safety Policy, Food Standards Agency, Clive House, 70 Petty France, London SW1H 9EX, UK

c The Food and Environment Research Agency (Fera), Sand Huttnn, Vork, YO41 1LZ, UK

d The University of Reading, School of Agriculture, Policy and Lovviopment, Centre for Dairy Research, POB 237, Reading, Berkshire, RG6 6AR, UK

e University of East Anglia, School of Environmental Scı ncf s, Norwich, NR4 7TJ, UK

* Author to whom correspondence should be add e_so d; E-Mail: s.r.smith@imperial.ac.uk; Tel.: +44 (0) 2075946051

Abstract: Many types of bioresource $\mathrm{ma}^{+} \_$riaı are recycled in agriculture for soil improvement and as bedding materials for livestock and hí.ve nutential for transfer into plant and animal foods.

Representative types of industrial $a_{1} .1$ municipal bioresources were selected to assess the extent of organic chemical contamination (biosolids), meat and bone, 'eai ash (MBMA), poultry litter ash (PLA), paper sludge ash (PSA) and compost-like-output (CLO), and (ii) bedding materials: recycled waste wood (RWW), dried paper sludge (DPS), paper sludge ash (PSA) and shredded cardboard.

The materials generally contained lower concentrations of polychlorinated dibenzo- $p$ dioxins/dibenzofurans (PCDD/Fs) and dioxin-like polychlorinated biphenyls (PCBs) relative to earlier reports, indicating the decline in environmental emissions of these established contaminants. However, concentrations of polycyclic aromatic hydrocarbons (PAHs) remain elevated in biosolids samples from urban catchments. Polybrominated dibenzo-p-dioxins/dibenzofurans (PBDD/Fs) were present in larger amounts in biosolids and CLO compared to their chlorinated counterparts and hence are of potentially greater significance in contemporary materials. The presence of non-ortho- 
polychlorinated biphenyls (PCBs) in DPS was probably due to non-legacy sources of PCBs in paper production. Emerging flame retardant compounds, including: decabromodiphenylethane (DBDPE) and organophosphate flame retardants (OPFRs), were detected in several of the materials. The profile of perfluoroalkyl substances (PFAS) depended on the type of waste category; perfluoroundecanoic acid (PFUnDA) was the most significant PFAS for DPS, whereas perfluorooctane sulfonate (PFOS) was dominant in biosolids and CLO. The concentrations of polychlorinated alkanes (PCAs) and di-2-ethylhexyl phthalate (DEHP) were generally much larger than the other contaminants measured, indicating that there are major anthropogenic sources of these potentially hazardous chemicals entering the environment. $T r_{1}$ study results suggest that continued vigilance is required to control emissions and sources 0 ; th'; se contaminants to support the beneficial use of secondary bioresource materials.

Keywords: ash; biosolids; compost-like-output; flame retaru गnts, livestock bedding; persistent organic pollutants; waste

\section{Introduction}

The practice of recycling industrial an $x$ micipal bioresources in agriculture has the benefits of reducing waste disposal in landfill or : $v$ incineration, recovery and reuse of resources and improving the economics of food production i $\mathrm{r} r \mathrm{t}$ en Alliance, 2007). For example, 78\% of the 1.14 million tonnes dry solids (DS) of bio ollis (treated sewage sludge) produced in the UK is beneficially used on farmland (Eurostat, 2015). In ' 'e UK, land application of biosolids is carried out in accordance with the Sludge (Use in Agriculture) Regulations (SI, 1989), and various official guidance and codes of practice (ADAS, 2001; SEPA, 2015; Defra and EA, 2018), which, amongst other measures, provide limits for potentially toxic elements (PTEs).

Additionally, outputs from certain biowaste combustion processes are commonly recycled as soil amendments. These include: meat and bonemeal ash (MBMA) and poultry litter ash (PLA), for phosphorus $(\mathrm{P})$ and potassium $(\mathrm{K})$ fertiliser replacement, and paper sludge ash (PSA), used as a liming agent. The Quality Protocol for the production and use of PLA in agriculture in the UK (WRAP, 2012a) includes limits for acceptable levels of contaminants, including PTEs and dioxins. The use of other biomass ashes in agriculture such as MBMA and PSA is controlled by the Environmental 
Permitting Regulations in England and Wales (SI, 2016), which permits the spreading of certain wastes on land.

Paper sludge ash may also be added into livestock bedding material as a desiccant and to reduce dust (EA, 2008). Other recycled materials used as livestock bedding include: kiln-dried paper sludge (DPS) from paper manufacturing, shredded cardboard and recycled untreated waste wood (RWW). These materials are marketed as alternatives to conventional bedding materials, such as straw, sand or virgin wood shavings. Recycled bedding materials were included in the study due to potential for incidental ingestion by livestock. Waste wood is divided into four grades depending on quality (Defra, 2012). Grade A waste wood should be untreated and can potentially io used in higher value markets such as a livestock bedding. However, since current detection anc $\varsigma_{0}$, Jaration practices in the wood recycling industry are based on visual inspection, and treateı wuid cannot always be detected visually, contaminants could potentially be present in an : npa ently untreated wood sample (WRAP, 2012b).

Mechanical biological treatment of commerrial, . ndustrial, and particularly for municipal solid waste (MSW) is expanding, and the stabilised residua compost-like-output (CLO), is potentially useful as a soil conditioner (Carbonell et al., 2011). C. irru ntly, CLO application in the UK is limited to use as a cover for landfills (Defra, 2013). The r y ' 'liciury position does not permit CLO use on agricultural land due to the potential presence of ph, sicar contaminants, such as glass, plastic and metal, as well as chemical contaminants. Howeve, , C,O is used in agriculture in other countries, and this may be

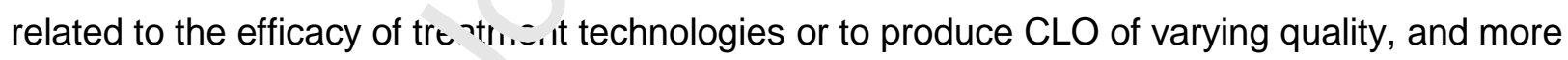
flexible control of the material depending on the demand and necessity for soil improving materials in regions of poor soil organic matter status (Stretton-Maycock and Merrington, 2009).

Organic compounds with important operational properties, but which are persistent and bioaccumulative, potentially represent a threat to human health and are found in environmental media, wastes and food (Semple et al., 2001; Smith and Riddell-Black, 2007; Smith, 2009). The consumption of animal food products is one of the major pathways of exposure to environmental sources of organic chemicals by the general population. This is due to the lipophilic nature of many organic compounds and the associated propensity to accumulate in fatty animal tissue and dairy products (EFSA, 2012). For these reasons, persistent organic contaminants present in bioresources 
recycled in agriculture could represent a potential risk to the human food chain if they were to transfer to food products (Amlinger et al., 2004; Smith and Riddell-Black, 2007; Smith, 2009; Clarke and Smith, 2011; Fernandes et al., 2019). Furthermore, developments in chemical manufacturing and analytical techniques mean that emerging contaminants are also being identified in materials that are considered to be well characterised chemically, such as compost and biosolids (Nicholson et al., 2016).

There are multiple groups of organic contaminants that demonstrate persistence, and the potential for bioaccumulation and toxicity, that may be candidates for investigation in terms of the potential content and transfer to the food chain from industrial and municipal wi resources. These include:

- Polychlorinated dibenzo-p-dioxins/dibenzofurans (PCDD/Fs) - $\epsilon^{-t+.}$. $l i s h e d$ organic contaminants that can form de novo during incomplete thermal combuction , rocesses and also as unintentional chemical by-products, for example, in commercial p€. tact orophenol (PCP) formulations (Ryan, 1983; Zhang et al., 2016). These and other dioxi' '-1' compounds bind to the aryl hydrocarbon (Ah) receptor leading to a range of harmful afte.ts including carcinogenicity, teratogenicity, immunotoxicity and embryotoxicity (Zacs $e_{\iota}$ э/., 2016).

- Dioxin-like polychlorinated biphenyls (nCLs): widely used in paint and dielectric fluid and similar products until their use was restric $t^{2}$ in the 1970s (Smith, 2009).

- Polybrominated dibenzo-p-dioxı . a and dibenzofurans (PBDD/Fs) and polybrominated biphenyls (PBBs): related compounde tc $\triangle \mathrm{JDD} / \mathrm{Fs}$ and PCBs, thought to have similar physicochemical properties and toxicity ('irriudum et al. 2003; Zacs et al., 2016). Having more recently emerged as a contaminant of concern, comparatively little is known about their abundance in the environment or their risk to human health, and they are not typically included in risk assessments (Fernandes et al., 2008a; 2009a). PBDD/Fs form unintentionally during the manufacture of commercial brominated flame retardants (BFRs). They are also produced during combustion processes in the presence of bromine containing compounds such as polybrominated diphenyl ethers (PBDEs) (Ren et al., 2011; Zacs et al., 2016).

- Mixed halogenated dibenzo-p-dioxins and dibenzofurans (PXDD/Fs) and mixed halogenated biphenyls (PXBs): may be formed via the utilisation, processing and combustion of electrical 
equipment and components that contain halogenated substances such as polyvinyl chloride and BFRs (Zacs et al., 2016).

- Polychlorinated napthalenes (PCNs) also have dioxin-like toxicity (Fernandes et al., 2017). Commercial production and use in applications such as dielectric fluids, engine oil additives and lubricants, was extensive between the 1930s and 1980s, but has since ceased or been prohibited; de novo formation of PCNs can also occur by combustion (Fernandes et al., 2017; Smith and Riddell-Black, 2007).

- Polycyclic aromatic hydrocarbons (PAHs) are established organic contaminants that arise through incomplete combustion (Hansen et al., 2017) and also as impurilt ? in wood preservatives such as creosote (Davou, 2014).

- Perfluoroalkyl compounds (PFASs): produced since the $94 \mathrm{us}$ and used in applications such as non-stick cookware, stain-resistant textiles, coatings $\iota$ ? fo sd packaging, components of firefighting foam, metal plating, hydraulic fluids and su iactants (Buck et al., 2011). These compounds are widely distributed in soil, water and for : ' $Q_{1} \cdot \cap$ et al., 2019) and, unlike other persistent organic contaminants, are sufficiently solubs in water to be taken up by crops (Ghisi et al., 2019). Perfluorooctane sulphonate (PFOS) rこ๙wien listed as a persistent organic pollutant (POP) under the Stockholm Convention (UN, 2'u!) sınce 2009 and controls will apply for perfluorooctanoic acid (PFOA) from 2020 (EP, 20 7). In 2019, perfluorohexane sulfonic acid (PFHxS) was also recommended for inclusion in.$^{\wedge}$, nex A of the Stockholm Convention (UN, 2019). Four PFASs, (PFOA, PFNA, PFHxS ana - FOS) are being considered by the EC for introduction into the regulatory framework on tood contaminants (EFSA, 2020). These four compounds show toxicokinetically similar effects in humans and test animals, with relatively long half-lives and similar potential for bio-accumulation. They also contribute most to the cumulative levels of measured PFASs that occur in human serum.

- BFRs: PBDEs, hexabromocyclododecanes (HBCDDs) and tetrabromobisphenol A (TBBPA) have been widely used for fire protection of products such as soft furnishings, building insulation foam, electronics, polymers, paints and plastic products (Ren et al., 2011; Garcia Lopez et al., 2018; Ganci et al., 2019), but their use has been banned or restricted in recent years (EC, 2003a). A 
number of alternative BFRs have also been developed, including 1,2-bis(2,4,6tribromophenoxy)ethane (BTBPE), hexabromobenzene (HBB) (Ganci et al., 2019).

- $\quad$ Organophosphate flame retardants (OPFRs): such as tris(phenyl) phosphate (TPHP), tris-(2chloroisopropyl) phosphate (TCIPP) and tris-(2,3-dichloropropyl)-phosphate (TDCPP) (Eulaers et al., 2014) have also increased in use.

- Phthalates, including di(2-ethylhexyl)phthalate (DEHP): used as plasticisers.

- Polychlorinated alkanes (PCAs, also known as chlorinated paraffins (CPs)):used as plasticisers, flame-retardants, lubricants and paint additives.

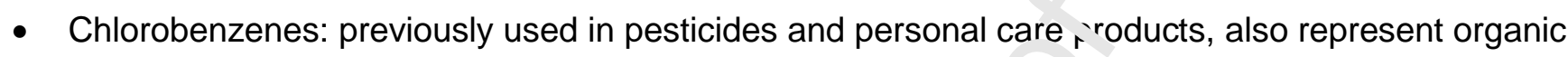
pollutants of potential significance to the food chain from the $x_{1}:$ ultural use of industrial and municipal bioresources (Kupper et al., 2008; Clarke and 'imıı, 2011).

The aim of the research reported here was to develop : df a ailed profile of the organic contamination of different major categories of indust ı' and municipal bioresources used in agriculture. This information is necessary to $b r_{.} \cdot h_{1}$. . $r k$ and compare contaminant concentrations in various bioresources and to contribute to the $d t$ 'elopment of appropriate quality standards for industrial and municipal recycled bioreso'.. ' es used in agriculture. This research will help inform policies to mitigate the risks from con'dr. inants entering the agricultural environment and the food chain via recycling of various biores ' Irces. It will assist producers of industrial or municipal bioresources to identify and minir, : 乞 sources of contamination and provide chemical quality data for risk assessment and quality ?Sourance purposes. This research was achieved by: (1) identifying and sampling materials representative of the different categories of bioresource products currently used in agriculture in the UK; (2) conducting targeted gas chromatography-mass spectrometry (GC-MS) and liquid chromatography-mass spectrometry (LC-MS), and non-targeted gas chromatography-time of flight-mass spectrometry (GC-ToF-MS) to quantify the concentrations of contaminants present in the materials that are important to human health; and (3) comparing the results against published data to assess patterns and trends in contaminant profiles, for example, in relation to the implementation of source control measures.

\section{Materials and Methods}




\subsection{Selection, Collection and Sampling of Industrial and Municipal Bioresources}

A total of 22 samples of eight representative types of bioresources were collected for investigation. These included land applied materials: biosolids (anaerobically digested sewage sludge) ( $n=3)$, CLO $(n=2)$, MBMA $(n=3)$ and PLA $(n=3)$. A range of representative bioresources used as livestock bedding were also sourced: RWW ( $n=5)$, DPS from paper manufacturing $(n=3$, N.B. samples were collected from the same manufacturer), and cardboard $(n=1)$. Paper sludge ash $(n=1)$ was also collected, which is used both for soil application as a liming agent and as a desiccant in livestock bedding. Details of the bioresources selected are provided in Table S1 (see Section 1.1 of the Supplementary Information). The materials were collected or delivered by the prodliv $\rightarrow r$ in sealed drums and stored in a cool, dry storage shed.

Biosolids1 and Biosolids2 were collected from two of the I tryiz wastewater treatment plants (WwTPs) in the UK accepting combined sewage flows fr: $n d$ mestic and industrial inputs from significant urban populations; these sources were se'.. ted as they potentially represented the upper range of biosolids chemical contamination. Biocnli'`3 was delivered by the operator and was from a WwTP receiving no commercial wastewater. I, a CLOs were selected as examples of the most highly refined materials currently in the UK and, whin:t not recycled to farmland land, they represented materials with the greatest potential fc. 'fitu. 2 use in agriculture. Representative composite subsamples of approximately $3 \mathrm{~kg}:$ esh weight (FW) of Biosolids1 and Biosolids2 and the two CLOs were collected at the production site ; and sub-samples of the remaining materials were taken shortly after delivery. The sub-sar., $\eta_{t}:$ :except for the RWWs) were collected in $1 \mathrm{~L}$ food-grade polypropylene containers lined with dichloromethane (DCM) - swabbed aluminium foil. The RWWs were collected in $5 \mathrm{~L}$ polypropylene containers, also lined with DCM-swabbed foil. Additional subsamples of biosolids and CLO were provided for DEHP analysis; approximately $1 \mathrm{~kg}$ of each material was collected in glass Duran bottles, prepared by heating in a muffle furnace at $400^{\circ} \mathrm{C}$ for 4 hours, and DCM - swabbed foil was placed between the bottle and the lid. All sub-samples were delivered by overnight courier to the accredited analytical laboratory at the Food and Environment Research Agency (Fera), York, in cool boxes with ice-packs. The laboratory undertakes rigorous quality control and is a national centre of excellence for this; this shows that the DCM used for cleaning foil is clear 
of contamination and that the procedure is effective in minimising contamination, which is also demonstrated through the reagent and process blank analysis.

On receipt at Fera, biosolids and CLO were frozen prior to analysis, and dry bioresources (RWWs, ash, DPS, cardboard) were stored away from direct lighting. The dry bioresources were analysed as received from the suppliers, and biosolids and CLO were dried at ambient temperature $\left(18-20^{\circ} \mathrm{C}\right)$, on DCM cleaned foil lined tray to constant weight. Shredded cardboard, RWW and CLO were homogenised in a centrifugal mill to reduce the particle size. The bioresources were all thoroughly mixed prior to analysis.

The general physicochemical properties and inorganic contamináı. ${ }^{+}$characteristics of a selection of the bioresources are described by Rigby et al. (2015).

\subsection{Rationale for Selection of Contaminants and Methods $n f$ r. nalysis}

The bioresources were analysed for a range of priority $e_{-}$ablished and emerging organic compounds. Consideration was given to the contam. ${ }^{n}$ in $s$ likely to be found in the different bioresources and that are important to food $r$ sali y arıd human health. For example, historically, $\mathrm{PCDD} / \mathrm{Fs}$ and PAHs were significant cont?minants of wood preservatives, whereas flame retardant chemicals are used for contemporary we or, ‘ zatment. PCDD/Fs and PAHs are known to occur in combustion ash products (MBMA, PL 1 and PSA). Flame retardants and other halogenated chemicals are ubiquitous in the built and genc “al environment (Cunha, 2010; D’Hollander et al., 2010), therefore, brominated chemicals and th $\mathrm{ir}$ i 'erivatives (e.g. PBDD/Fs), PFASs and PXDD/Fs were expected to be extensively represented in nany examples of the recycled bioresources examined. In particular, all of the categories of organic contaminants tested were anticipated in the biosolids and CLO samples since these were from combined domestic/commercial wastewater flows and mixed sources of MSW. The following contaminant groups were analysed using validated and accredited methodologies:

- Polychlorinated dibenzo-p-dioxins/dibenzofurans (PCDD/Fs) and polychlorinated biphenyls (PCBs) (Fernandes et al., 2004; 2008a);

- Polybrominated dibenzo-p-dioxins/dibenzofurans (PBDD/Fs) and polybrominated biphenyls (PBBs) (Fernandes et al., 2004; 2008a);

- Mixed halogenated dibenzo-p-dioxins/dibenzofurans (PXDD/Fs) and mixed halogenated biphenyls (PXBs) (Fernandes et al., 2011); 
- Polybrominated diphenyl ethers (PBDEs) (Fernandes et al., 2004; 2008a);

- Polychlorinated naphthalenes PCNs (Fernandes et al., 2010a);

- Hexabromocyclododecane (HBCDD), tetrabromobipshenol A (TBBPA) and pentabromocyclododecene (PBCD) (Driffield et al., 2008; Fernandes et al., 2012; GarciaLopez et al., 2018);

- Polycyclic aromatic hydrocarbons (PAHs) (Rose et al., 2007);

- Perfluoroalkyl substances (PFAS) (Lloyd et al., 2009; Clarke et al., 2010);

- Polychlorinated alkanes (PCAs) (Fernandes et al., 2008b; EFSA CONTAM, 2018b);

- Chlorobenzenes (CBs) (Fernandes et al., 2019a);

- Phthalates (Fernandes et al., 2009b);

Following a gas chromatography-time of flight-mass spectroı. 'etry (GC-ToF-MS) screen of the waste samples, a number of additional compounds were identifı $\mathrm{f} f \mathrm{\nu}$ targeted analysis, including:

- Hexabromobenzene (HBB), 1,2 bis(2,4,6-trik ' 0 n phenoxy) ethane (BTBPE), and decabromodiphenylethane (DBDPE) ( ${ }^{r} \cdot e_{1}$ רar, ${ }^{\top}$ es et al., 2010b);

- Organophosphate flame retardants (OPF, ?s).

The methods of analysis for each of te centaminant groups are described in detail in the Supplementary Information. This i'sc , provides details of the quality assurance procedures that were routinely used during the ana'yo 's, including the use and evaluation of procedural blanks, analytical recoveries, limits of quantification, reference materials, and proficiency testing. Values in the tables in Section S.2.2 (Supplementary information) may occasionally be marked as indicative, due to low recovery, incorrect ion ratios or unresolved peaks. All the values reported are upper bound concentrations, except where indicated. Upper bound values were used to calculate sum calculations.

\section{Results and Discussion}

\subsection{Dioxins and Dioxin-like Contaminants}

\subsubsection{Polychlorinated dibenzo-p-dioxins and dibenzofurans}


The PCDD/F $\sum \mathrm{WHO}_{2005}$-TEQ in the samples was $0.12-83.1 \mathrm{ng} \mathrm{kg}^{-1} \mathrm{DS}$ (Table 1), with the smallest value measured in PSA and the largest in MBMA1. The $\Sigma \mathrm{WHO}_{2005}-\mathrm{TEQ}$ for PCDD/Fs in biosolids were similar and in the range $8.7-12.4 \mathrm{ng} \mathrm{kg}^{-1} \mathrm{DS}$ (Table 1). This was consistent with the findings of Clarke et al. (2008a) who reported a mean $\sum \mathrm{WHO}_{2005}$-TEQ of $4 \mathrm{ng} \mathrm{kg}^{-1} \mathrm{DS}$ (range $0.9-12.7 \mathrm{ng} \mathrm{kg}^{-1}$ DS) for sewage sludge samples from 14 Australian WwTPs. The slightly lower value measured in Biosolids3 of $8.7 \mathrm{ng} \mathrm{kg}^{-1}$ DS may reflect that this material was sourced from a WwTP serving a rural area in comparison to Biosolids1 and Biosolids2, collected from highly urban areas (Table S1, Supplementary Information), a pattern also observed by Clarke et al. (2008a).

The $\sum \mathrm{WHO}_{2005}$-TEQs for CLO1 and CLO2 were 18.2 and $11.2 \mathrm{ng} \cdot \mathrm{i}^{-1} \mathrm{DS}$, respectively, similar to the overall TEQs measured in the biosolids. The PCDD/F concent, sti, nns in the biosolids and CLOs were generally significantly lower than European limit values ari' sroposed limits for these compounds in biosolids and compost (EC, 2003b; Savey: anı Eder, 2014). For example, the

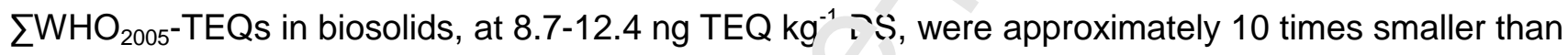
an early proposal for an EC limit on PCDD/Fs in bi solids of $100 \mathrm{ng}$ TEQ $\mathrm{kg}^{-1}$ DS (EC, 2003b), subsequently withdrawn. The values were alsc :maller than an Austrian limit value for compost of 20 ng TEQ kg-1 DS, and a proposed European $\mathrm{L}^{-1} \mathrm{~d}$ of Waste Criteria limit value for digestate and compost of $30 \mathrm{ng} \mathrm{TEQ} \mathrm{kg}{ }^{-1}$ DS (Save „ „ эrı Eder, 2014). The CLOs analysed by Saveyn and Eder (2014) in a European survey had s. 'aller TEQs equivalent to 3.0-5.5 ng -TEQ kg ${ }^{-1}$ DS, indicating that it is possible to produce CLO witı. sr ıaller contaminant concentrations.

Dioxin-like PCBs are dis ฯı:こd separately in Sections 3.1.2 and 3.1.3, however, overall, the $\Sigma \mathrm{WHO}_{2005}$-TEQ values for HUDD/Fs and dioxin-like PCBs was 9.5-14.4 $\mathrm{ng}$ TEQ kg ${ }^{-1}$ DS for the biosolids, $19.0 \mathrm{ng}$ TEQ $\mathrm{kg}^{-1}$ DS for CLO1 and $12.1 \mathrm{ng}$ TEQ $\mathrm{kg}^{-1}$ DS for CLO2. Similar values were reported by Brambilla et al. (2016) for 54 biosolids spread to land across the Veneto region of Italy, which contained a mean PCDD/F and dioxin-like PCB concentration of $15.8 \mathrm{ng}$ TEQ kg ${ }^{-1}$ DS (range 0.56-112.8 $\mathrm{ng}$ TEQ kg $\left.{ }^{-1} \mathrm{DS}\right)$. Similar, if slightly lower, $\Sigma \mathrm{WHO}_{2005}-\mathrm{TEQ}$ values for PCDD/Fs and dioxinlike PCBs were also reported by Clarke et al. (2008a) in their survey of 14 Australian sludge samples, with a mean value of 5.6 (range 1.2-15.3 $\mathrm{ng} \mathrm{TEQ} \mathrm{kg}^{-1} \mathrm{DS}$ ). However, the values measured here in 
Journal Pre-proof

Table 1 Toxic equivalencies (TEQs) and estimated TEQs for dioxins, dioxin-like biphenyls and PCNs in municipal and industrial bioresources (for each compound group, the proportion (\%) of the overall estimated TEQ is shown in parentheses)

\begin{tabular}{|c|c|c|c|c|c|c|c|c|c|c|c|}
\hline & $\mathrm{PCDD} / \mathrm{Fs}^{\mathrm{a}}$ & PBDD/Fs ${ }^{b}$ & PXDD/Fs ${ }^{c}$ & $\begin{array}{l}\text { Non ortho- } \\
\text { PCBs }^{a}\end{array}$ & Ortho-PCBs ${ }^{a}$ & $\begin{array}{c}\text { Non ortho- } \\
\text { PBBs }^{b}\end{array}$ & $\mathrm{PXBs}^{\mathrm{c}}$ & $\mathrm{PCNs}^{\mathrm{d}}$ & $\begin{array}{l}\Sigma P C D D / F s \\
\text { and dioxin- } \\
\text { like PCBs }\end{array}$ & $\begin{array}{l}\Sigma P B D D / F s \\
\text { and dioxin- } \\
\text { like PBBs }\end{array}$ & $\Sigma$ TEQ $^{\mathrm{f}}$ \\
\hline \multicolumn{12}{|c|}{ ng TEQ kg $^{-1}$ DS } \\
\hline Biosolids1 & $10.5(20.0)$ & $40.3(76.8)$ & $0.2(0.4)$ & $1.1(2.0)$ & $0.11(0.2)$ & $0.02(0.04)$ & $0.02(0.04)$ & $0.3(0.5)$ & $11.7(22.2)$ & $40.3(77.2)$ & 52.5 \\
\hline Biosolids2 & $12.4(13.3)$ & $77.9(83.8)$ & $0.3(0.3)$ & $1.7(1.8)$ & $0.3(0.3)$ & $0.02(0.02)$ & $0.02(0.02)$ & $0.4(0.4)$ & $14.4(15.4)$ & $77.9(83.8)$ & 92.9 \\
\hline Biosolids3 & $8.7(14.5)$ & $49.9(83.4)$ & $0.3(0.5)$ & $0.7(1.2)$ & $0.07(0.1)$ & $0.02(0.03)$ & $0.02(0.02)$ & $0.2(0.4)$ & $9.5(15.8)$ & $49.9(83.8)$ & 59.9 \\
\hline CLO1 & $18.2(34.7)$ & $32.2(61.4)$ & $0.2(0.3)$ & $0.7(1.4)$ & $0.09(0.2)$ & $0.04(0.08)$ & $0.01(0.02)$ & $1.0(2.0)$ & $19.0(36.2)$ & $32.2(61.5)$ & 52.5 \\
\hline CLO2 & $11.2(36.5)$ & $18.0(58.6)$ & $0.3(0.9)$ & $0.8(2.5)$ & $0.09(0.3)$ & $0.04(0.1)$ & $0.02(0.17)$ & $0.3(0.9)$ & $12.1(39.3)$ & $18.0(58.7)$ & 30.7 \\
\hline MBMA1 & $83.1(97.0)$ & $0.3(0.3)$ & $0.6(0.7)$ & $1.7(2.0)$ & $<0.001 \quad(<0.001)$ & $0.01(0.01)$ & (..( $3(0) 3)$ & $0.02(0.02)$ & $84.8(99.0)$ & $0.26(0.3)$ & 85.7 \\
\hline MBMA2 & $7.4(90.9)$ & $0.3(3.1)$ & $0.2(2.9)$ & $0.08(1.0)$ & $<0.001(<0.01)$ & $0.01(0.1)$ & ¿ $01(0.1)$ & $0.2(1.9)$ & 7.5 (91.9) & $0.3(3.2)$ & 8.2 \\
\hline MBMA3 & $8.2(86.7)$ & $0.5(4.7)$ & $0.5(5.2)$ & $0.3(3.1)$ & $<0.01(<0.1)$ & $0.0 n \cap(r .0<$, & $\begin{array}{c}0.003 \\
(0.005)\end{array}$ & $0.03(0.3)$ & $8.5(89.9)$ & $0.5(4.8)$ & 9.5 \\
\hline PLA1 & $0.9(57.8)$ & $0.4(23.5)$ & $0.2(13.3)$ & $0.06(3.8)$ & $<0.001$ (<0 r & $0 . n^{n}(0.2)$ & $0.01(0.8)$ & $0.008(0.5)$ & $1.0(61.7)$ & $0.4(23.7)$ & 1.6 \\
\hline PLA2 & $12.3(68.7)$ & $5.1(28.5)$ & $0.06(0.3)$ & $0.4(2.01)$ & $\left.<0.001(<0)^{1}\right)$ & $\therefore .01(0.06)$ & $0.01(0.07)$ & $0.06(0.3)$ & $12.7(70.7)$ & $5.1(28.6)$ & 17.9 \\
\hline PLA3 & 34.4 (93.9) & $0.2(0.5)$ & $1.1(2.9)$ & $1.0(2.7)$ & $<0.01$ '<0.0's, & $0.002(0.01)$ & $0.01(0.01)$ & $0.05(0.14)$ & $35.3(96.6)$ & $0.2(0.5)$ & 36.6 \\
\hline PSA & $0.12(30.1)$ & $0.09(22.6)$ & $0.1(25.1)$ & $0.03(7.5)$ & $<1.0 .1(=0.3)$ & $0.003(0.8)$ & $0.06(14.0)$ & $<0.04(<8.7)$ & $0.15(37.6)$ & $0.09(23.4)$ & 0.40 \\
\hline Virgin wood & $0.24(58.2)$ & $0.10(25.4)$ & $0.03(7.1)$ & 0.04 & $0.01(<2.5)$ & $0.002(0.5)$ & $\begin{array}{l}0.004 \\
(0.97)\end{array}$ & $<0.01(<1.6)$ & $0.27(58.3)$ & $0.11(25.9)$ & 0.41 \\
\hline RWW1 & $26.3(85.7)$ & $3.1(9.9)$ & $0.2(0.7)$ & $0 . \wedge(1 . . ?)$ & $0.08(0.3)$ & $0.004(0.01)$ & $0.03(0.08)$ & $0.6(2.1)$ & 26.8 (87.2) & $3.1(9.9)$ & 30.7 \\
\hline RWW2 & $14.8(90.6)$ & $0.9(5.3)$ & $0.2(1.2)$ & $0 . ?(12)$ & $0.04(0.2)$ & $0.01(0.06)$ & $0.02(0.1)$ & $0.2(1.3)$ & $15.0(92.0)$ & $0.87(5.3)$ & 16.3 \\
\hline RWW3 & $2.1(72.5)$ & $0.3(11.7)$ & $0.3(9.5)$ & $\therefore こ \vartheta(3.2)$ & $0.02(0.7)$ & $0.01(0.4)$ & $0.02(0.6)$ & $0.04(1.5)$ & $2.2(76.3)$ & $0.3(12.0)$ & 2.8 \\
\hline RWW4 & $1.3(61.9)$ & $0.5(24.2)$ & 0.08 (3.7, & $0.1(6.1)$ & $0.03(1.4)$ & $0.01(0.47)$ & $0.02(0.7)$ & $0.03(1.6)$ & $1.5(69.4)$ & $0.5(24.7)$ & 2.2 \\
\hline RWW5 & $0.2(47.9)$ & $0.08(25.8)$ & $0.03(9.0)$ & $0.05(14.8)$ & $<0.01(<3.2)$ & $0.002(0.6)$ & $0.02(0.6)$ & $0.006(1.9)$ & $0.20(65.9)$ & $0.09(26.4)$ & 0.3 \\
\hline Cardboard & $8.1(79.0)$ & $1.5(14.3)$ & $0.06(0.6)$ & $0.45(4.5)$ & $0.07(0.7)$ & $0.003(0.03)$ & $0.02(0.7)$ & $0.10(1.0)$ & $8.6(84.1)$ & $1.5(14.3)$ & 10.2 \\
\hline DPS1 & $6.1(56.2)$ & $2.5(22.8)$ & $0.1(1.0)$ & $1.9(17.0)$ & $0.1(1.1)$ & $0.02(0.2)$ & $0.06(0.6)$ & $0.1(1.1)$ & $8.1(74.3)$ & $2.5(23.0)$ & 10.9 \\
\hline DPS2 & $7.7(68.0)$ & $1.7(14.8)$ & $0.1(0.9)$ & $1.5(13.4)$ & $0.1(1.1)$ & $0.02(0.2)$ & $0.06(0.5)$ & $0.1(1.2)$ & $9.4(82.5)$ & $1.7(14.9)$ & 11.4 \\
\hline DPS3 & $7.4(68.7)$ & $1.6(14.7)$ & $0.04(0.3)$ & $1.4(12.8)$ & $0.2(2.0)$ & $0.002(0.02)$ & $\mathrm{e}$ & $0.2(1.5)$ & $8.9(83.5)$ & $1.6(14.7)$ & 10.7 \\
\hline
\end{tabular}

CLO, compost-like-output; MBMA, meat and bonemeal ash; PLA, poultry litter ash; PSA, paper sludge ash; RWW, recycled waste wood; DPS, dried paper sludge;

${ }^{\mathrm{a}} \mathrm{WHO}_{2005} \mathrm{TEQ}$; ${ }^{\mathrm{b}} \mathrm{WHO}_{1998}$-TEQ calculated assuming the same toxicity Toxic Equivalency Factor (TEF) values for Dioxin TEQ; ${ }^{\circ}$ Estimated TEQ calculated using relative

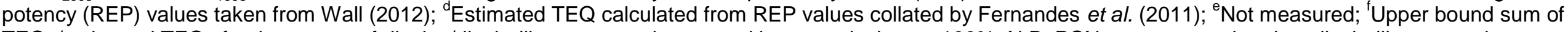
TEQs/estimated TEQs for the groups of dioxins/dioxin-like compounds reported here, equivalent to $100 \%$. N.B. PCNs are not regulated as dioxin-like contaminants,

however, EFSA (2004) and van den Berg et al. (2006) recommend including dioxin-like PCNs in the TEF system; <, indicates below the limit of quantification 
contemporary biosolids, particularly those collected from two major urban WwTP, were smaller than the mean TEQ value of $36.5 \mathrm{ng} \mathrm{kg}^{-1}$ DS attributable to PCDD/Fs and PCBs reported by Smith (2009) from a literature survey of organic contaminants in biosolids, suggesting a decline in PCDD/Fs and dioxin-like PCBs in the environment in general and in biosolids in particular.

The largest PCDD/F $\sum \mathrm{WHO}_{2005}$-TEQ value for the combustion residues was measured in MBMA1, at $83.1 \mathrm{ng} \mathrm{kg}^{-1}$ DS (Table 1). The $\mathrm{WHO}_{2005}$-TEQ for PLA3 was smaller at $34.4 \mathrm{ng} \mathrm{kg}^{-1} \mathrm{DS}$, but exceeded the maximum limit for PCDD/Fs stipulated in the UK PLA Quality Protocol of $20 \mathrm{ng}$ $\mathrm{WHO}_{2005}$-TEQ kg-1 DS (WRAP, 2012a). However, PLA2 was obtained from a different batch from the same supplier as PLA3 and, in this case, the $\mathrm{WHO}_{2005}-\mathrm{TEQ}$ was ar,- oximately 3 times smaller, at $12.3 \mathrm{ng} \mathrm{kg}^{-1} \mathrm{DS}$. This indicated that, as would be expected, the P :DC 'F concentration of PLA may vary, but that it is feasible to achieve the dioxin standard (the $r$ ' $\mathrm{Axi}$ ' num limit of $20 \mathrm{ng} \mathrm{WHO}_{2005}-\mathrm{TEQ}$ $\mathrm{kg}^{-1} \mathrm{DS}$ ) set by the End-of-Waste criteria for PLA. The co' 'ce. 'trations of PCDD/Fs in the other ash samples were relatively small and in the range: 0.12 (PSA) - $2.2 \mathrm{ng} \mathrm{kg}^{-1} \mathrm{DS}$ (MBMA3). The concentrations of PCDD/Fs in the combustion ash res:„ues of different biowaste materials measured here were generally similar to previous repoı - ' or example, bottom and fly ash from a poultry litter combustion plant (EA, 2012) contained 4.I ?nd $9.4 \mathrm{ng} \mathrm{WHO}_{2005}-\mathrm{TEQ} \mathrm{kg}^{-1} \mathrm{DS}$, respectively, and bottom ash from a paper sludge boiler ( $\mathrm{f}, \mathrm{f}, 008)$ had an TEQ of $0.51 \mathrm{ng} \mathrm{kg}^{-1} \mathrm{DS}\left(\mathrm{WHO}_{2005} \mathrm{TEQ}\right.$ not reported). The Waste Incineration T. ire $\iota^{+i v e}$ (EC, 2000b) and Integrated Pollution Prevention and Control Directive $(E C, 2010)$ set limı $\sim$ on atmospheric emissions of PCDD/Fs and other contaminants from waste incinerators, and hes 2 results demonstrate that well operated waste combustion processes prevent PCDD/F fr. mation leading to the presence of only small concentrations of $\mathrm{PCDD} / \mathrm{Fs}$ in the ash residues.

PCDD/Fs were also found in RWW, which is typical for wood treated with the preservative, PCP (Davou, 2014). RWW1 had the largest value, equivalent to $26.3 \mathrm{ng} \mathrm{WHO}_{2005}-\mathrm{TEQ} \mathrm{kg}{ }^{-1} \mathrm{DS}$, compared to the other RWW samples, which were in the range $0.15-14.8 \mathrm{ng} \mathrm{WHO}_{2005}-\mathrm{TEQ} \mathrm{kg}^{-1} \mathrm{DS}$ (Table 1). RWW1 was a Grade A recycled wood, and should be free of contaminated material, whereas RWW2 was a lower Grade C product, but had a smaller PCDD/F content (14.8 ng WHO $2005-\mathrm{TEQ} \mathrm{kg}^{-1} \mathrm{DS}$ ). These results therefore emphasised the difficulty in classifying the quality grading of RWW. The smallest PCDD/F WHO $\mathrm{WH}_{205}$-TEQ for RWW was $0.15 \mathrm{ng} \mathrm{kg}^{-1} \mathrm{DS}$ in RWW5, which was composed of 
waste virgin wood shavings and, consequently, had a similar $\mathrm{WHO}_{2005}-\mathrm{TEQ}$ to virgin wood of $0.24 \mathrm{ng}$ $\mathrm{kg}^{-1}$ DS (Table 1).

The TEQ of PCDD/Fs in cardboard was $8.06 \mathrm{ng} \mathrm{WHO}_{2005}{ }^{-T E Q ~} \mathrm{~kg}^{-1} \mathrm{DS}$, similar to DPS, where TEQs of 6.1-7.7 $\mathrm{ng} \mathrm{kg}^{-1} \mathrm{WHO}_{2005}$-TEQ DS were measured (Table 1), Three separate samples of kilndried paper sludge obtained from the same supplier had relatively consistent PCDD/F concentrations (Table S4, Supplementary Information). The findings indicated that cardboard and DPS were less relevant as sources of PCDD/Fs compared to RWW1 or MBMA1 for example.

OCDD and HpCDD were the most dominant dioxin congeners in the bioresources, particularly for the biosolids and CLO, which is a typical pattern observed for seway sludge and compost (Zennegg et al., 2013; Beníšek et al., 2015; Rodenburg et al., 2017) as well c c c sil and sediments. However, the most dominant OCDD/Fs and HpCDD/Fs have the lowecr oviall toxicities, compared to the other dioxin and furan congeners (Van den Berg et al., 2005). 'CD ) was found at concentrations of 1170 $\mathrm{ng} \mathrm{kg}^{-1}$ DS in Biosolids2 and up to $3300 \mathrm{ng} \mathrm{kg}^{-1}$ DS ir. ㄴ' LOO2 (Table S4, Supplementary Information). Biosolids2 contained $269 \mathrm{ng} \mathrm{kg}^{-1}$ DS of 1,2,3,4 $\bullet$ \%, २-HpCDD and, in CLO1, the concentration was $986 \mathrm{ng} \mathrm{kg}^{-1} \mathrm{DS}$. The OCDD concentrations obs 'rved in the specific biosolids samples were greater than the mean value of approximately $90 n \mathrm{ny}^{\mathrm{kg}^{-1}} \mathrm{DS}$ measured by Zennegg et al. (2013) in Swiss sewage sludge sampled in 2012, how . $3800 \mathrm{ng} \mathrm{kg}^{-1}$ DS found in 1993 (Ze. negy et al., 2013). In a survey of compost samples from European countries, Beníšek et c' ('2015) also found OCDD and 1,2,3,4,6,7,8-HpCDD were the most abundant congeners in CLר call. 8.7-99 $\mathrm{ng} \mathrm{kg}^{-1} \mathrm{DS}$, respectively, compared to those found in similar materials measured here. Should the ratio of $1,2,3,6,7,8-\mathrm{HxCDD} / 1,2,3,4,7,8-\mathrm{HxCDD}$ increase above 20 and the quota of 1,2,3,4,6,7,8$\mathrm{HpCDF}$, within the sum of the HpCDF, fall below 0.5 in sewage sludge, then it is likely that the banned wood preservative, PCP, is the dominant source of dioxins (Zennegg et al., 2013). For our data, the ratio of $1,2,3,6,7,8-\mathrm{HxCDD} / 1,2,3,4,7,8-\mathrm{HxCDD}$ was between 5.5-11.8 and the quota of $1,2,3,4,6,7,8-\mathrm{HpCDF}$ was between $0.9-1.0$, indicating that PCP was unlikely to be a significant source of dioxins to the biosolids. This was consistent with Zennegg et al. (2013) for more recent sewage sludge samples and reflects the impact of restrictions on the use and marketing of PCP, introduced in 1993, reducing emissions of dioxins and furans to the environment (SI, 1993). Amongst the PCDFs, 
those found in relatively higher concentrations were the related OCDF and 1,2,3,4,6,7,8-HpCDF congeners. However, industrially produced chemicals, such as p-chloranil, used as a fungicide or for synthesis of dioxazin-dyes used on textiles, can still represent a source of emissions of these furan congeners to wastewater and the environment (Zennegg et al., 2013).

OCDD was also the dominant congener in RWW and was present at concentrations between 1.39 $\mathrm{ng} \mathrm{kg}{ }^{-1}$ DS for RWW5 (the recycled virgin wood shavings) to an indicative concentration of $16,500 \mathrm{ng}$ $\mathrm{kg}^{-1}$ DS for RWW1 (Table S4, Supplementary Information). Additionally, 1,2,3,4,6,7,8-HpCDD was found at a concentration of $1190 \mathrm{ng} \mathrm{kg}^{-1} \mathrm{DS}$ in RWW1 and $608 \mathrm{ng} \mathrm{kg}^{-1} \mathrm{DS}$ in RWW2. Again, the PCDFs found in relatively high concentrations were the related congt ners, OCDF and 1,2,3,4,6,7,8HpCDF, at concentrations of 812 and $500 \mathrm{ng} \mathrm{kg}^{-1}$ DS in RWW1 ar. $\mathrm{F}$.NW2, respectively. The relatively high concentrations of OCDD and 1,2,3,4,6,7,8-Hp ;Lこ compared with $\mathrm{HxCDD}$, were indicative of PCP being the source of contamination in th: : ca ie (e.g. Zennegg et al., 2013).

\subsubsection{Dioxin-like non-ortho-polychlorinated biphen!/}

The upper bound $\sum \mathrm{WHO}_{2005}$-TEQ values r, ota nea for dioxin-like non-ortho-PCBs (PCBs 77, 81, 126 and 169) were in the range 0.03 (PS.^ - 1.7 (MBMA, Biosolids2) $\mathrm{ng} \mathrm{kg}^{-1} \mathrm{DS}$ (Table 1). For biosolids, the $\sum \mathrm{WHO}_{2005}$-TEQs were 1.1 1., and $0.7 \mathrm{ng} \mathrm{kg}^{-1} \mathrm{DS}$ for Biosolids1, Biosolids2 and Biosolids3, respectively (Table 1), ag, in ir,dicating that contamination with these PCB congeners was slightly reduced for Biosolids3 fror, the rural catchment area.

For the combustion residu' $\lrcorner$, he largest $\mathrm{WHO}_{2005}-\mathrm{TEQ}$ values for non-ortho-PCBs were observed for MBMA1 and PLA3, which , ontained 1.7 and $0.97 \mathrm{ng} \mathrm{kg}^{-1} \mathrm{DS}$, respectively, consistent with the higher values recorded for PCDD/Fs in these samples. In general, however, non-ortho-PCBs were present in ash materials in relatively small amounts in the range 0.03 (for PSA) -0.36 ng $\mathrm{WHO}_{2005^{-}}$ TEQ kg ${ }^{-1}$ DS (for PLA2) (Table 1).

The TEQ contribution from non-ortho-PCBs was relatively small for RWW compared to some of the other bioresources and in the range $0.05 \mathrm{ng} \mathrm{TEQ} \mathrm{kg}^{-1} \mathrm{DS}$ (for RWW5) to $0.38 \mathrm{ng}$ TEQ kg ${ }^{-1} \mathrm{DS}$ (for RWW1) (Table 1).

Interestingly, DPS1 had the largest upper bound $\mathrm{WHO}_{2005}$-TEQ value for non-ortho-PCBs relative to any other bioresource material examined, equivalent to $1.9 \mathrm{ng}$ TEQ $\mathrm{kg}^{-1} \mathrm{DS}$ (Table 1). The concentrations in DPS2 and DPS3 were similar, equivalent to 1.5 and $1.4 \mathrm{ng}$ TEQ kg-1 DS, 
respectively, which were also elevated above the majority of the other bioresources (except Biosolids2 and MBMA1). The most dominant congener was PCB 77, present at concentrations between 398-807 ng TEQ kg-1 DS (Table 1); next highest concentration of this congener was found in CLO1, at $264 \mathrm{ng} \mathrm{TEQ} \mathrm{kg}^{-1}$ DS. One of the many historic uses of PCBs was in the production of carbonless copy paper, however, PCBs may also be currently unintentionally generated by-products from the manufacture of certain pigments used in printing inks, for example (Grossman, 2013), which may explain their presence in DPS from recycled paper processing. Indeed, the results presented here are consistent with the reported detection of PCBs in magazine and newspaper samples, paints and pigments and wastewater from a paper recycling plant (Grossmia? 2013).

PCB 77 was also the congener present in the greatest concent, ntir, ns in biosolids, CLO and RWW from non-virgin sources. In biosolids the PCB 77 concentrat on ... as in the range $127-239 \mathrm{ng} \mathrm{kg}^{-1} \mathrm{DS}$ in biosolids and was 264 and $255 \mathrm{ng} \mathrm{kg}^{-1}$ DS in CLO1 $\mathrm{ar}^{\prime}{ }^{\prime} \mathrm{CL}$ )2, respectively, (Table S5, Supplementary Information) and the concentration ir ... n-virgin RWW was in the range 41-108 $\mathrm{ng} \mathrm{kg}$ ${ }^{1}$ DS (Table S5, Supplementary Information).

The $\mathrm{WHO}_{2005}$-TEQ kg-1 DS value for non-orı ${ }^{-1}$-PCBs in cardboard was $0.45 \mathrm{ng}$, 3-4 times smaller than in DPS, and was also less comparen to :-iosolids and CLOs, but the $\mathrm{WHO}_{2005}-\mathrm{TEQ} \mathrm{kg}^{-1} \mathrm{DS}$ in cardboard was generally greater than iv rivi-ortho-PCBs in ash and RWW.

\subsubsection{Dioxin-like ortho-polychlorina'?a biphenyls}

The $\sum \mathrm{WHO}_{2005}$-TEQ value s tc $\cdot$ the dioxin-like ortho-PCBs (PCBs: 105, 114, 118, 123, 156, 167 and 189) were relatively low. I or biosolids, CLO and DPS the values were in the range of $0.07 \mathrm{ng} \mathrm{kg}^{-1}$ (Biosolids3) to $0.29 \mathrm{ng} \mathrm{kg}^{-1}$ DS (Biosolids2) (Table 1). For the RWW materials from non-virgin wood sources, and cardboard, the values were $0.02-0.08 \mathrm{ng} \mathrm{TEQ} \mathrm{kg}^{-1} \mathrm{DS}$, and for ash residues, RWW5 and virgin wood bedding the concentrations were below the limit of quantification (Table 1).

\subsubsection{Polybrominated dibenzo-p-dioxins and dibenzofurans and dioxin-like polybrominated biphenyls}

PBBs are a legacy BFR and PBDD/Fs are generated during combustion e.g. incineration of domestic waste, but both also occur as impurities in commercial BFRs (Ventkatesan and Haldan, 2014). This explains their presence in municipal biosolids and CLO derived from MSW. Therefore, as 
would be expected, all 11 of the measured PBDD/F congeners and 3 dioxin-like PBBs were detected in both biosolids and CLO samples (Table S6 and S7 Supplementary Information).

The total sum of congener concentrations in the biosolids samples was $776-4410 \mathrm{ng} \mathrm{kg}^{-1}$ DS with the largest amount detected in Biosolids2 and the smallest in Biosolids3, the sample from the rural catchment. Venkatesan and Halden (2014) investigated the presence of PBDD/Fs in archived biosolids from the US EPA 2001 National Sewage Sludge Survey and detected 7 of 12 measured PBDD/Fs in the samples. However, the limits of quantification were higher and between 2-10 $\mathrm{ng} \mathrm{kg}^{-1}$ DS compared to $0.01-0.37 \mathrm{ng} \mathrm{kg}^{-1} \mathrm{DS}$ in the present study. The total mean concentration of PBDD/Fs detected by Venkatesan and Halden (2014) was $10,000 \mathrm{ng} \mathrm{kg}^{-1} \mathrm{DS}, \mathrm{i} 13$ times greater than the total measured in the contemporary biosolids samples examined here. Thi, may reflect the different background status of PBDD/Fs between the two countries, $h$ tt $\iota$ ulso indicative of the decline in PBDD/Fs in the environment since 2001 when the US EF A sć mples were collected.

By far the largest concentration measured for a s' $s^{\prime} y^{\prime}$ congener was for $1,2,3,4,6,7,8-$ HeptaBDF (Table S6, Supplementary Material), with valuen in, hiosolids and CLO in the range: $716-4150 \mathrm{ng} \mathrm{kg}^{-1}$ DS. This congener represented $93-94 \%$ of the : val mass of BDD/BDF congeners in the biosolids samples and was consistent with the $95 \%$ ot : he total mass for this congener reported by Venkatesan and Halden (2014). Indeed, the domir a.' $\mathrm{Cu}_{t}$ of 1,2,3,4,6,7,8-HeptaBDF observed in both studies may be largely attributed to the degradain of $\mathrm{PBDE}$ containing deca-BDE in the environment (Venkatesan and Halden, 2014). Th's next most significant congener was 1,2,3,4,7,8-HexaBDF with concentrations from $53.2 \mathrm{k}_{\mathrm{k}} \mathrm{ky}^{-1} \mathrm{DS}$ in CLO1 to $132 \mathrm{ng} \mathrm{kg}^{-1} \mathrm{DS}$ in Biosolids2.

PBDD/Fs are not currently considered in risk assessments of dioxins and dioxin-like chemicals, although they have been detected in most commonly consumed foods (Fernandes et al., 2009; Fernandes et al., 2014). World Health Organisation toxic equivalencies (WHO-TEQs) take into account the concentration and the toxicity of each PCDD/F or dioxin-like PCB congener relative to 2,3,7,8 TCDD, and were calculated for PBDD/Fs using Toxic Equivalency Factors (TEF) from analogous PCDD/F congeners, which have not been formally assigned to PBDD/Fs, but provide an indicative overall TEQ (Van den Berg et al., 2013). The earlier TEFs assigned by the WHO in 1998 for dioxin and dioxin-like substances were used for consistency with other studies that have estimated $\mathrm{WHO}_{1998}-\mathrm{TEQs}$ for $\mathrm{PBDD} / \mathrm{F}$, and because there is not yet sufficient evidence to indicate that $\mathrm{WHO}_{2005^{-}}$ 
TEQs are more applicable to the brominated congeners. The $\mathrm{WHO}_{1998}-\mathrm{TEQ}$ values for $\mathrm{PBDD} / \mathrm{Fs}$ were $40.3 \mathrm{ng} \mathrm{kg}^{-1}$ DS for Biosolids1, $78.0 \mathrm{ng} \mathrm{kg}^{-1}$ DS for Biosolids2 and $49.9 \mathrm{ng} \mathrm{kg}^{-1}$ DS for Biosolids3 (Table 1). Note that, if the 2005 TEFs were used, the $\mathrm{WHO}_{2005}-\mathrm{TEQ}$ values were very similar, albeit slightly lower at 38.2, 72.1 and $47.6 \mathrm{ng} \mathrm{kg}^{-1}$ DS for Biosolids1, Biosolids2 and Biosolids3 respectively. Interestingly, the $\mathrm{WHO}_{1998}-\mathrm{TEQ}$ for Biosolids3, which tended to show lower levels of contamination overall was higher than for Biosolids1, perhaps indicating that the main sources of PBDD/Fs are not only in urban catchments. Furthermore, the $\mathrm{WHO}_{1998}-\mathrm{TEQ}$ contribution from PBDD/Fs in the biosolids samples measured here was 4-7 times greater than the $\mathrm{WHO}_{2005}-\mathrm{TEQ}$ for PCDD/Fs (Table 1). The observed pattern between PCDD/Fs and PBDD/Fs was consistent wi.h Venkatesan and Haldan (2014), who found an estimated $\mathrm{WHO}_{1998}$ TEQ contribution from $\mathrm{PL}_{\mathrm{L}} \mathrm{T} / / \mathrm{Fs}$ of $162 \mathrm{ng} \mathrm{kg}^{-1} \mathrm{DS}$, approximately 3.7 times greater than the contribution of $44 n_{y} k_{y}{ }^{-1} \mathrm{DS}$ from their chlorinated analogues.

The estimated contributions of the different group' ' dioxin-like compounds to the estimated overall dioxin-like toxicity are shown in Table $1 . w_{1}$ - h h demonstrated that, for biosolids, the contribution from PBDD/Fs was $76-84 \%$ compa ed to $13-20 \%$ for PCDD/Fs. The CLOs had lower $\mathrm{WHO}_{1998}$-TEQ values for PBDD/Fs than the $\mathrm{u}$ : $s$ solids, equivalent to 18.0-32.2 $\mathrm{ng} \mathrm{kg}^{-1}$ DS (Table S6,

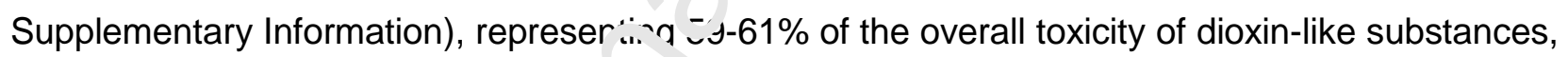
compared to a contribution of $35-3 i \%$ frum PCDD/Fs. It is emphasized that the TEQs presented in Table 1 have an associated unce. ${ }^{+}{ }^{i}$. thy, although this is lower for PCDD/Fs and PCBs, as their toxicology has been more $u$ vtt.:-_ively studied. Furthermore, fewer PBDD/Fs congeners (10 + one tribromo compound, which does not have an assigned TEF value) were analysed, compared to 17 PCDD/F congeners, due to the restricted availability of analytical standards that correspond to the most toxicologically relevant PBDD/Fs. Hence, determination of the missing congeners could also contribute to the overall TEQ, further increasing the potential significance of PBDD/Fs in comparison to PCDD/Fs.

The greatest $\mathrm{WHO}_{1998}$-TEQ values for non-ortho-PBBs were recorded for the CLOs with upper bound values of $0.04 \mathrm{ng} \mathrm{kg}^{-1}$ (Table 1 and Table S7 Supplementary Information). The WHO ${ }_{1998}$-TEQ values for the biosolids were lower at $0.02 \mathrm{ng} \mathrm{kg}^{-1} \mathrm{DS}$. These concentrations were lower than those measured for the chlorinated analogues. 
Overall, the contributions of PBDD/Fs and dioxin-like PBBs to the estimated WHO-TEQ values for biosolids were equivalent to $40.5-78.1 \mathrm{ng} \mathrm{kg}^{-1}$ DS compared to 9.5-14.4 $\mathrm{ng} \mathrm{kg}^{-1}$ DS for PCDD/Fs and PCBs (Table 1). Thus, risk assessments that only consider PCDD/Fs and PCBs underestimate the potential total toxicity of dioxin-like compounds present in environmental media.

The concentrations of PBDD/Fs in biowaste ash and RWW were significantly smaller compared to the biosolids and CLOs, with upper bound $\mathrm{WHO}_{2005}-\mathrm{TEQ}$ generally $<1 \mathrm{ng} \mathrm{kg}^{-1} \mathrm{DS}$, except for PLA2, which had a $\mathrm{WHO}_{2005}$-TEQ value of $5.1 \mathrm{ng} \mathrm{kg}^{-1} \mathrm{DS}$, and RWW1, which had a $\mathrm{WHO}_{1998^{-}}$TEQ value of $3.1 \mathrm{ng} \mathrm{kg}^{-1}$ DS (Table 1). Furthermore, in contrast to the biosolids and CLOs, the concentrations of PBDD/Fs in ash and RWW were smaller than their chlorinated courı roarts. This pattern of behaviour may be explained because ash is produced from source separatę' hi Jmass feedstocks (Table S1, Supplementary Material) that are unlikely to be contaminater win. orominated precursors, such as BFRs, which can potentially influence the amount of PBC J/F s formed during combustion (Fernandes et al., 2014). On the other hand, wood treatments wi+', 3FRs represent a potential source of RWW contamination with PBDD/Fs, as well as non-orthc DBBs (Venkatesan and Halden, 2014), however, there was no evidence that this was significanı or the RWW samples tested here. The $\mathrm{WHO}_{1998}-\mathrm{TEQ}$ values for non-ortho-PBBs in biowaste ashes and RWW were also lower than those measured for the chlorinated analogues, between 0.00r ? 0: $\mathrm{ng} \mathrm{kg}^{-1}$ DS (Table 1).

For cardboard, the estimated W: ' $\mathrm{O}_{1998}$-TEQ contribution from PBDD/Fs was $1.5 \mathrm{ng}$ TEQ $\mathrm{kg}^{-1}$ DS. For DPS it was similar and betwe गn 1.6-2.5 $\mathrm{ng}$ TEQ $\mathrm{kg}^{-1} \mathrm{DS}$, approximately 3 times smaller than the $\sum \mathrm{WHO}_{2005}$-TEQ contributic. t几 $\ldots . . \mathrm{PCDD} / \mathrm{Fs}$ (Table 1). For the non-ortho-PBBs, the $\mathrm{WHO}_{1998}-\mathrm{TEQ}$ was small and equivalent to u.002-0.03 ng TEQ kg-1 DS for DPS and $0.003 \mathrm{ng} \mathrm{kg}^{-1}$ DS for cardboard (Table 1).

\subsubsection{Mixed halogenated dibenzo-p-dioxins and dibenzofurans and mixed halogenated biphenyls}

The concentrations of PXDD/Fs and PXBs in waste samples are presented in Tables S9 and S10 (Supplementary Information). For the biosolids and CLOs, between 8-10 of the 13 measured congeners were detected. The congener found in the greatest concentration was 2-Br-7,8-CIDF at concentrations of up to $1.36 \mathrm{ng} \mathrm{kg}^{-1} \mathrm{DS}$ in Biosolids2. The $\Sigma \mathrm{PXDD} / \mathrm{Fs}$ that could be quantified was significantly lower than for PCDD/Fs or PBDD/Fs (Tables S4 and S7, Supplementary Information). However, the compounds measured here are a small sub-set of the potentially large number of 
laterally substituted, potentially toxic, mixed halogenated congeners (Fernandes et al., 2011a; Fernandes et al., 2014). The TEQ values for mixed halogenated dioxins and biphenyls were estimated using relative potency (REP) values generated and used in earlier studies (Fernandes et al., 2011; 2014; Wall, 2012). However, it should be noted that the dataset of congeners was not comprehensive, and hence the TEQs calculated will significantly underestimate the contribution of these diverse groups of compounds to the overall TEQ (Fernandes et al., 2014).

For PLA1 and PSA most or all of the limited number of individual PXDD/F congeners measured were below the limits of quantification (Tables S9 and S10, Supplementary Information). However, between 7-12 of the congeners were detected in the MBMAs, PLA2 a nd PLA3 of . The congeners found in the greatest concentrations were 2-Br-3,6,7,8,9-CIDx, wh, -h : vas present at $1.07 \mathrm{ng} \mathrm{kg}^{-1} \mathrm{DS}$ in PLA2, and 2-Br-7,8-CIDf, at up to $0.82 \mathrm{ng} \mathrm{kg}^{-1}$ DS in PLA.2 1ィこ MBMAs had the greatest estimated TEQ values of $0.24-0.57 \mathrm{ng} \mathrm{kg}^{-1} \mathrm{DS}$ compared to values $0.2 \mathrm{ng}^{\prime} \mathrm{TEQ} \mathrm{kg}^{-1} \mathrm{DS}$, estimated for the other materials (Table 1 ).

Most or all of the limited number of individu>l F, 'DD/F and PXB congeners measured were below detection limits in RWW3, RWW4 and RWW5 ; ables S9 and S10, Supplementary Information). However, seven of the PXDD/F congenerc wre detected in RWW1 and RWW2. The $\mathrm{WHO}_{1998}$-TEQ values for the RWW materials from nr ., viı yin sources were between 0.1-0.3 ng TEQ $\mathrm{kg}^{-1} \mathrm{DS}$, whereas the upper bound $\mathrm{WHO}_{1998}{ }^{\top} \mathrm{EQ}$ for RWW5 and virgin wood bedding material was $0.01 \mathrm{ng}$ TEQ kg ${ }^{-1}$ DS (Table 1).

The smallest $\mathrm{WHO}_{1998^{-}} \mathrm{I}^{-} \mathrm{C}_{\mathrm{i}}$ u ue to the $\mathrm{PXDD} / \mathrm{Fs}$ were measured for cardboard, $0.06 \mathrm{ng}$ TEQ kg-1 DS, and DPS, 0.04-0.1 ng $1 \sqsubset \mathrm{Q} \mathrm{kg}^{-1}$ DS (Table 1).

\subsubsection{Polychlorinated naphthalenes}

Nine PCN congeners were measured (Table S10, Supplementary Information), which were selected reflecting their abundance in the environment and toxicological characteristics (Fernandes et al., 2010a). Biosolids, CLO, RWW1 and RWW2 contained the largest concentrations of PCNs. CLO1 contained the largest overall $\sum \mathrm{PCN}_{9}$, equivalent to $1980 \mathrm{ng} \mathrm{kg}^{-1} \mathrm{DS}$, compared to $680 \mathrm{ng} \mathrm{kg}^{-1} \mathrm{DS}$ for CLO2, similar to Biosolids1 (743 $\mathrm{ng} \mathrm{kg}^{-1}$ DS). Biosolids2 and Biosolids3 contained similar, smaller, amounts of $\sum \mathrm{PCN}_{9}$, equivalent to 541 and $533 \mathrm{ng} \mathrm{kg}^{-1} \mathrm{DS}$, respectively. The $\sum \mathrm{PCN}_{9}$ values detected here were significantly smaller than the mean $\Sigma \mathrm{PCN}$ concentration from a literature survey of sewage 
sludge contaminants of $44,000 \mathrm{ng} \mathrm{kg}^{-1} \mathrm{DS}$ (Clarke and Smith, 2011). Zhang et al. (2014) collated data for PCNs in sewage sludge reported in the scientific literature between 1988 and 2011 and found the concentration range was between $4490-124,000 \mathrm{ng} \mathrm{kg}^{-1} \mathrm{DS}$. Therefore, the results presented here for three biosolids samples, two of which are from major UK, urban WwTP, suggest that PCNs appear to have significantly diminished as biosolids contaminants, reflecting the general decline in emissions and concentrations in the environment.

EFSA (2004) and van den Berg et al. (2006) have previously recommended that those PCNs that are dioxin-like should be covered by the TEF system. An estimated TEQ for PCNs was calculated using the estimated TEF values applied by Fernandes et al. (2011b, I'Table 1). However, REP values were only estimated for the most abundant and/or the most poten $\mathrm{D}_{\mathrm{i}} \mathrm{V}$ congeners; hence, the dioxinlike toxicity for PCNs is an underestimate. Furthermore, the $\mathrm{E}_{r}$ alues applied have not been widely used or adopted by regulatory bodies (Fernandes et al., : 011 ); 2017). Nevertheless, this analysis showed that PCNs accounted for a relatively small $p v$, ortion of the overall dioxin-like toxicity, equivalent to $<1 \%$ for the biosolids and CLO2. nnci ग\% for CLO1.

PCNs have been used as wood preservativ : (Fernandes et al., 2017) and this may explain why they were found in RWW samples and məv a 'so explain the larger $\sum P C N_{9}$, compared to biosolids and CLO. Thus, RWW1 contained $1210 n_{1}^{\prime}:{ }^{\prime} \gamma$ ' 'JS, followed by RWW2 with 604 ng kg$^{-1}$ DS. RWW3 and RWW4 contained generally similar . mounts of $\sum \mathrm{PCN}_{9}$, equivalent to 121 and $88.3 \mathrm{ng} \mathrm{kg}^{-1} \mathrm{DS}$ (as upper bound values) (Table S10, Sı'splementary Information), respectively. The findings indicated that PCNs generally accou. 'te' '. .Jr a greater proportion of the overall estimated TEQ in RWW compared to the other recycied bioresources examined. Nevertheless, the PCN contribution represented a relatively small fraction of the total estimated TEQ, between $1.3 \%$ (RWW2) to $2.1 \%$ (RWW1), compared to other more significant contaminant groups (Table 1).

PCNs (upper bound $\sum \mathrm{PCN}_{9}$ ) were detected in the ash materials at concentrations between $8.8 \mathrm{ng}$ $\mathrm{kg}^{-1}$ DS in PLA1 to $108 \mathrm{ng} \mathrm{kg}^{-1}$ DS in MBMA2 (Table S10, Supplementary Information). PCN 52 contamination is typically associated with combustion processes (Zhang et al., 2014) and this was consistent with the observed significance in several of the ash products, including: MBMA1, MBMA3, PLA2 and PLA3, at concentrations between 5.5-39.6 $\mathrm{ng} \mathrm{kg}^{-1}$ DS (Table S10, Supplementary Information). MBMA2 contained the largest concentration of PCN 73, equivalent to $43.9 \mathrm{ng} \mathrm{kg}^{-1} \mathrm{DS}$, 
compared to the other bioresources examined. This contributed to one of the higher estimated TEQ values associated with PCN contamination of $0.2 \mathrm{ng} \mathrm{TEQ} \mathrm{kg}^{-1} \mathrm{DS}$, which was comparable to the estimated PCN TEQ for biosolids: 0.2-0.4 ng TEQ kg ${ }^{-1}$ DS (Table 1). The concentrations of PCNs in PSA were all below the limit of quantification. With the exception of MBMA2, where PCNs contributed an estimated $1.9 \%$ of overall dioxin-like toxicity, the overall TEQ estimated for PCNs in ash materials was small and $<1 \%$ (Table 1$)$.

The upper bound $\sum \mathrm{PCN}_{9}$ in cardboard was $161 \mathrm{ng} \mathrm{kg}^{-1} \mathrm{DS}$ and was smaller than for biosolids, CLO, DPS and RWW1, but was larger than in the other RWW samples and ash. The estimated contribution to the overall TEQ of cardboard was approximately $1 \%$ (T.7ble 1). The presence of detectable traces of PCNs in the cardboard bedding may reflect th,$h$ storical use of PCNs as a cardboard preservative (Fernandes et al., 2017) or in adhesi 'es ‘: amashita et al., 2003).

The upper bound $\sum$ PCNs in the DPS samples was $28^{\prime}-43 \mathrm{ng} \mathrm{kg}^{-1}$ DS (Table S10, Supplementary Information) and was approximately 2-3 times greatf, ' 'ian for cardboard and could be related to de novo formation in the combustion process (Liu nt a.' 2014). Nevertheless, the estimated contribution to the total dioxin-like TEQ was small and in th range 1.1-1.5\% (Table 1).

\subsection{Non Dioxin-Like Polychlorinated Bik hf $r_{1}$ 's and Polybrominated Biphenyls}

The largest concentrations of the $\sum$ 'nter national Council for the Exploration of the Sea (ICES) 6 (nondioxin like) ortho-PCB congener = (2s, 52, 101, 138, 153 and 180) (Table S11, Supplementary Information) (Elskens et a., ¿ $i^{1} \Sigma_{\text {f }}$, were found in the biosolids and were $41.0 \mu \mathrm{g} \mathrm{kg}^{-1} \mathrm{DS}$ for Biosolids2 and $17.3 \mu \mathrm{g} \mathrm{kg}^{-1}$ Lj for Biosolids1 (Figure 1a). The $\sum \mathrm{ICES}_{6}$ for Biosolids3, from a rural area, was smaller and equivalent to $13.5 \mathrm{\mu g} \mathrm{kg}^{-1} \mathrm{DS}$. Nevertheless, these values, including for biosolids from major urban WwTP, were smaller than the mean $\sum \mathrm{ICES}_{6}$ measured in 54 biosolids samples from Italian WwTPs by Brambilla et al. (2016), of $44.03 \mu \mathrm{g} \mathrm{kg}^{-1}$ DS (range $5.65-616.7 \mu \mathrm{kg}^{-1}$ DS). The $\sum \mathrm{ICES}_{7}\left(\mathrm{ICES}_{6}+\mathrm{PCB} 118\right)$ values for ortho-PCBs in the biosolids were in the range 14.7$46.9 \mu \mathrm{g} \mathrm{kg}^{-1} \mathrm{DS}$ and were significantly smaller than a proposed European limit in biosolids of $800 \mu \mathrm{g}$ $\mathrm{kg}^{-1}$ DS (EC, 2003b), which was not adopted.

The CLOs had similar $\sum$ ICES 6 values to Biosolids2 and Biosolids3, equivalent to 15.7 and $17.1 \mu \mathrm{g}$ $\mathrm{kg}^{-1} \mathrm{DS}$, for CLO2 and CLO1, respectively (Figure 1a), and $\sum \mathrm{ICES}_{7}$ concentrations a little higher and 
a.

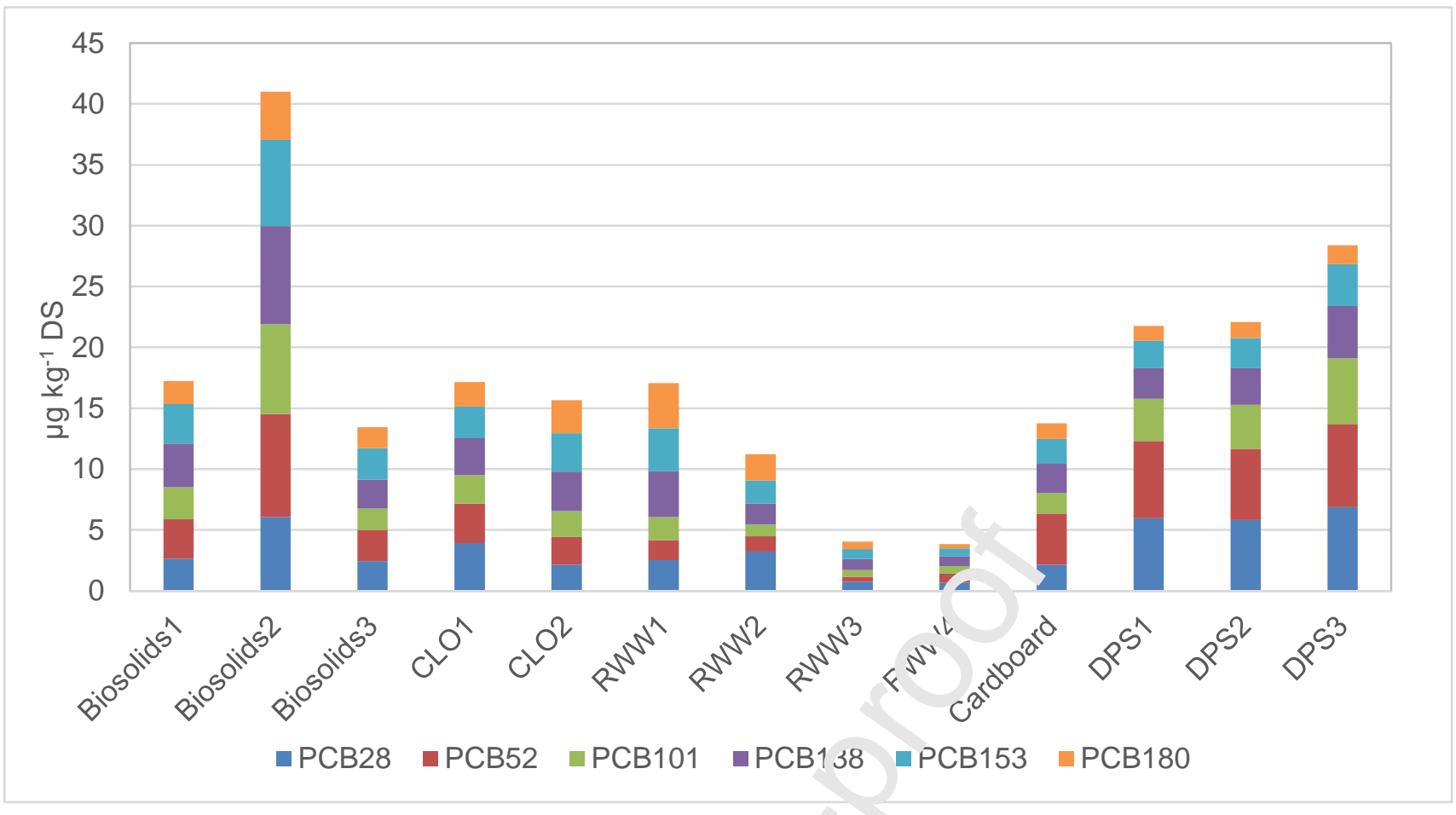

b.

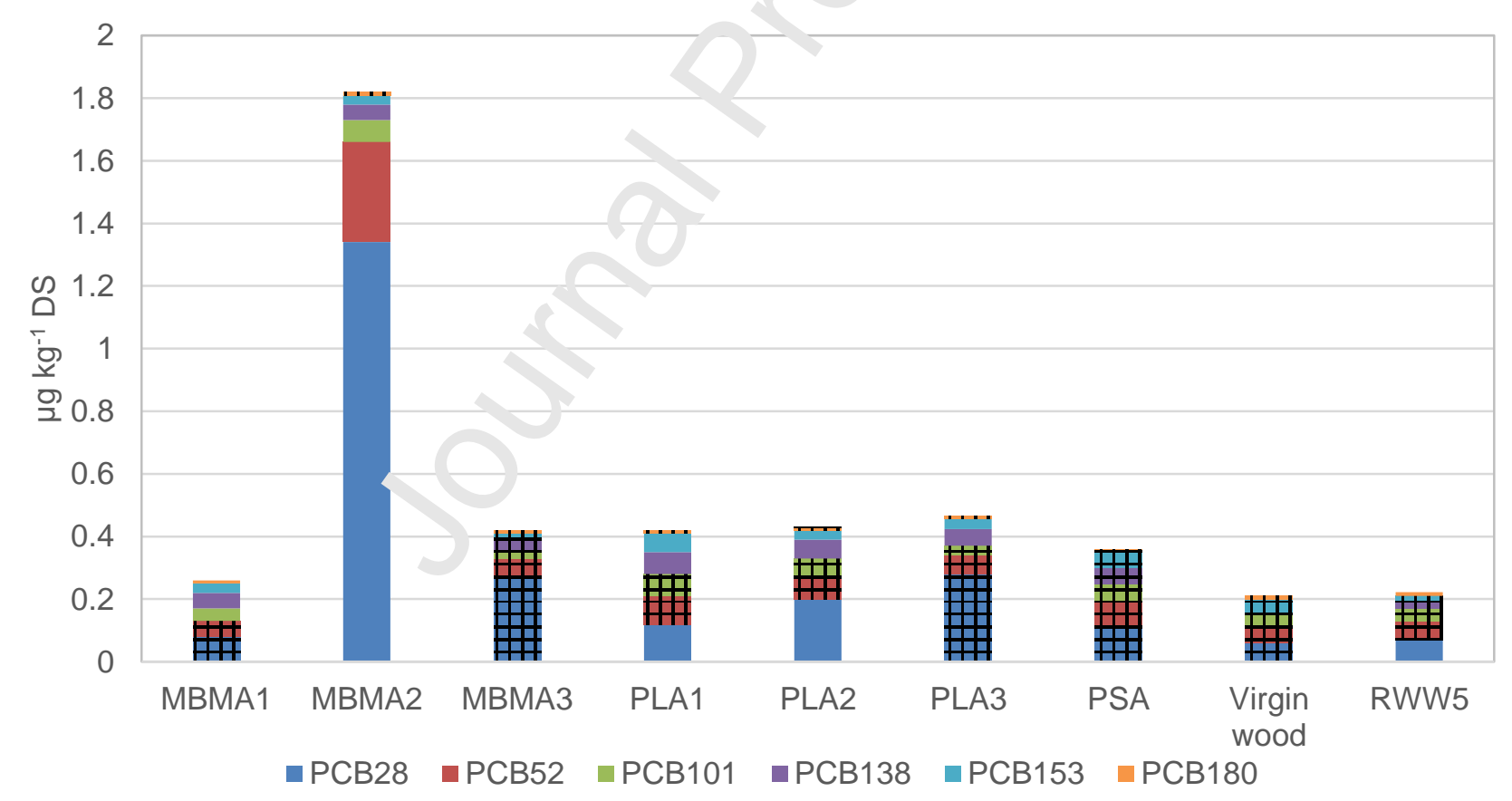

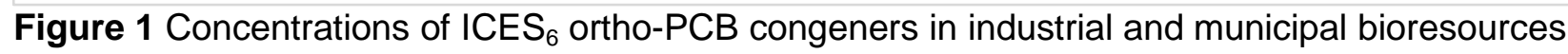
used in agriculture, according to data range: (a) Biosolids, CLOs, RWW1-4, cardboard, DPS; (b) MBMAs, PLAs, PSA, virgin wood, RWW5.

Data points with a grid pattern were below the limit of quantification, which is displayed.

CLO, compost-like-output; MBMA, meat and bonemeal ash; PLA, poultry litter ash; PSA, paper sludge ash; RWW, recycled waste wood; DPS, dried paper sludge 
equivalent to 17.2 (CLO2) and $18.9 \mu \mathrm{g} \mathrm{kg}^{-1} \mathrm{DS}$ (CLO1). These values were also significantly below an End of Waste Criteria limit proposed for composts and digestates for the $\sum \mathrm{ICES}_{7}$ PCBs of $200 \mu \mathrm{g} \mathrm{kg}^{-1}$ DS, and the $\sum \mathrm{ICES}_{6}$ limit in compost of $200 \mu \mathrm{g} \mathrm{kg}^{-1} \mathrm{DS}$ in Austria, and $\sum \mathrm{ICES}_{7}$ of $800 \mu \mathrm{g} \mathrm{kg}^{-1} \mathrm{DS}$ for both Belgium and France (Saveyn and Eder, 2014).

The dominant $\sum \mathrm{ICES}_{6}$ congeners in the biosolids and CLO tended to be PCB 52 and PCB 138 (Figure 1a). Needham and Ghosh (2019) also found significant concentrations of PCB 52 in biosolids as well as other tetrachlorobiphenyls and suggested this was a consequence of the dechlorination of Aroclor 1260. The microbial dechlorination of legacy PCBs in sewers (Needham and Ghosh, 2019) may also account for the relatively high concentrations of PCB 52 on_ arved in the biosolids samples.

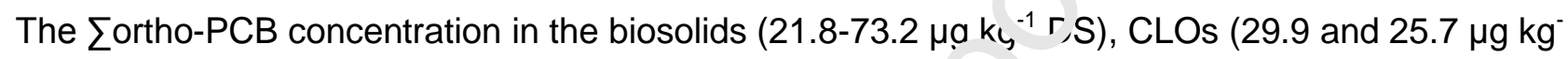
${ }^{1}$ DS for CLO1 and CLO2, respectively) and MBMA2 (3.22 $\mu^{\prime \prime l ~ k y ~}{ }^{-1}$ DS) (Table S11) exceeded the values typically found in UK rural and urban soils (respec ivelı, 1.01 and $1.86 \mu \mathrm{g} \mathrm{kg}^{-1}$ dry soil (ds) (Table S3) (UKSHS, 2007)). The biosolids and CLO c. ults, in particular indicate, that these chemicals continue to circulate in the environmant ?fter the placement of restrictions on their production and use. However, the $\sum$ ortho-PCb $n$ the remaining ashes (PLAs, MBMA1 and PSA) were below the median concentrations in UK snils ,'Table S3). PBB 209 was detected in MBMA samples at concentrations between 0.006-0.02 $\mathrm{n}, ; \cdot \gamma \quad J S$ and in PLA2 and PLA3 at concentrations of 0.02 and $0.009 \mathrm{ng} \mathrm{kg}^{-1} \mathrm{DS}$, respectively (TaL. ? S 12 , Supplementary Information). No other ortho-PBB congeners were detected in the $\mathrm{L}:\urcorner v$ aste ash materials. The small concentrations detected in the ash samples were consistent $w^{\text {th }}$ in: destruction of ortho-PBBs during waste incineration (North, 2004).

The $\sum$ ICES ${ }_{6}$ PCB congeners present in samples of RWW from non-virgin sources and cardboard were similar to the biosolids and CLO materials in the range: $11.2-17.1 \mu \mathrm{gg}^{-1} \mathrm{DS}$ (Figure 1), and were significantly greater (by 2 orders of magnitude) compared to $0.22 \mathrm{\mu g} \mathrm{kg}^{-1}$ DS in RWW5 and 0.21 $\mu \mathrm{g} \mathrm{kg}{ }^{-1}$ DS in virgin wood bedding. PBB 209 was present in concentrations of 0.01-0.22 $\mathrm{ng} \mathrm{kg}^{-1} \mathrm{DS}$ in RWW from non-virgin sources and was below the quantification limit in RWW5 and the virgin wood shavings (Table S12, Supplementary Information).

The concentrations of $\sum \mathrm{ICES}_{6}$ PCB congeners measured in the DPS samples were relatively large compared to the other recycled bioresources, equivalent to $21.8-28.4 \mu \mathrm{g} \mathrm{kg}^{-1} \mathrm{DS}$ (Figure 1), with 
the exception of Biosolids2, which contained $41 \mathrm{\mu g} \mathrm{kg}^{-1} \mathrm{DS}$, and were probably explained from the occurrence of PCBs as by-products in the manufacture of inks and dyes (Grossman, 2013).

With the exception of PBB 209, the ortho-PBBs were present in small concentrations in the waste materials, and generally below the quantification limit (Table S12, Supplementary Information). The congener found in the largest concentrations was PBB 209 at $0.59 \mathrm{ng} \mathrm{kg}^{-1}$ DS in CLO1, and $0.35 \mathrm{ng}$ $\mathrm{kg}^{-1} \mathrm{DS}$ in Biosolids2, and at concentrations between 0.01-0.5 $\mathrm{ng} \mathrm{kg}^{-1} \mathrm{DS}$ in most of the other bioresource materials. However, certain other congeners, for example, PBB 15 and PBB 153 were detected in biosolids, RWW1, RWW2, cardboard and DPS at concentrations between 0.002-0.145 $\mu \mathrm{g}$ $\mathrm{kg}^{-1}$ DS. The concentrations of ortho-PBBs were significantly smalle, :han the equivalent ortho-PCB analogues (Table S11, Supplementary Information).

\subsection{Polycyclic Aromatic Hydrocarbons}

The results from the assessment of the PAH contr...'s in the recycled bioresources are presented in Table S13 in the Supplementary Information $B_{1}$ solıds2 had the largest concentrations of PAHs, consistent with the findings for the majority of $\_$- other contaminants, equivalent to a $\sum \mathrm{PAH}_{16}(16$ EPA PAHs; US ATSDR, 2013) of $9415 \mu \mathrm{kg}{ }^{-1}$ DS, compared to $5158 \mu \mathrm{g} \mathrm{kg}^{-1}$ DS for Biosolids1 (N.B. PAHs were not measured in Biosolids?', E; contrast, Smith (2009) reported an overall mean $\sum$ PAH of $130,000 \mathrm{\mu g} \mathrm{kg}^{-1}$ DS from a survey $c^{-}$lite ature of contaminants in biosolids, which is $12-22$ times greater than the overall mean $\sum_{1} \sim 4 H_{16}$ measured here. However, Smith (2009) included a

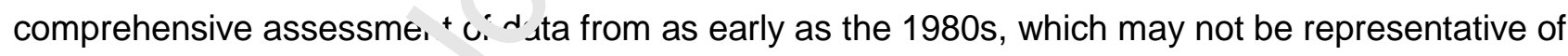
contemporary biosolids. Moı recently, Jones et al. (2014) measured eight PAH congeners in primary and secondary sludge from UK WwTPs. The median concentrations of the most dominant congeners: benzo[a]pyrene and fluoranthene, were equivalent to 320 and $520 \mu \mathrm{kg}^{-1} \mathrm{DS}$, respectively, which were approximately $50 \%$ of the amounts found in Biosolids2, from a major urban WwTP (Table S13, Supplementary Information).

A proposed European limit value for PAHs in biosolids of $6000 \mathrm{~g} \mathrm{~kg}^{-1} \mathrm{DS}$ for nine congeners (acenaphthene, fluorene, phenanthrene, fluoranthene, pyrene, benzo[b+j+k]fluoranthene, benzo[a]pyrene, benzo[ghi]perylene, indeno[1,2,3-c,d]pyrene) (EC, 2003b) was marginally exceeded at the upper bound sum of $6250 \mu \mathrm{g} \mathrm{kg}^{-1} \mathrm{DS}$ for the equivalent group of congeners in Biosolids2. 
However, the $\mathrm{\Sigma PAH}_{9}$ congeners in Biosolids1 was approximately $60 \%$ of the proposed standard, equivalent to $3500 \mu \mathrm{g} \mathrm{kg}^{-1}$ DS. Furthermore, the biosolids samples from both urban WWTP would comply with a proposed EU limit for benzo[a]pyrene currently under consideration in biosolids of 2000 $\mu \mathrm{kg}^{-1}$ DS (Eriksson et al., 2011).

PAHs are metabolised by livestock and humans and do not bioaccumulate (Fries, 1996; Moorthy et al., 2015), however, their metabolites may be carcinogenic (Moorthy et al., 2015). PAH concentration is widely adopted as an indicator of the general levels of organic chemical contamination in environmental media, including bioresources for recycling. Thus, the presence of

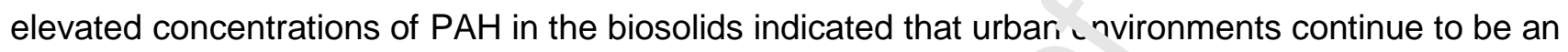
emission source of this group of pollutants.

The $\sum \mathrm{PAH}_{16}$ in $\mathrm{CLO}$ samples were within a similar order $\mathrm{f} \mathrm{n}_{\ln \mathrm{y}}$ nitude, albeit in a smaller range, compared to the biosolids with the largest content in CLC?, el , uivalent to $4938 \mu \mathrm{g} \mathrm{kg}^{-1} \mathrm{DS}$, compared to $3239 \mu \mathrm{g} \mathrm{kg}^{-1}$ DS in CLO1 (Table S13, Supplemen+al ; Information). Hence, these values fell below a proposed European End of Waste Criteria limit $\mathrm{l}^{-}$- digestates and composts of $6000 \mu \mathrm{g} \mathrm{kg}^{-1} \mathrm{DS}$ for the $\sum \mathrm{PAH}_{16}$ (Saveyn and Eder, 2014).

PAHs are produced de novo during the in amplete thermal destruction of organic matter and are emitted from combustion processes a ^'Cair therefore also be found in ash residues (van der Drift, 2001). However, the concentratior , found in the ash samples were generally significantly smaller compared to the other waste tVDc $\leqslant$ xamined, indicating that they were effectively destroyed during the combustion of biowaste res:'ues. For example, the $\sum \mathrm{PAH}_{16}$ concentrations measured in ash were between $8.7 \mu \mathrm{g} \mathrm{kg}^{-1}$ DS in MıMA1 and $182.0 \mu \mathrm{g} \mathrm{kg}^{-1}$ DS in MBMA2 (Table S13, Supplementary Information).

The Grade C RWW2 had the largest overall $\sum \mathrm{PAH}_{16}$ value of $9784 \mu \mathrm{g} \mathrm{kg}^{-1} \mathrm{DS}$, compared to the other wood samples, which contained between 1806-7157 $\mu \mathrm{g} \sum \mathrm{PAH}_{16} \mathrm{~kg}^{-1} \mathrm{DS}$ (Table S13, Supplementary Information). PAHs may be present as impurities in creosote, which, although no longer used as a preservative to treat wood, may be present as a legacy contaminant (Davou, 2014). Interestingly, the PAH congener present in the greatest concentration in the RWW samples was phenanthrene, followed by fluoranthene, corresponding with the compounds most commonly found in the largest amounts in creosote treated wood (Davou, 2014). 
DPS contained PAHs concentrations in a similar range to the less contaminated RWW samples with $\sum \mathrm{PAH}_{16}$ values of 1491 and $1805 \mathrm{\mu g} \mathrm{kg}^{-1} \mathrm{DS}$ (Table S13, Supplementary Information). PAHs may be produced during paper processing due to the combustion of coal and wood and the use of chemicals, heat and pressure (Gupta, 2017), which may explain their presence in DPS.

\subsection{Flame Retardants}

\subsubsection{Polybrominated diphenyl ethers}

Biosolids contained more PBDEs compared to any of the other bioresources tested, with an upper bound $\sum$ PBDEs (for tri-, tetra-, penta-, hexa- and hepta-, excluding L.?E 209) of 90.1-124 $\mu \mathrm{g} \mathrm{kg}^{-1} \mathrm{DS}$ (Figure 2a). This was similar, although slightly lower than the mea.' $\Sigma^{\prime}$ 'BDEs (excluding BDE 209) in biosolids from 16 Australian WwTPs of $417 \mu \mathrm{g} \mathrm{kg}^{-1}$ DS (rand $\geqslant 1.1,150 \mathrm{gg} \mathrm{kg}^{-1}$ DS) reported by Clarke et al. (2008b). PBDEs are additive BFRs, which m ?an: that they are mixed directly into products during manufacture, and are not chemically : רund to the polymers present, and hence they can readily leach and transfer to the environment ; 1 laee et al., 2003). Consequently, they tend to be relatively abundant in wastewater biosolids (Li- - ke et al., 2008b).

In contrast to the other contaminant grnuk - however, the largest concentrations of PBDEs were observed in Biosolids3 obtained from $=r u_{1} \sim{ }^{\prime}$ WwTP, compared to Biosolids1 and Biosolids2, which were sourced from highly urbanise: catchments. This suggested that inputs of PBDEs from diffuse domestic sources are a critical s' 'urce of these pollutants entering the wastewater collection system. A similar pattern was also ins $\neg n$ ad by Clarke et al. (2008b), who found no significant difference between the PBDE concenti uilions of biosolids from rural or urban areas. The PBDE concentrations were similar to those measured in sewage sludge samples from 11 German WwTPs, which had a median total concentration of $108 \mu \mathrm{g} \mathrm{kg}^{-1}$ DS of 6 congeners $(28,47,99,153,154$ and 183) (Knoth, 2007), compared to $77-104 \mu \mathrm{gg}^{-1}$ DS for the same congeners measured here. The CLOs also contained relatively elevated concentrations of $\sum$ PBDEs compared to biosolids, with total (upper bound) concentrations of $40.5 \mu \mathrm{g} \mathrm{kg}^{-1}$ DS for CLO1 and $66.8 \mu \mathrm{g} \mathrm{kg}^{-1}$ DS for CLO2 (Figure 2a).

The upper bound $\sum$ PBDEs in the combustion residues were relatively small compared to the biosolids and CLOs and in the range $0.14-0.33 \mu \mathrm{g} \mathrm{kg}^{-1} \mathrm{DS}$ (Figure 2b). The concentrations of decaBDE 209 were also small and between $<0.17 \mu \mathrm{gg}^{-1}$ DS for MBMA2 to $3.01 \mu \mathrm{g} \mathrm{kg}^{-1}$ DS for PLA2 
(Figure 3). PBDEs are destroyed during combustion, therefore the small concentrations detected in the biowaste ashes were as expected (North, 2004). The absence of significant accumulation of $\mathrm{PBDD} / \mathrm{Fs}$ in ash (see Section 3.2.1.3), which form during combustion of PBDEs, also confirmed that the contamination of these source separated biomass feedstocks with PBDEs was unlikely.

The upper bound $\sum$ PBDEs (except BDE 209) in RWW from non-virgin sources were 0.21-4.34 $\mu \mathrm{g}$ $\mathrm{kg}^{-1}$ DS (Figure 2c), which were significantly smaller than for biosolids and CLO, although greater than those measured in ash. For virgin wood and RWW5 (recycled virgin wood shavings) the upper bound $\sum$ PBDEs was equivalent to $0.12 \mu \mathrm{kg}^{-1} \mathrm{DS}$ and $0.012 \mu \mathrm{g} \mathrm{kg}^{-1} \mathrm{DS}$, respectively. Again, BDE 209 was found in the greatest concentrations, between 7.9-246 $\mathrm{g} \mathrm{hy}^{-1}$ DS in RWW from non-virgin sources (Figure 3); this reflected the use of deca-BDEs as BFRs ${ }_{11}$. $f_{1}$. niture manufacture (Fernandes et al., 2009), for example in synthetic fabrics or padding mate riai ' "Vang et al., 2019) that may contaminate wooden furniture.

The PBDE profile of cardboard was similar to RW' $\sim \mathbf{v}$, the RWW containing the largest amounts of PBDEs. The upper bound $\sum$ PBDEs (excluding $\mathrm{RD}_{\mathrm{L}}^{-2}$ 209) was $4.6 \mu \mathrm{gg}^{-1} \mathrm{DS}$ (Figure 2c), and the indicative concentration of BDE 209 was $225 \mu_{\mathrm{i}} \mathrm{kg}^{-1}$ DS (Figure 3).

Upper bound $\sum$ PBDEs (excluding BDF ? $\urcorner$ ? for DPS were in the range of $2.8-3.5 \mu \mathrm{g} \mathrm{kg}^{-1} \mathrm{DS}$ (Figure 2c), which was similar to the r.ust untaminated RWW, for example, the upper bound $\sum$ PBDEs for RWW1 and RWW2 $\mathrm{wc}_{\mathrm{c}} \bullet 2.2 \mu \mathrm{g} \mathrm{kg}^{-1} \mathrm{DS}$ and $4.3 \mu \mathrm{g} \mathrm{kg}^{-1} \mathrm{DS}$, respectively (Figure 2c). The BDE 209 concentration was ${ }^{-1} 5^{-}-429 \mu \mathrm{g} \mathrm{kg}^{-1}$ DS in DPS, compared to 246 and $143 \mathrm{\mu g} \mathrm{kg}^{-1}$ DS in RWW1 and RWW2, respec 'ive:; (Figure 3).

The PBDE congeners present in the greatest concentrations were BDE 47 and BDE 99, representing $83-84 \%$ and $80-81 \%$ of the sum of tetra- and penta-BDEs in biosolids and CLO samples, respectively (Figure 2a). Indeed, BDE-99 is one of the main constituents of commercial penta-BDE formulations, which may explain its relatively high abundance in biosolids and CLO (Smith and Riddell-Black, 2007). Brambilla et al. (2016) also found that these were the most abundant congeners in biosolids from 54 Italian WwTPs, representing $80 \%$ of the sum of tetra- and penta-BDEs. 


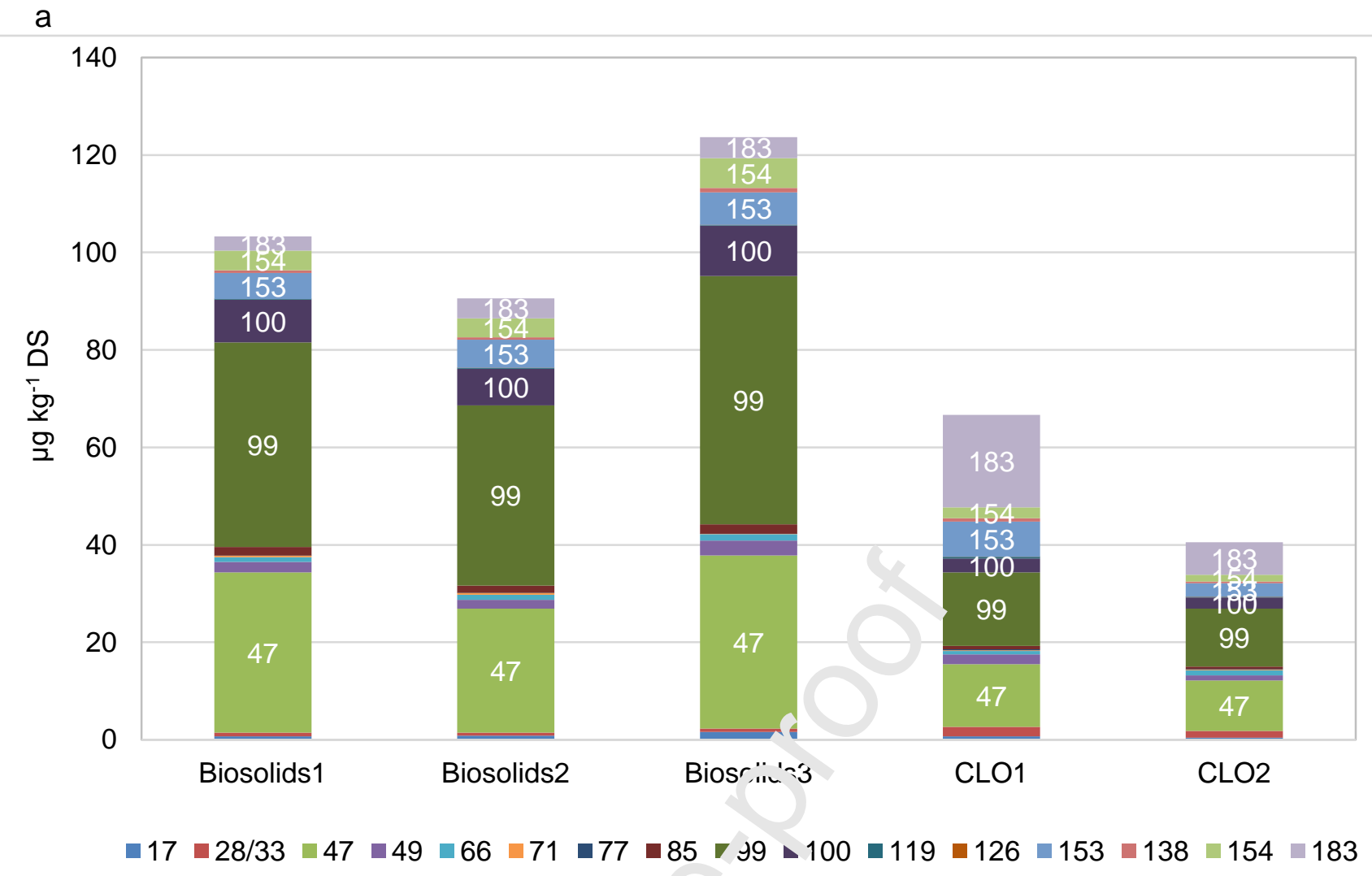

b

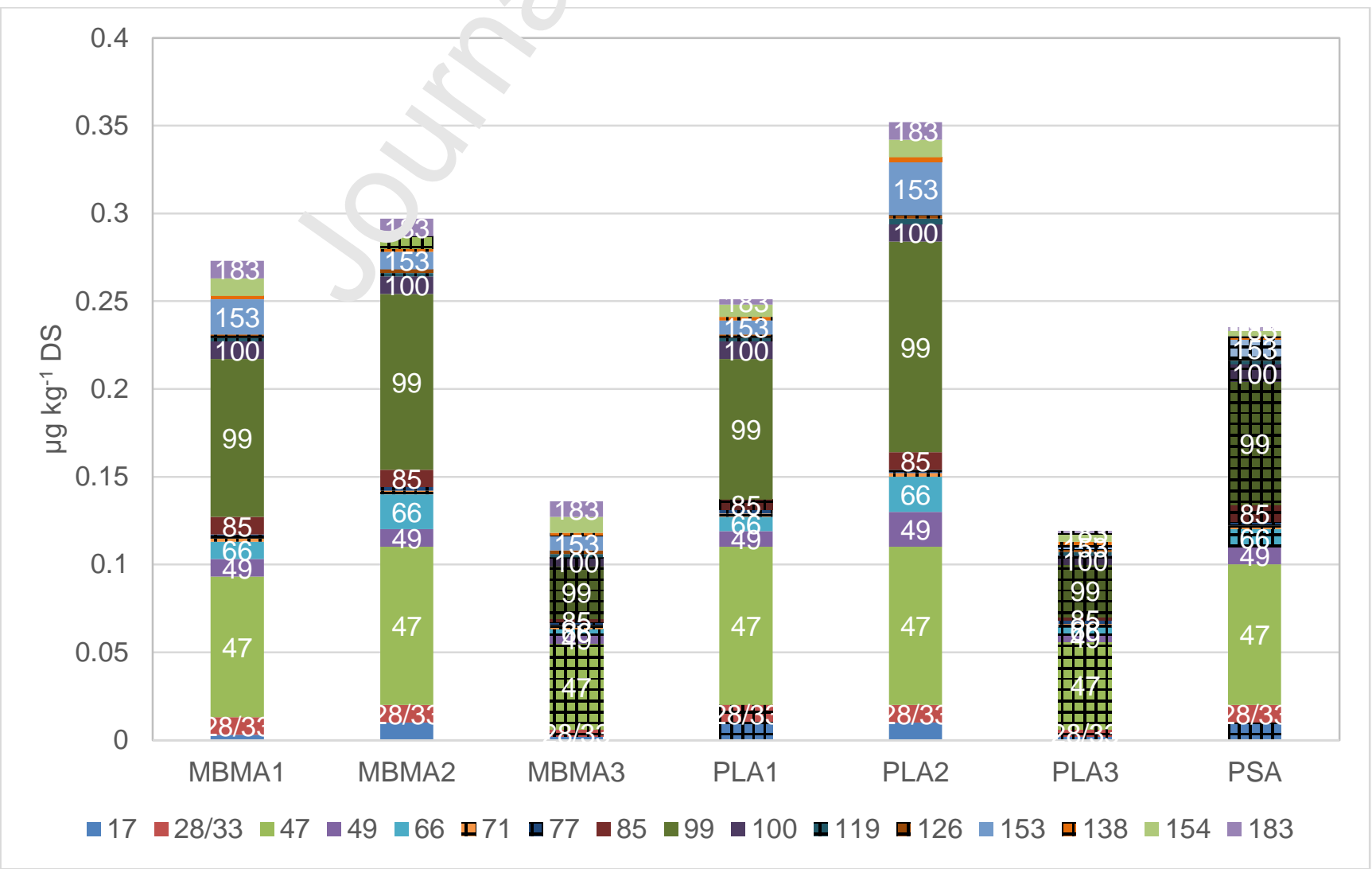


C.

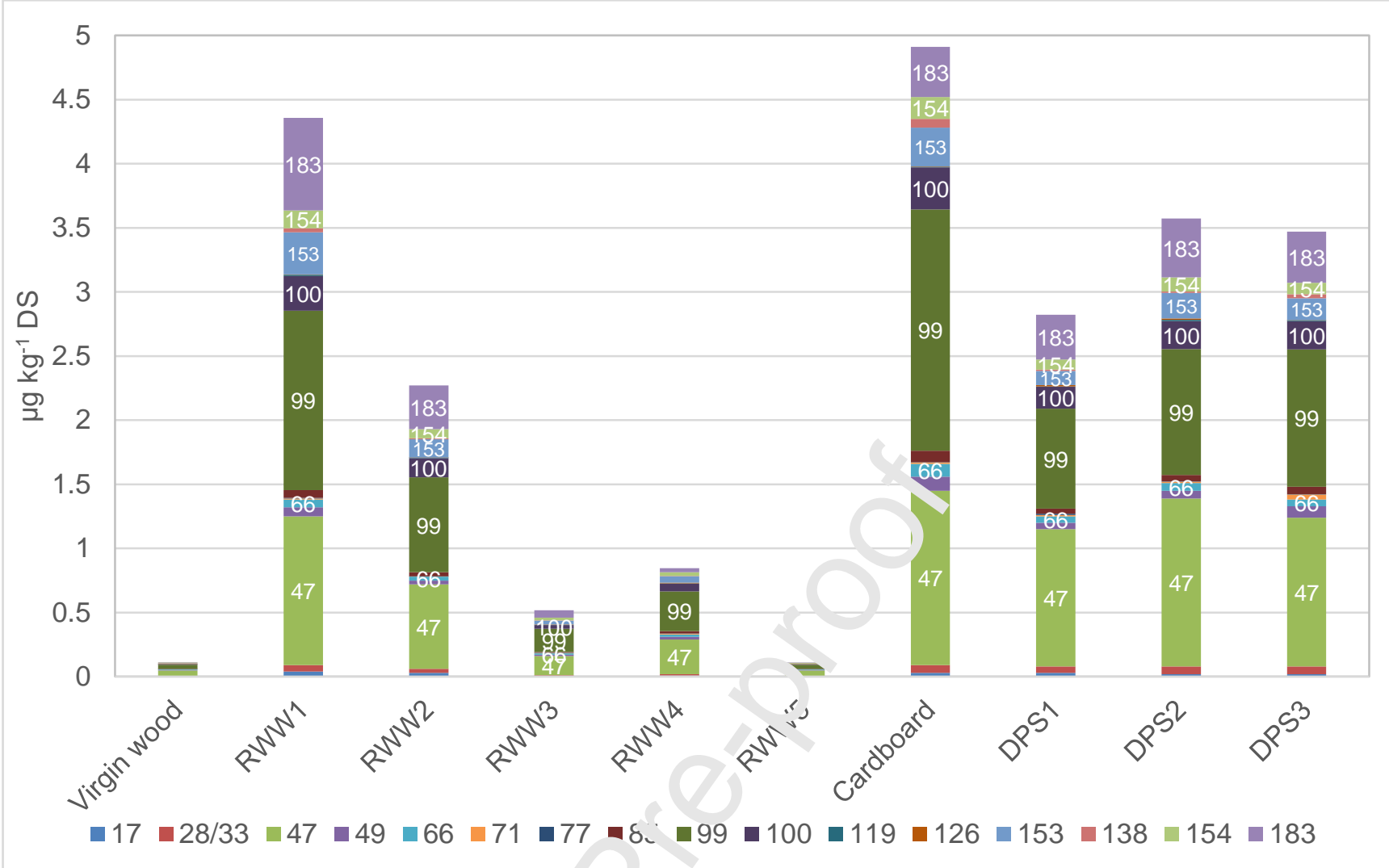

Figure 2 Polybrominated diphenyl ether (tr-, tetra-, penta-, hexa- and hepta-PBDE) concentrations in (a) biosolids and CLO; (b) biowaste ashes =nd (c) virgin wood, RWW, cardboard and DPS.

Legend shows BDE number

Data points with a grid pattern wr $\cdots$ L.'Jw the limit of quantification, which is displayed.

CLO, compost-like-output; Mt: ${ }^{1} \mathrm{~A}$, , leat and bonemeal ash; PLA, poultry litter ash; PSA, paper sludge ash; RWW, recycled waste wood; DrS, dried paper sludge.

However, the concentrations of BDE 47 and 99 in biosolids samples collected here were several times greater than those measured by Brambilla et al. (2016). Thus, we found BDE 47 and BDE 99 in the ranges: $25.4-35.5$ and 37.0-51.0 $\mathrm{g} \mathrm{kg}^{-1} \mathrm{DS}$ (Figure 2a), respectively, whereas Brambilla et al. (2016) reported values in the range of $0.41-17.4 \mu \mathrm{g} \mathrm{kg}^{-1}$ DS for BDE 47 and $0.56-22.3 \mu \mathrm{g} \mathrm{kg}^{-1} \mathrm{DS}$ for BDE 99.

CLO contained less than half the amount of BDE-47 compared to the biosolids samples, equivalent to 12.9 and $10.4 \mu \mathrm{g} \mathrm{kg}^{-1} \mathrm{DS}$, for CLO1 and CLO2, respectively (Figure 2a). Furthermore, 
the concentration of BDE 99 in the CLOs was approximately 3-5 times smaller than for the biosolids samples and was equivalent to 15.1 and $11.9 \mathrm{\mu g} \mathrm{kg}^{-1} \mathrm{DS}$ in CLO1 and CLO2, respectively (Figure 2a). Both CLO and biosolids contained BDE congeners 49, 66, 100, 153, 154 and 183 generally in the range between 1-10 $\mathrm{g} \mathrm{kg}^{-1} \mathrm{DS}$, and the remaining PBDE congeners were $<1 \mu \mathrm{g} \mathrm{kg}^{-1} \mathrm{DS}$ (Figure 2a).

The biosolids samples contained the largest amounts of deca-BDE (4200 - $\left.9206 \mu \mathrm{gg}^{-1} \mathrm{DS}\right)$, (Figure 3) and the deca-BDE 209 content was significantly greater than the median concentration measured by Knoth et al. (2007) of $108 \mu \mathrm{g} \mathrm{kg}^{-1} \mathrm{DS}$ (range: $12.5-288 \mu \mathrm{g} \mathrm{kg}^{-1} \mathrm{DS}$ ). The CLO samples had lower amounts of deca-BDE compared to biosolids, equivalent ic 1720 and $1650 \mu \mathrm{g} \mathrm{kg}^{-1} \mathrm{DS}$ for CLO1 and CLO2, respectively (Figure 3).

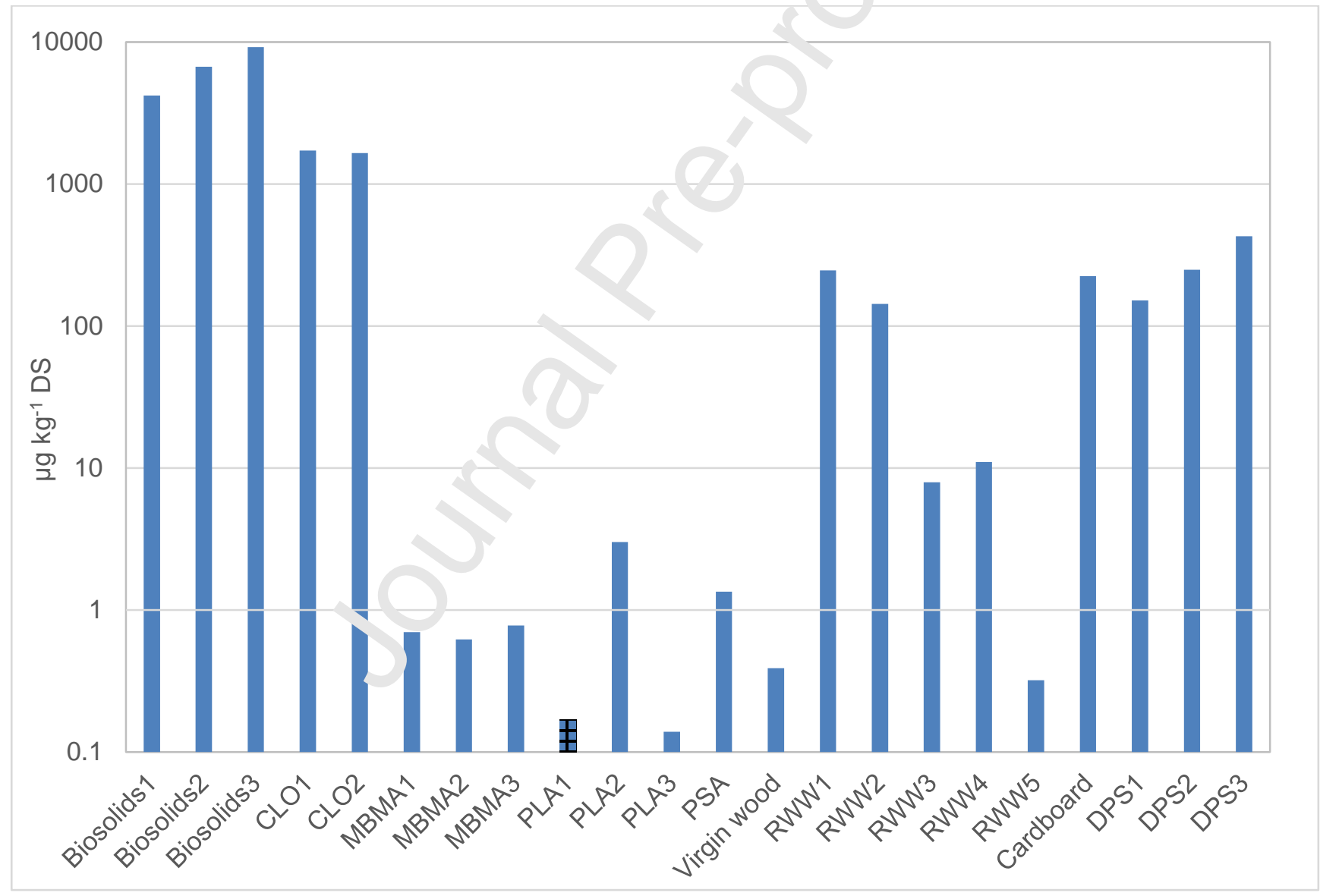

Figure 3 Deca-BDE 209 in the industrial and municipal bioresources (logarithmic scale)

Data points with a grid pattern were below the limit of quantification, which is displayed.

CLO, compost-like-output; MBMA, meat and bonemeal ash; PLA, poultry litter ash; PSA, paper sludge ash; RWW, recycled waste wood; DPS, dried paper sludge

These relatively high concentrations of deca-BDE 209 in comparison to the other PBDEs in biosolids and CLO may reflect the increased use of deca-BDEs in Europe, which expanded following 
the prohibition of flame retardant preparations containing penta- and octa-BDE in 2003 (EU, 2003). However, deca-BDE was also banned in electrical and electronic equipment in the EU from 2008 (EC, 2008), therefore, the high concentrations observed are largely the legacy of this earlier use and from imported goods containing the deca-BDE BFR. Deca-BDE is listed alongside penta- and octa-BDEs as a POP (UN, 2001), therefore eliminating the production and use of this BFR is also a priority (Vandermeersch et al., 2015). High concentrations of deca-BDE in biosolids and CLOs may explain the prevalence of PBDD/Fs also observed in these materials (Section 3.1.4), due to transformation of deca-BDE, for example, during heating (Vetter et al., 2015; Yang et al., 2020).

Certain PBDEs show dioxin-like toxicity; however, because their n'FP values are several orders of magnitude smaller than TCDD (Venkatesan and Halden, 2014) $\operatorname{ar}^{\mathrm{N}} \mathrm{r}$ onsequently, they were not included in the estimated assessment of overall dioxin-like tr.xici, in Table 1. For example, BDE 47 and BDE 99 were present in the largest concentrations $a^{\prime} d$ al $ə$ assigned REPs of $7.1 \times 10^{-7}$ and $5.9 \times$ $10^{-6}$, respectively (Eljarrat and Barcelo, 2013). Hencr, ; r Biosolids3 (which typically contained the

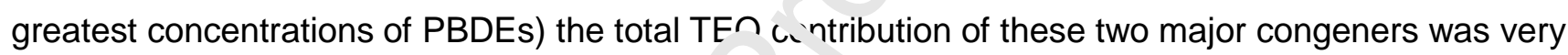
small and equal to $0.0003 \mathrm{ng}$ TEQ $\mathrm{kg}^{-1} \mathrm{DS}$.

\subsubsection{Hexabromocyclododecane, tetrabı or «'ipshenol A and pentabromocyclododecene}

The largest concentrations of HBCDE s were found in the CLOs, Biosolids1, Biosolids2, and RWW1 and were generally in similar range $=1$, these materials (Figure $4 a$ ). However, the concentrations were significantly smaller in Biosol asu For example, Biosolids1 and Biosolids2 samples contained $\gamma^{-}$ HBCDD at concentrations bel reen 302-392 $\mathrm{g} \mathrm{kg} \mathrm{k}^{-1} \mathrm{DS}$, whereas the concentration in Biosolids3 was below the limit of quantification, $<1.29 \mathrm{\mu g} \mathrm{kg}^{-1} \mathrm{DS}$ (Figure 4a). CLO2 contained the largest amounts of $\alpha-, \beta$ - and $\gamma-H B C D D$, equivalent to $121-302,34-78$ and $139-836 \mu \mathrm{g} \mathrm{kg}^{-1} \mathrm{DS}$, respectively, and also the most PBCDD, compared to the other bioresources, equivalent to $42-351 \mu \mathrm{g} \mathrm{kg}^{-1}$ DS. TBBPA was present in relatively large concentrations compared to the other compounds in this group of BFRs. CLO1 contained the largest amounts of TBBPA, equivalent to $493-517 \mu \mathrm{gg}^{-1} \mathrm{DS}$, and Biosolids1 and Biosolids2 contained concentrations between $33-45 \mu \mathrm{g} \mathrm{kg}^{-1}$ DS (Figure 4a). The relatively large concentrations of these BFRs in biosolids and CLO may be explained because they are used in many

a. 


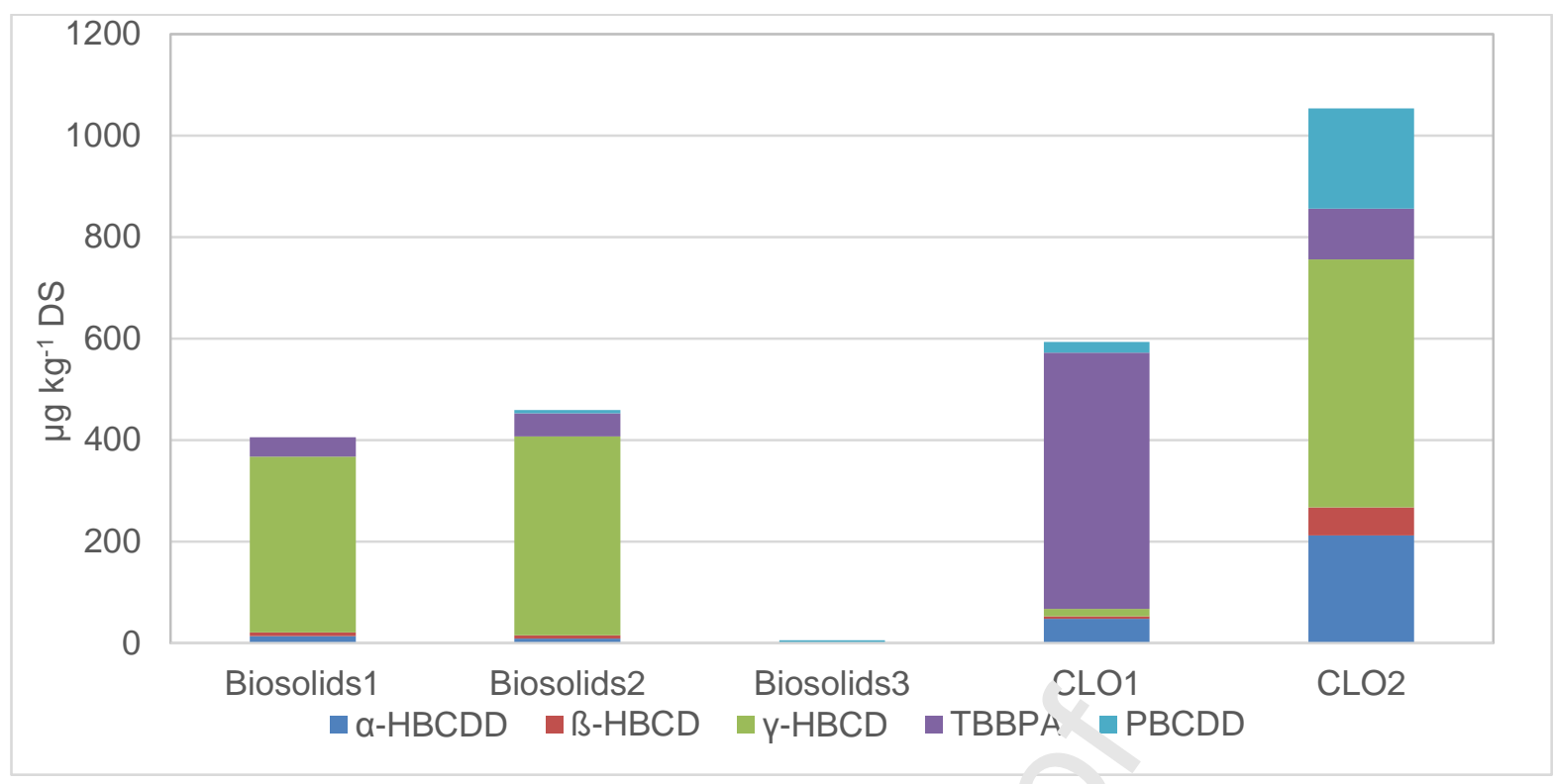

b.

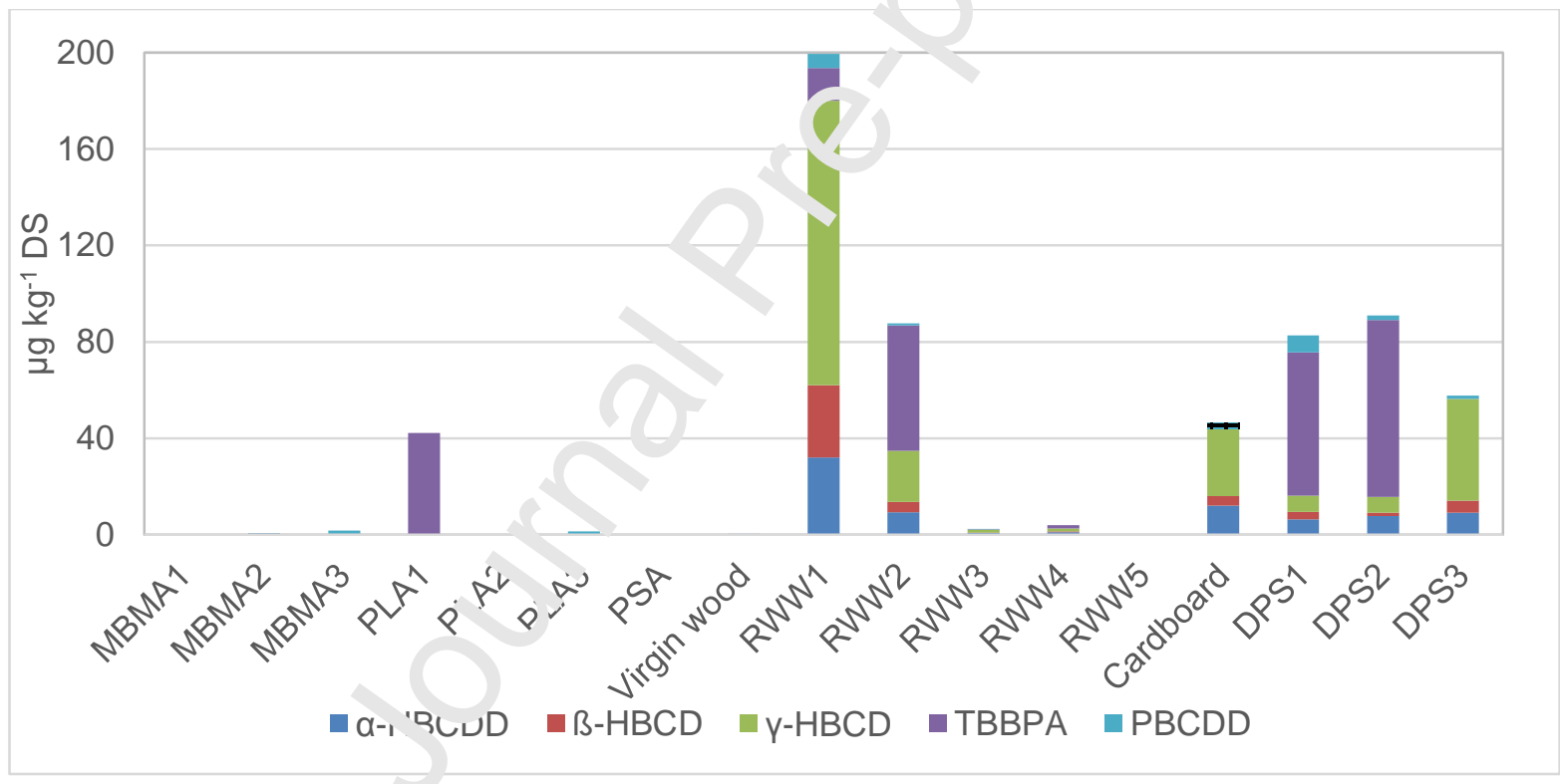

Figure 4 Hexabromocyclododecane (HBCDD), tetrabromobipshenol A (TBBPA) and pentabromocyclododecene (PBCDD) concentrations in (a) biosolids and CLO; and (b) biowaste ashes, virgin wood, RWW, cardboard and DPS

N.B. For Biosolids1, CLO1, CL2 and RWW1 repeatability was varied due to sample heterogeneity and mean values are presented; Data points with a grid pattern were below the limit of quantification, which is displayed. CLO, compost-like-output; MBMA, meat and bonemeal ash; PLA, poultry litter ash; PSA, paper sludge ash; RWW, recycled waste wood; DPS, dried paper sludge 
domestic applications including fabrics, packaging materials and plastics (Smith and Riddell-Black, 2007), and hence would be expected to transfer to wastewater and domestic refuse. RWW1 tended to contain the largest concentrations of HBCDD, TBBPA and PBCDD compared to the other RWW samples, with 67-169 $\mathrm{g} \mathrm{kg} \mathrm{k}^{-1}$ DS of $\mathrm{Y}^{-H B C D D}$ and 19-45 $\mu \mathrm{g} \mathrm{kg}^{-1}$ DS of $\alpha-H B C D D$ (Figure 4b), consistent with the general concentration profile of other contamination groups in this RWW material.

These compounds were also detected in elevated amounts in RWW2, but the concentrations were generally smaller compared to RWW1, with the exception of TBBPA, which was present at an indicative concentration of $52 \mu \mathrm{g} \mathrm{kg}^{-1}$ DS in RWW2, compared to 8.2-18.9 $\mathrm{gg} \mathrm{kg}^{-1}$ DS in RWW1. HBCDDs, PBCDD and TBBPA were also detected in RWW3, RWW'4 and RWW5 and the virgin wood shavings, although concentrations were generally very small and i, ni, ally $\leq 1 \mu \mathrm{g} \mathrm{kg}^{-1} \mathrm{DS}$.

Concentrations of HBCDD, TBBPA and PBCDD were ger era."., below the limit of quantification in the ashes (Figure 4b). However, TBBPA was detected ir. PLA I at $42 \mu \mathrm{gg}^{-1}$ DS, PBCDD was detected in MBMA3 and PLA3 at concentrations of ${ }^{1} .0^{-} \mathrm{ug} \mathrm{kg}^{-1} \mathrm{DS}$ in both materials and $\alpha^{-}, \beta^{-}$and $\gamma$-HBCDD stereoisomers were also detected, $\because:$ " elc ${ }^{+i v e l y ~ l o w ~ c o n c e n t r a t i o n s ~ o f ~} \leq 0.13 \mu \mathrm{g} \mathrm{kg}^{-1} \mathrm{DS}$ in MBMA2 and/or PLA1. The relatively low concer r' rations of HBCDDs were consistent with the near complete destruction of HBCDDs observ', d du.ing MSW incineration (Mark et al., 2015).

$\alpha-, \beta$ - and $\gamma^{-}$HBCDD were detect $\epsilon \unlhd$ I . sardboard at concentrations of $12.1,4.0$ and $27.8 \mu \mathrm{g} \mathrm{kg}^{-1}$ DS, respectively, similar to the conce ntrations measured in RWW2 (Figure 4b). However, PBCDD was below the limit of quantifir:_tic...

\subsubsection{Organophosphate flame retardants}

The concentrations of six OPFRs are shown in Figure 5 (OPFRs were not measured in Biosolids3). Tris(1-chloro-2-propyl) phosphate (TCPP) was found in the largest concentrations in biosolids and CLO at concentrations between $197 \mu \mathrm{g} \mathrm{kg}^{-1} \mathrm{DS}$ in Biosolids 1 to $1530 \mu \mathrm{g} \mathrm{kg}^{-1} \mathrm{DS}$ in CLO1, reflecting its more widespread use since the phasing out of triethyl-chloro-phosphate (TCEP) 


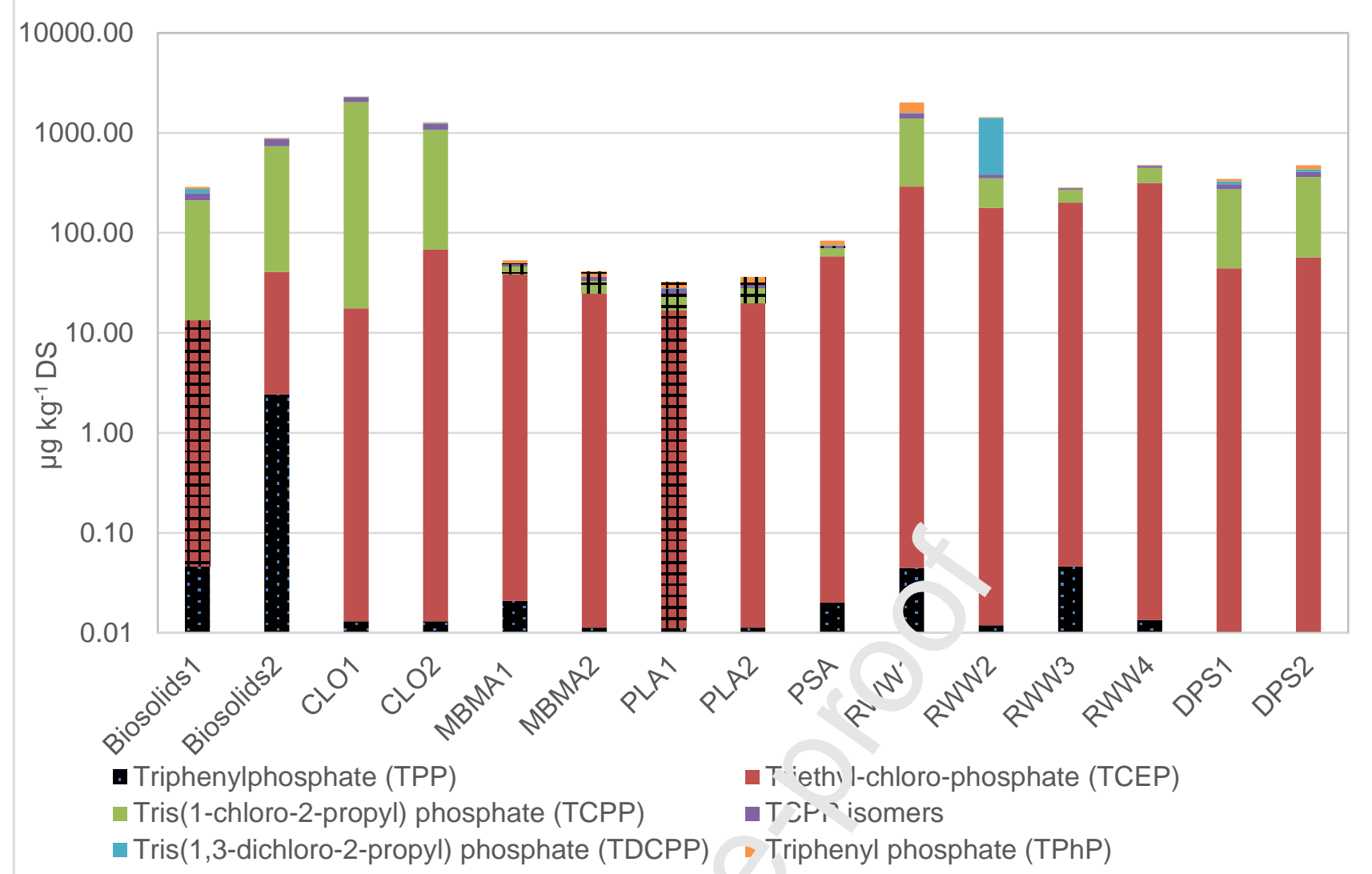

Figure 5 Organophosphate flame retardants $\left(\mathrm{Ur}_{\mathrm{r}} \mathrm{Fh}_{\boldsymbol{}}\right.$ ) in industrial and municipal bioresources used in agriculture (log scale)

Data points with a grid pattern were below th $\_1$. nit of quantification, which is displayed.

CLO, compost-like-output; MBMA, meat : ina 'ronemeal ash; PLA, poultry litter ash; PSA, paper sludge ash; RWW, recycled waste wood; DPS, drie` naper sludge

(Eggen et al., 2013). TCPr 'su....ers (the three most commonly measured isomers) were also found in relatively high concentrations in biosolids and CLOs, between $8-193 \mu \mathrm{g} \mathrm{kg}^{-1} \mathrm{DS}$.

Concentrations of OPFRs were small and generally below the limit of quantification in ash, with the exception of triethyl-chloro-phosphate (TCEP), which was measured at indicative concentrations between $<17 \mu \mathrm{g} \mathrm{kg}^{-1}$ DS in PLA1 to $58 \mu \mathrm{g} \mathrm{kg}^{-1}$ DS in PSA (Figure 5), potentially indicating a greater resistance to incineration than the other OPFR chemicals.

TCPP was found in relatively large concentrations in RWW1, similar to CLO, at $1101 \mu \mathrm{g} \mathrm{kg}^{-1} \mathrm{DS}$ (Figure 5). Of the OPFR compounds detected, TCPP was also found in relatively larger concentrations, equivalent to 227 and $306 \mathrm{\mu g} \mathrm{kg}^{-1} \mathrm{DS}$, in DPS1 and DPS2, respectively (Figure 5). However, in RWW2, the most abundant OPFR was tris(1,3-dichloro-2-propyl) phosphate (TDCPP), 
used extensively as a fire retardant in the foam padding in furniture and cars (Betts, 2013), which was found at a concentration of $1032 \mu \mathrm{g} \mathrm{kg}^{-1} \mathrm{DS}$. Another OPFR, TCEP, was present in the largest amounts in RWW3 and RWW4, at concentrations equivalent to 201 and $314 \mu \mathrm{g} \mathrm{kg}^{-1}$ DS, respectively.

\subsubsection{Hexabromobenzene, 1,2 bis(2,4,6-tribromophenoxy) ethane, and decabromodiphenylethane}

HBB, BTBPE and DBDPE were measured in the CLO and RWW samples (Section 3.3.5) (Table S14, Supplementary Information) after their presence was indicated in these materials following the GC-TOF-MS screen. Of this group of emerging flame retardant conta ninants, the largest concentrations were of DBDPE, which was present at 3418 and $1: 97 \mathrm{\mu g} \mathrm{kg}^{-1}$ DS in CLO1 and CLO2. This observation reflects the trend of increasing DBDPE con :er.'scilions in the environment due to the ban on penta-BDEs (Davies, 2013).

HBB, BTBPE and DBDPE were not detected in th: '-iowaste ashes in the TOF screen and hence no further targeted analysis was conducted for tht, compounds in the ashes.

HBB, BTBPE and DBDPE were measured .: RWW and CLO Table S14, Supplementary Information). DBDPE was detected in the lar ast concentrations in RWW1 at $244 \mu \mathrm{gg}^{-1}$, however, this was significantly smaller than the $:$ nc =.Itrations measured in CLO1 and CLO2, which were equivalent to 3418 and $1387 \mu \mathrm{kg}^{-}$DS, respectively.

HBCDDs, TBBPA and PBCL乞 w',re also measured in DPS samples in relatively large amounts (Figure 4b). TBBPA was tc ' $n \iota^{\prime}$ ' ir the largest concentrations compared to the other compounds in this group, equivalent to 59.4 anu $73.4 \mu \mathrm{g} \mathrm{kg}^{-1}$ DS in DPS1 and DPS2, respectively (not measured in DPS3). With the exception of CLO, these were the largest concentrations of TBBPA determined in the different types of industrial and municipal bioresources examined, probably reflecting the use of TBBPA as a flame retardant to treat paper (Cato et al., 2014).

\subsection{Perfluoroalkyl Substances}

Nine perfluoroalkyl carboxylic acids (PFCAs) and perfluoroalkane sulfonic acids (PFSAs) were measured (Figure 6). PFASs were present in the greatest concentrations in the biosolids samples 
compared to the other sample types examined, with a total upper bound sum of 9 PFAS compounds $\left(\sum \mathrm{PFAS}_{9}\right.$ ) of 99 and $231 \mu \mathrm{g} \mathrm{kg}^{-1} \mathrm{DS}$ in Biosolids1 and Biosolids2, respectively. These concentrations were 3.5-8.5 larger than those measured in sewage sludge samples (activated sludge and lagoon sludge) from 19 Australian WwTPs by Coggan et al. (2019) who found a mean concentration of $28 \mu \mathrm{g}$ $\mathrm{kg}^{-1}$ DS for the same compounds (excluding PFOSA, which was not measured). The greater contamination of the biosolids samples examined here with PFAS may not unexpected as they were from WwTP serving highly urban catchments receiving combined domestic and industrial effluent.. They were also found in CLO, which contained $\sum \mathrm{PFAS}_{9}$ of 28.6 and $74.8 \mu \mathrm{g} \mathrm{kg}^{-1}$ DS in CLO1 and CLO2, respectively; however, the values measured in composted mia'?rial from mixed MSW treatment by MBT fell below the limit of $100 \mu \mathrm{g} \mathrm{kg}^{-1}$ DS for PFA.S.$\sim \sim$ smpost in Austria and Germany (Saveyn and Eder, 2014). PFOS was found in the largest ar oun... compared to the other PFAS compounds, equivalent to 60.9 and $204 \mathrm{\mu g} \mathrm{kg}^{-1}$ DS in Bic olic s1 and Biosolids2, respectively, and 8.9 and $35.4 \mathrm{\mu g} \mathrm{kg}^{-1}$ DS in CLO1 and CLO2, respectivel igure 6a). This pattern in relative PFAS concentrations in biosolids was consistent with r.o ran et al. (2019), although the mean PFOS concentration reported by Coggan et al. (2015; for 19 sewage sludge samples in Australia was smaller and equivalent to $14 \mu \mathrm{g} \mathrm{kg}^{-1}$ DS (rany ? <limit of quantification - $90 \mu \mathrm{g} \mathrm{kg}^{-1} \mathrm{DS}$ ). PFOS was also significantly raised compared to ${ }^{\prime \prime}$. $n_{\text {ivan }}$ content of $12.6 \mathrm{\mu g} \mathrm{kg}^{-1} \mathrm{DS}$ and, in the case of Biosolids2, the maximum (range 4.i-89.j $\mu \mathrm{g}$ PFOS $\mathrm{kg}^{-1} \mathrm{DS}$ ) reported by Brambilla et al. (2016) in Italian biosolids. The PFOS conc int ation detected in Biosolids2 was similar to the average reported

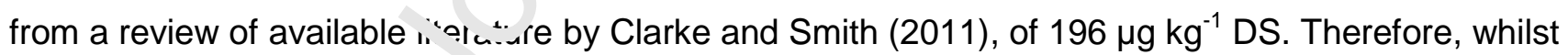
restrictions have been introauced on the marketing and use of PFOS in the EU (EP, 2006), the concentrations of PFOS in biosolids and CLO, and particularly in Biosolids2, indicated that a significant presence of legacy PFOS remains in the environment.

After PFOS, perfluorodecanoic acid (PFDA) was the next most abundant PFAS, present in Biosolids1 at a concentration equivalent to $19.9 \mu \mathrm{g} \mathrm{kg}^{-1} \mathrm{DS}$ (Figure 6a). Another substance of note was perfluorobutane sulfonate (PFBS), which was present in CLO2 at a concentration of $25.2 \mu \mathrm{gg}^{-1} \mathrm{DS}$. The other PFAS were typically detected in concentrations greater than $1 \mu^{g ~ g^{-1}} \mathrm{DS}$, but generally they were below $10 \mathrm{\mu g} \mathrm{kg}^{-1} \mathrm{DS}$ in the biosolids and CLOs. 
a.

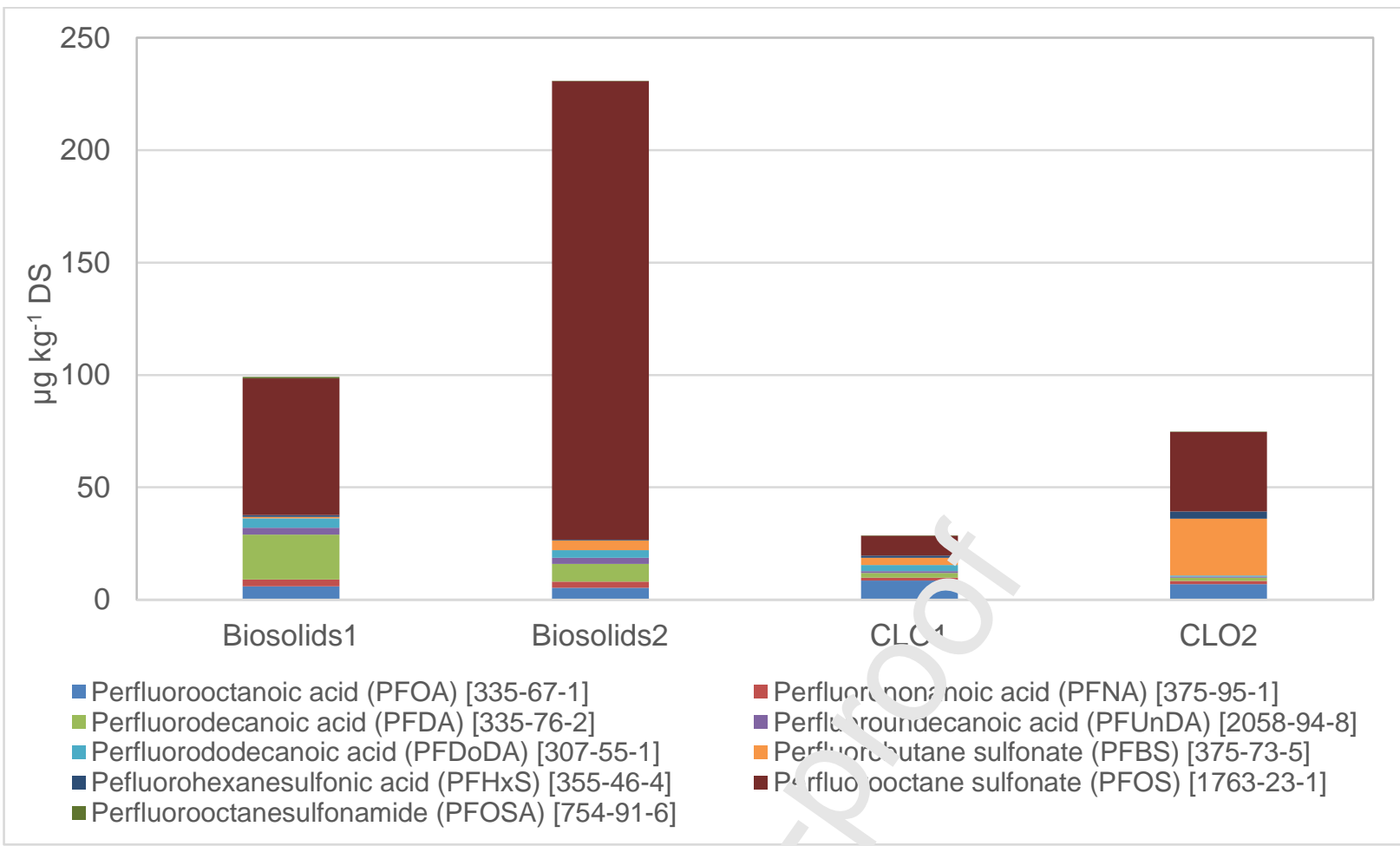

b.

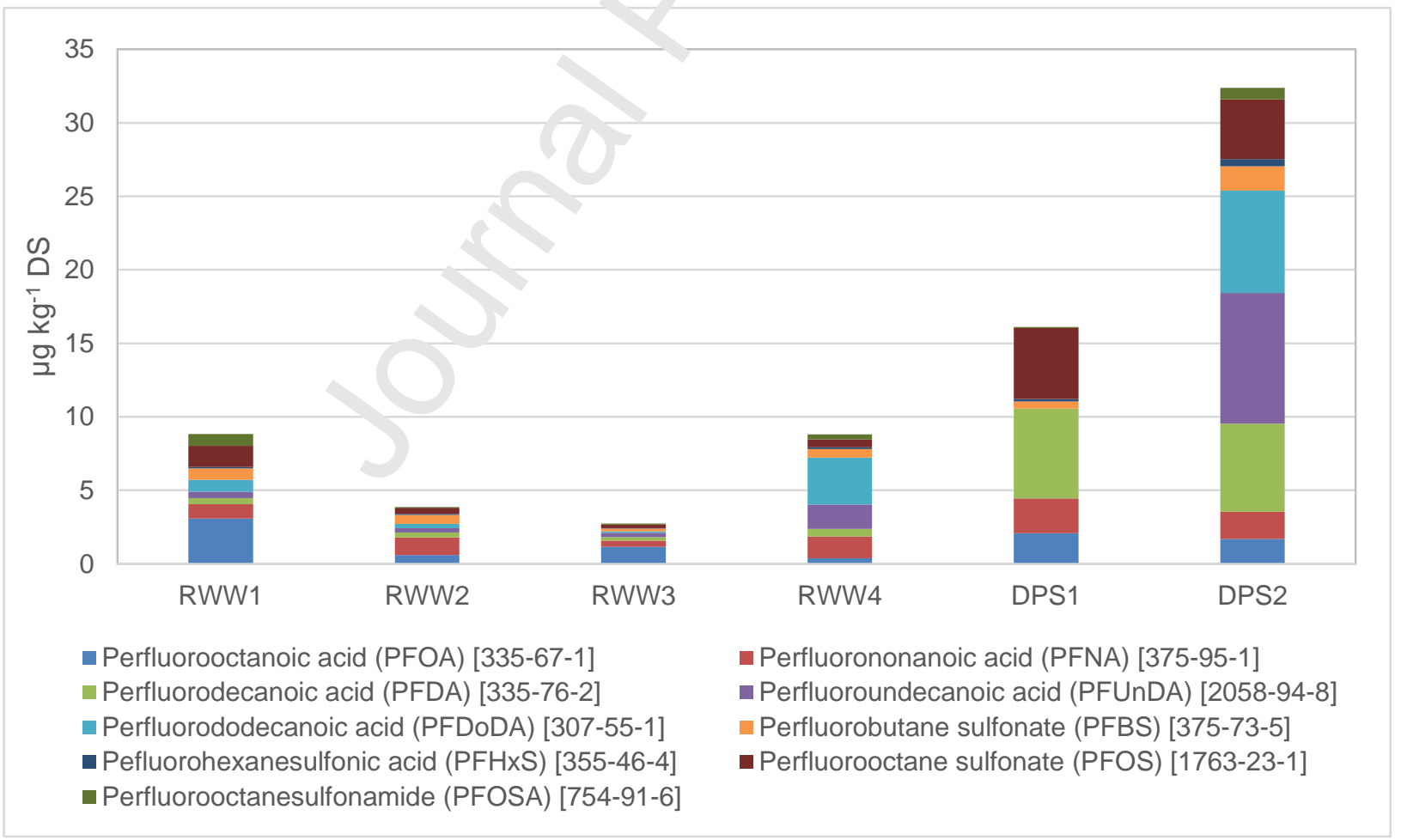

Figure 6. Perfluoroalkyl substances (PFASs) in industrial and municipal bioresources used in agriculture in (a) biosolids and CLO; and (b) RWW and DPS (log scale) 
The concentrations of PFOA were 6.0 and $5.4 \mu \mathrm{g} \mathrm{kg}^{-1}$ DS in Biosolids1 and Biosolids2, respectively, and were lower than the mean concentration reported by Clarke and Smith (2011) of 75 $\mu \mathrm{kg}^{-1}$ DS. Controls will apply to PFOA from July 2020 (EP, 2017), and hence its presence in the environment should continue to decrease.

The concentrations of PFAS in Biosolids3 were analysed in a screen, which used a 3-point calibration (Table S15, Supplementary Information) and are not directly comparable to the targeted quantification data presented in Figure 6a. However, the screening results indicated that the concentrations of PFAS in Biosolids3 from the rural WwTP were within a similar range to the other biosolids samples collected from major urban catchments and, as wai the case with PBDEs, this

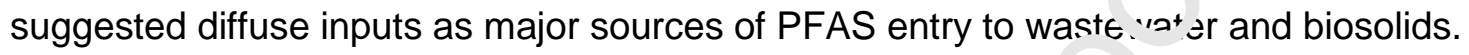

No PFAS were detected in any of the biowaste ash mater als $\stackrel{1}{ }$. able $S 15$, Supplementary Information), indicating that if PFAS were present in the f:eds ock, they were destroyed during combustion.

All of the PFAS were detected in the RWW $\leadsto n_{1}$,les from non-virgin sources (Figure 6b). However, the concentration pattern of the most significar. PFAS differed from biosolids and CLO. In this case, PFOA was the most abundant compound or sent at concentrations of up to $3.1 \mu \mathrm{g} \mathrm{kg}^{-1} \mathrm{DS}$ in RWW1; perfluorononanoic acid (PFN'; 'Nau present in the largest amount in RWW4, equivalent to $1.5 \mu \mathrm{gg}^{-1} \mathrm{DS}$, and RWW 1 contai, . $\mathrm{d} 1.4 \mathrm{\mu g} \mathrm{kg}^{-1}$ DS of PFOS. The PFAS screen indicated that a number of compounds were pres $\mathrm{nn}^{\mathrm{t}}$ in virgin wood bedding, recycled wood shavings from virgin sources (RWW5) and carcin a. ‥, including: PFOA, PFNA, PFDA and perfluorododecanoic acid (PFDoDA), and perfluorounciecanoic acid (PFUnDA), PFOS and perfluorooctanesulfonamide (PFOSA) were also detected in virgin wood (Table S15, Supplementary Material).

DPS contained relatively large concentrations of PFASs compared to the other industrial and municipal bioresources examined, although, overall, they were present in smaller amounts compared to biosolids and CLO (Figure 6b). However, the PFAS profile tended to differ from the biosolids, CLO and also RWW1. The compound present in the largest concentration was PFUnDA, measured at 8.9 $\mu \mathrm{kg}^{-1}$ DS in DPS2 (Figure 6b). PFUnDA could not be quantified in DPS1 and DPS3 did not undergo full quantification for PFASs, however, for DPS3, PFUnDA was present in the second largest concentrations in the semi-quantitative screen (Table S16, Supplementary Material), equivalent to 14 
$\mu \mathrm{gg}^{-1}$. PFUnDA is used in paper packaging (Posner, 2013), which may explain its occurrence in the

DPS from paper recycling. PFDA and PFDoDA were also present in relatively large amounts in DPS2, equivalent to 6.0 and $7.0 \mu \mathrm{g} \mathrm{kg}^{-1} \mathrm{DS}$, respectively. The screen results also indicated that both of these compounds were present in the largest concentrations in DPS3, equivalent to 16 and $10 \mu \mathrm{g}$ $\mathrm{kg}^{-1}$ DS for PFDA and PFDoDA, respectively.

\subsection{Polychlorinated Alkanes}

The concentrations of polychlorinated alkanes (PCAs) (total of short and medium chain) in the industrial and municipal bioresources are presented in Figure 7. Thc -oncentrations of PCAs were larger than any of the other organic contaminants measured, with :he exception of phthalates (Section 3. 8). Biosolids2 contained the most PCAs, equivalent to $14 \Gamma, 6 c^{2} \mu \mathrm{g} \mathrm{kg}^{-1} \mathrm{DS}$ and, whilst Biosolids1 contained less than 20 times this amount, the value was ' till $r$ 'gh relative to the other contaminants, at $6425 \mu \mathrm{gg}^{-1} \mathrm{DS}$. The concentrations in CLO were ." ${ }^{\text {thin }}$ a similar range to the biosolids at 59,526 and $11,079 \mu \mathrm{g} \mathrm{kg}^{-1}$ DS for CLO1 and CLO2, recnt tively. Global production of PCAs was approximately 1,100,000 $\mathrm{t}$ in 2012, the majorn, of which is in China (Glüge et al., 2016) and PCAs are used in a wide range of industrial application such as flame retardants, plasticisers, and in paints, adhesives and textiles. Their significar:. $a_{1} \cdot{ }^{\prime}$ in certain cases unrestricted, use means that they are present in a range of environmentá' com partments (Clarke and Smith, 2011), which explains their abundance in biosolids and CLC. P(;As are persistent, bioaccumulative and may have significant toxic properties (Glüge et c $^{\prime} .2^{n+1}$ ò; van Mourik et al., 2016) and hence they should be an urgent priority for source control mtasures to protect beneficial recycling systems. However, there are considerable uncertainties in estimating concentrations of these contaminants due to the complexity of commercial mixtures and their environmental fate (Fernandes et al., 2020).

The concentrations of PCAs in ash were typically small relative to the biosolids and CLOs and were generally in the range: $5.5-27.6 \mu \mathrm{g} \mathrm{kg}^{-1} \mathrm{DS}$ (Figure 7), although MBMA1 contained significantly more PCAs, equivalent to $243.8 \mu \mathrm{g} \mathrm{kg}^{-1} \mathrm{DS}$, compared to the other ash materials. The source of PCAs in the MBMA sample is unknown, however, this pattern of contamination was consistent with the elevated concentration of PCDD/Fs also found in MBMA1 (Table1), suggesting the incomplete destruction of organic contaminants during the combustion process. 


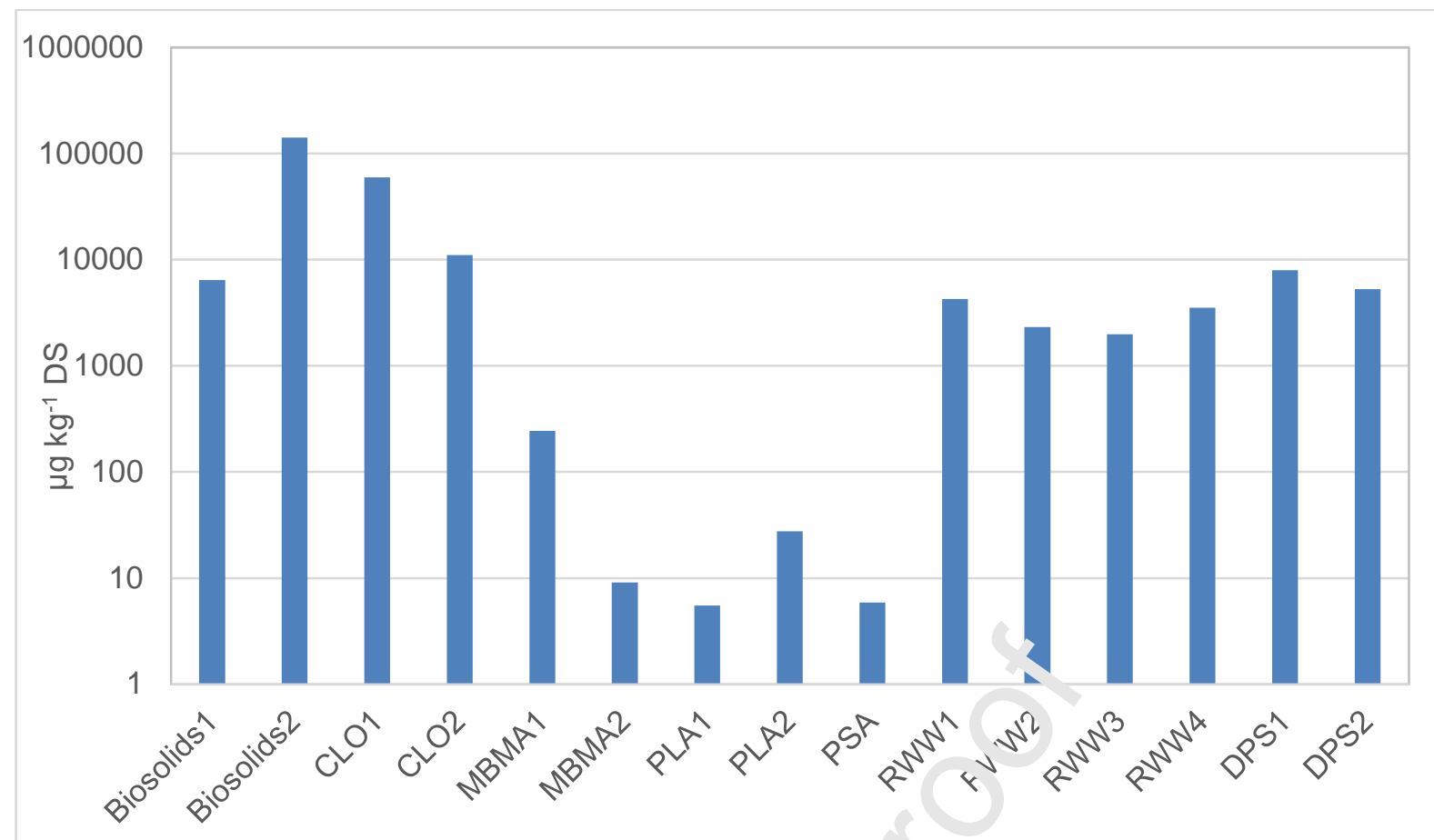

Figure 7. Polychlorinated alkanes (PCA) in industrial and mu, icipal bioresources used in agriculture

CLO, compost-like-output; MBMA, meat and bonem - ₹I ^ sh; PLA, poultry litter ash; PSA, paper sludge ash; RWW, recycled waste wood; DPS, dried paper slun, e

The concentrations of PCAs in RWW/ $\mathrm{n}$ ar $ə$ equivalent to $1989-4260 \mu \mathrm{gg}^{-1}$ DS (Figure 7), reflecting their use in wood treatme. its, is flame retardant coatings and paints. The concentrations of PCAs measured in RWW were : mal er than for biosolids and CLO, but were significantly greater than the amounts detected in $\mathrm{a}^{-h}$.

The concentrations of PC ${ }^{\wedge} . \mathrm{s}$ in DPS were $7981 \mu \mathrm{g} \mathrm{kg}^{-1}$ DS in DPS1 and $5255 \mathrm{\mu g} \mathrm{kg}^{-1}$ DS in DPS2 (Figure 7) and were similar to the concentration measured in Biosolids1. Historically, medium chained PCAs were used in the production of carbonless copy paper (EA, 2007), and hence paper recycling is a potential source of PCAs in DPS.

\subsection{Chlorobenzenes}

The concentrations of chlorobenzenes in the bioresources are presented in Table S16 (Supplementary Information). Hexachlorocyclobutadiene (HCBD), and pentachlorobenzene (PeCBz) were generally below the limit of quantification. Hexachlorobenzene (HCB) was the most abundant 
form found in biosolids and CLO samples at concentrations in the range $1.26-2.52 \mu \mathrm{gg}^{-1} \mathrm{DS}$. HCB is not currently manufactured but is a by-product from the synthesis of other industrial chemicals, and from chlor-alkali and wood preserving plants; small amounts may also be produced during combustion of MSW (US ATSDR, 2015), which may explain its presence in the biosolids and CLO samples. PeCBz was measured in biosolids and CLO samples, at concentrations of $0.47-0.65 \mu \mathrm{kg}^{-1}$ DS.

Chlorobenzenes were generally below or close to the limits of quantification in the biowaste ashes (Table S16, Supplementary Information); for example, PeCBz and HCB were detected in PLA2 at low concentrations of 0.19 and $0.09 \mu \mathrm{g} \mathrm{kg}^{-1} \mathrm{DS}$, respectively, and HCB wis also detectable at a concentration of $0.12 \mu \mathrm{g} \mathrm{kg}^{-1}$ DS in PSA.

HCBD and PeCBz were generally below the limit of quant fica: however, HCB was detected at concentrations of 0.14 ar. $10.9 \mu \mathrm{kg}^{-1} \mathrm{DS}$ in RWW2 and RWW1 respectively. The presence of HCB in RWW may be ${ }_{n}$ ) llained because it is a legacy by-product from historical wood preservation treatments (US ATSL.? 2015).

As was observed for biosolids and CLO (St, tion 3.1.8), HCB was the most abundant chlorobenzene found in DPS at concentration - in the range 1.00-1.32 $\mathrm{gg} \mathrm{kg}^{-1} \mathrm{DS}$. This may be explained because HCB is a by-prod' $v$ i fr...l the synthesis of other industrial chemicals, and in pulp and paper processing (US ATSDR, ?015).

\subsection{Phthalates}

Phthalates were measurtu in the biosolids and CLO samples and are reported in Table S17 (Supplementary Information) and were found in significantly greater concentrations than any other organic contaminant group, with the exception of PCAs (Section 3.6). The most significant phthalate was DEHP at a concentration of $163,000 \mathrm{gg} \mathrm{kg}^{-1} \mathrm{DS}$ in CLO2, which was significantly in excess of the compost standard for DEHP of $50,000 \mathrm{~g} \mathrm{~kg}^{-1}$ DS in both Belgium and Denmark (Saveyn and Eder, 2014). The concentration of DEHP in biosolids was similar in both samples that were examined (Biosolids1 and Biosolids2), at approximately $58,000 \mu \mathrm{g} \mathrm{kg}^{-1} \mathrm{DS}$. This was consistent with the mean value reported by Clarke and Smith (2011) from the international literature, but was less than a limit proposed by the EC of $100,000 \mu \mathrm{gg}^{-1}$ DS (EC, 2000a), which was subsequently withdrawn, but was 
in excess of the Danish limit value for DEHP in biosolids of $50,000 \mu \mathrm{gg}^{-1} \mathrm{DS}$ (Saveyn and Eder, 2014). DEHP has been widely used as a plasticiser, although its production has been prohibited in Europe since 2015 under EU REACH regulations (EC, 2015), nevertheless, the results reflect the abundant legacy sources of DEHP in the environment.

Diisononyl phthalate (DINP) was also found in relatively large concentrations of 92,700 and $104,000 \mu \mathrm{g} \mathrm{kg}^{-1} \mathrm{DS}$ in Biosolids1 and Biosoldis2, respectively, and 93,800 and 36,900 $\mu \mathrm{g} \mathrm{kg}^{-1} \mathrm{DS}$ in CLO1 and CLO2, respectively. DINP cannot be used in the production of toys that are mouthed by infants under REACH (EC, 2015), but it is otherwise widely used, which explains why it is present in high concentrations in both biosolids and CLOs. As for PBDEs, a maj $r$ r reason why phthalate plasticizers are so abundant in the environment is that they are no: $n$ valently bound with the main plastic forming polymer and, consequently, they leach out of the ... atrix in which they were placed at manufacture when they are used in domestic or commer : ial s sttings; for example vehicle washing is a major source of emissions of phthalates to the enviv iment (IC Consultants, 2001).

\section{General Discussion}

Overall, the concentrations of organic corri aminants measured in the representative examples of industrial and municipal bioresources _.'^ı. $\therefore$ ied here were generally smaller relative to reported literature values from earlier studie: (for example, Smith and Riddell-Black, 2007; Clarke and Smith, 2011), surveys or environmentaı -ta' Idards. The concentrations of PCDDs/Fs and PCBs in biosolids, CLO and ash were signific $\eta_{1}$; $r$, naller than proposed and implemented limits for these compounds across Europe for biosolids, womposts and recycled ash. Thus, source controls introduced to limit emissions of these contaminants have been demonstrably effective at reducing the primary sources and release of these organic contaminants to the environment and, consequently, improving the chemical quality of bioresources recycled in agriculture. Nevertheless, concentrations of PAHs in one of the biosolids samples collected from an urban catchment were large and exceeded a previously proposed European limit of $6000 \mu \mathrm{g} \mathrm{kg}^{-1} \mathrm{DS}$, emphasising that continued vigilance is necessary to curb emissions of established persistent organic contaminants, particularly in an urban context.

The results also demonstrated that other important contaminant groups may primarily originate from diffuse and domestic sources. For example, the biosolids collected from an entirely rural 
catchment (Biosolids3) contained larger concentrations of PBDEs and similar concentrations of PFASs compared to samples from two of the largest WwTP in the UK, serving major urban centres. This indicated that the presence of these substances in the built environment is highly pervasive and that there is likely to be a major legacy of release from multiple diffuse sources.

In other cases, we found that bioresources from source separated feedstocks, which usually is an effective approach to minimising potential contaminant entry into recycled waste materials, contained elevated amounts of historically source controlled, established organic contaminants, such as PCBs. Indeed, we found the largest concentrations of non-ortho-PCBs in DPS, which contributed an estimated $13-17 \%$ of the overall dioxin-like toxicity, compared to an citimated contribution of approximately $1-3 \%$ for the biosolids and CLO materials. The larqc st joncentrations of ortho-PCBs were also generally found in DPS. This may be explained be sauı PCBs may be unintentional impurities from the manufacture of pigments and dyes us ' $d$ ir printing inks. Therefore, it is important that vigilance is maintained to identify all possible so $\Perp$ as of potentially harmful organic contaminants, including those with already well as, ?blished regulatory controls on manufacture and use. In general, however, we found that the co, ribution of such dioxin-like compounds, other than PCDD/Fs and PBDD/Fs, to the overall estima ${ }^{+}$ad TEQ was generally not predominant.

PBDD/Fs are a major group of org ${ }_{11}:$ ? untaminants whose occurrence and significance in environmental media, and recycliny systems in particular, has received very little attention. However, this contaminant group made a la'nf $r$ contribution to the overall TEQ of biosolids and CLOs compared to PCDD/Fs, inci 'ainy that they are now of potentially greater significance for human health compared to their regulated chlorinated counterparts, and should be taken into account in risk assessments. The widespread and significant occurrence of PBDD/Fs in the bioresource materials examined could be explained to a large degree by the extensive use of BFRs including in domestic and industrial products, electronics, furnishing and textiles, which are transformed to PBDD/Fs in industrial processes, during waste treatment and in the environment (Ebert and Bahadir, 2003; Kajiwara et al., 2013; Zennegg et al., 2014; Wang et al., 2019).

PXDD/Fs are related compounds to PCDD/Fs and PBDD/Fs, representing a large and complex range of laterally substituted mixed halogenated congeners, and their formation mechanisms as byproducts of combustion and chemical processes are similar (Nakao et al., 2002; Söderström and 
Marklund, 2004). The TEQ of the PXDD/Fs that could be quantified was significantly smaller than for PCDD/Fs or PBDD/Fs, as the analysis is limited by the currently available analytical standards. Hence, the contribution of this group of compounds to the overall TEQ could be significant considering the many possible congeners potentially present in the environment.

PBDEs are a major group of BFRs and were detected in most of the different types of bioresources examined, including: biosolids, CLOs, RWWs, cardboard and DPS. However, they are destroyed under effective combustion conditions and, therefore, were not found in any of the ash materials. Deca-BDE 209 was the most significant PBDE, compared to the lower brominated BDEs, reflecting the expanding use of deca-BDEs as flame retardant chemicals in Eur רpe, since the prohibition of penta- and octa-BDE (EC, 2003a). Indeed, we would speculate th $c^{+}+h_{\text {g gh }}$ usage and concentrations of deca-BDE may be responsible for the formation, and high crnct.irations, of PBDD/Fs also found in the bioresource materials. The BFRs: HBCDD, TBBPA a: d P 3CDD were also detected in the biosolids and CLOs and, as observed for the PBDEs, v are generally found in very small amounts or were not detected in ash. Y-HBCDD was also moá ' 'Ired in elevated amounts in RWW1 and cardboard, and TBBPA was found in DPS, retı -ting its use as a BFR in paper.

The emerging flame retardant, DBDPF $w_{c}$ s found in relatively large concentrations in CLO and RWW samples, and this was probably ussuviated with the increasing use of DBDPE as an alternative flame retardant. Similarly, another y oup of alternative emerging flame retardant chemicals, OPFRs, were detected in the bioresource: TCPP was the dominant OPFR in biosolids and CLO; TDCPP and TCEP were also found in $\epsilon$ : गvated amounts in RWW.

Indeed, the research shoved that flame retardant chemicals are amongst the most significant and extensive sources of organic contamination of bioresources, and this occurs from direct treatment, e.g. RWW, DPS and cardboard, presence of materials treated with flame retardants, such as traces of plastic, textiles and wood in CLO or indirect contamination due to leaching and transfer to wastewater and biosolids. The occurrence of such a wide range of flame retarding compounds emphasised how readily these chemicals transfer into recycled products. A critical question that should be asked from an environmental and human health perspective, therefore, is how effective and necessary are flame retardants for protecting human life and whether fire safety could be achieved by alternative more sustainable means, compared to the wider consequences arising for 
health and beneficial recycling systems from the extensive contamination of the environment with flame retardant chemicals.

PFOS was the most significant PFAS in biosolids and the concentrations $\left(60.9\right.$ and $204 \mu \mathrm{gg}^{-1}$ DS) were similar to, or greater than values previously reported for biosolids (Clarke and Smith, 2011, Brambilla et al., 2016; Coggan et al., 2019). Restrictions have been introduced on the marketing and use of PFOS in the EU, nevertheless, the concentrations of PFAS measured in a diverse range of bioresource types indicated that there is a significant presence of legacy PFOS in the environment, which is entering recovered waste streams and hence bioresources destined for use in agriculture. DPS also contained relatively large concentrations of PFAS, compa ${ }_{1} \gamma$ to the other recycled bioresources although, overall, the amounts were smaller relative $\cap$ r.osolids and CLO. However, the PFAS profile of DPS differed from the biosolids and CLO anc $F_{1}^{-1}$ UnDA was the most significant in this case, which is probably explained due to its application ir oap er packaging. Clarke and Smith (2011) identified PFAS as one of the priority groups of orgar.iu compounds for agricultural recycling of biosolids and it is reassuring that source contrn' $\eta_{1}$ ₹sures for PFOA and PFOS have been or are in the process of being introduced in Europe.

PCAs are bioaccumulative, persistent, hav potential for long-range transport in the atmosphere

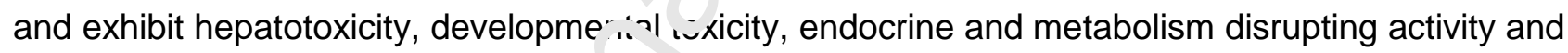
carcinogenicity (Gong et al., 2019). The concentrations of PCAs in the bioresources (in particular biosolids, CLO, RWW and DPS) :e'e amongst the largest of all the organic contaminants examined (e.g. Biosolids samples co, $\left.{ }^{+} 7_{11}=\right\lrcorner 6425$ and $140,688 \mu \mathrm{g} \mathrm{kg}^{-1} \mathrm{DS}$ short and medium chain PCAs), with the exception of phthalates, emphasising this compound class as a priority for source control to protect the chemical quality of recycled materials, especially when they are used in the food production cycle.

The concentrations of phthalates were analysed in the collected biosolids and CLO samples and were also relatively very high, in particular DEHP and DINP. DEHP production was prohibited in Europe in 2015, however the large concentrations found in biosolids and CLO indicate there remains a very significant legacy source of this contaminant in the environment. DINP, on the other hand, is still widely used, and the high concentrations measured in biosolids and CLO indicate that control 
measures will also be required to reduce the sources of environmental contamination of this plasticiser.

The results presented here emphasise the vital role that regulatory source control measures play in protecting beneficial recycling systems for bioresources. A modern society is heavily dependent upon functional chemical products, but chemicals development needs to not only take account of the direct, effective functional aspects, but should also design them to either remain bound within the system in which they are placed, unlike additive, labile, chemicals such as PBDEs and phthalates, and/or so they are not potentially persistent, bioaccumulative and toxic. Indeed, the presence of elevated concentrations of a contaminant does not necessarily repre snt a risk to health or the environment. For example, linear alkylbenzene sulfonate (LAS) is nə ufactured and used in extensive quantities as an anionic surfactant in detergents aıd u'-aning products and is present in biosolids in significant amounts, but it is rapidly degradak $?$ wi h very low toxicity (Schowanek et al., 2007).

Furthermore, the compounds consistently of $n_{0}$ ? nern in recycled bioresources are halogenated chemicals. Regulatory action to implement sou. 'e control measures may be taken, but this is usually only after a substantial period of use and rolt:-se of chemicals and when they have already become widely distributed in different environr.c nta. media, including bioresources, for example, BFRs, phthalates and PFASs. Indeed, the esiaual biosolids generated from the urban wastewater collection system provide an effective indic ' ${ }^{\text {to }}$ ' of the general chemical quality and status of the environment. The general process of eve ${ }^{\text {th }}+\ldots$...at follows with the current regulatory system is that limits on emissions of such chemicals are introduced step by step, and in some cases congener by congener (e.g. PBDEs) or chemical by chemical (e.g. PFASs). This approach is well intentioned; however, it can often encourage the manufacture and use of related compounds with even greater degrees of aromatic complexity and/or halogenation, which can increase persistence and the potential for bioaccumulation and toxicity. Given the broad range of halogenated chemicals that are a primary concern for the quality of recycled bioresources, food quality and the environment in general, an alternative, more radical strategy would be not to regulate specific groups, compounds or congeners of halogenated chemicals, but to place restrictions on all halogenated organic chemicals, unless it is proven that individually they are not persistent, bioaccumulative or toxic to human health and the 
environment, in which case they should not pose a threat to the beneficial use of bioresources in agricultural systems for food production.

\section{Conclusions}

This study provides a snapshot of the range and abundance of organic contaminants present in a selection of industrial and municipal bioresources used in agriculture as soil amendments and livestock bedding. This evidence will assist the quantitative assessment of the potential risks to human health from organic contaminants to underpin the policy and practice of recycling bioresources in agriculture. It also emphasises the importance of implementing rigi rous source control policies and measures for organic contaminants to protect important bioresour a $r$;cycling systems. Further work to investigate the potential transfer of organic contaminants $f$ ol. . .'.lese industrial and municipal bioresources to food products through the dairy, land apr ied sioresources, animal bedding, poultry (Fernandes et al., 2019b), pig (Fernandes et al., 201我 and crop pathways will be reported separately.

\section{Acknowledgments}

The Authors gratefully acknowleds? the Food Standards Agency for funding the research [grant number FS102009b]. The opinions arıu conclusions expressed in this article are solely the views of the authors and do not neces sari'v reflect those of the Food Standards Agency.

We would like to thank Sunhia Acker' and Radu Rautiu, Imperial College London Consultants for project management, and Malcolm Drifford, Fera, for his contribution to the text on the GC-ToF-MS screen methodology (Supplementary Information).

\section{Potential Conflict of Interests}

Alan Dowding, co-author, is an employee of the Food Standards Agency, who funded the research, and was involved in the selection of contaminants for analysis, and in reviewing and editing the paper.

\section{References}


ADAS, 2001. The safe sludge matrix: guidelines for the application of sewage sludge to arable and horticultural crops. 3rd ed. Available from: http://adlib.everysite.co.uk/resources/000/094/727/SSMatrix.pdf (Last accessed 11.03.14).

Alaee, M.; Arias, P.; Sjödin, A; Bergman, Å., 2003. An overview of commercially used brominated flame retardants, their applications, their use patterns in different countries/regions and possible modes of release. Environ. Int. 29(6), 683-689. doi: 10.1016/S0160-4120(03)00121-1

Amlinger, F.; Pollak, M.; Favoino, E., 2004. Heavy Metals and Organic Compounds from Wastes Used as Organic Fertilisers. ENV.A.2./ETU/2001/0024. Final Report to DG Environment: Brussels. Belgium, 2004. Available at:

http://ec.europa.eu/environment/waste/compost/pdf/hm_finalrepor . nr. (Last accessed June 2018).

Beníšek, M. Kukučka, P; Mariani, G.; Suurkuusk, G.; f.aw...., B.M.; Locoro, G.; Giesy, J.P.; Bláha, L. 2015. Dioxins and dioxin-like compounds in co' 'oos s and digestates from European countries as determined by the in vitro bioassay and $\sim$ i zmical analysis. Chemosphere 122, 168-175.

Betts, K.S., 2013. Exposure to TDCPP annecrs widespread. Environ. Health Perspec. 121. Birnbaum, L.S.; Staskal, D.F.; Diliberto, v. I., 2003. Health effects of polybrominated dibenzo-pdioxins (PBDDs) and dibenzofurans (PBDFs, Environ Int. 29, 855-860.

Brambilla, G.; Abate, V; Battacc « L., De Filippis, S.P.; Esposito, M.; Esposito, V.; Miniero, R., 2016. Potential impact on food saft : $y$ and food security from persistent organic pollutants in top soil improvers on Mediterranean pasi irf. Sci. Total Environ. 543, 581-590.

Buck, R.C.; Franklin, 1 ; Zこiger, U.; Conder, J.M.; Cousins, I.T.; de Voogt, P.; Jensen,A.A.; Kannan, K.; Mabury, S.A.; van Leeuwen, S.P.J., 2011. Perfluoroalkyl and polyfluoroalkyl substances in the environment: terminology, dlassification, and origins. Integr Environ. Assess. Manag. 7(4): 513541.

Carbonell, G.; de Imperial, R.M.; Torrijos, M.; Delgado, M.; Rodriguez, J.A., 2011. Effects of municipal solid waste compost and mineral fertilizer amendments on soil properties and heavy metals distribution in maize plants (Zea mays L.). Chemosphere 85, 1614-1623.

Cato, A.; Celada, L.; Kibakaya, E.C.; Simmons, N.; Whalen, M.M., 2014. Brominated flame retardants, tetrabromobisphenol $\mathrm{A}$ and Hexabromocyclododecane, activate mitogen-activated protein kinase (MAPKs) in human natural killer cells. Cell. Biol. Toxicol. 30. 344-360. 
Clarke, B.; Porter, N.; Symons, R.; Blackbeard, J.; Ades, P.; Marriott. P., 2008a. Dioxin-like compounds in Australian sewage sludge - Review and national survey. Chemosphere 72,1215-1228.

Clarke, B.; Porter, N.; Symons, R.; Marriott, P.; Ades, P.; Stevenson, G.; Blackbeard, J., $2008 b$. Polybrominated diphenyl ethers and polybrominated biphenyls in Australian sewage sludge. Chemosphere 73(6), 980-989.

Clarke, D.; Bailey, V.; Routledge, A.; Lloyd, A.; Hird, S., Mortimer, D. Gem, M., 2010. Dietary intake estimate for perfluorooctanesulphonic acid and other perfluorocompounds in UK retail foods following determination using standard addition LC-MS/MS. Food Addit. Contam. A 27 (4), 530-545.

Clarke, B.O.; Smith, S.R., 2011. Review of 'emerging' organ. - $r$ sntaminants in biosolids and assessment of international research priorities for the agricu' ura' use of biosolids. Environ. Int. 37, 226-247.

Coggan, T.L.; Moodie, D.; Kolobaric, A.; Szabr, I.; Shimeta, J.; Crosbie, N.D.; Lee, E.; Fernandes, M.; Clarke, B.O., 2019. An investicntic.' into per- and polyfluoroalkyl substances (PFAS) in nineteen Australian wastewater treatment plc nts (WWTPs). Heliyon e02316

Cunha, S.C.; Kalachova, K.; Pulkrahova J.; Fernandes, J.O.; Oliveira, M.B.P.P.; Alves, A.; Hajslova, J., 2010. Polybrominated dir, $r_{1} r_{1}, ;$ ethers (PBDEs) contents in house and car dust of Portugal by pressurized liquid extra 'tion (PLE) and gas chromatography-mass spectrometry (GCMS). Chemosphere 78(10), 12601271.

Davies, E., 2013. Aru:' ¿־JPE levels on the increase. Chemical Watch: Global Risk and Regulation News. Available at: https://chemicalwatch.com/16937/arctic-dbdpe-levels-on-the-increase (Last accessed June 2019).

Davou, E., 2014. Environmental Impacts of Recycled Wood. MSc. dissertation, Department of Civil and Environmental Engineering, Imperial College London: London, UK.

Defra: Department for Environment, Food and Rural Affairs, 2012. Wood Waste: A Short Review of Recent Research. Department for Environment, Food and Rural Affairs, London. Available at: https://www.gov.uk/government/uploads/system/uploads/attachment_data/file/82571/consultwood-waste-researchreview-20120731.pdf (Last accessed June 2018). 
Defra: Department for Environment, Food and Rural Affairs, 2013. Mechanical Biological Treatment of Municipal Solid Waste. Available at:

https://www.gov.uk/government/uploads/system/uploads/attachment_data/file/221039/pb13890treatment-solid-waste.pdf (Last accessed May 2019).

Defra and EA: Department for Environment, Food and Rural Affairs and Environment Agency, 2018. Sewage sludge in agriculture: code of practice for England, Wales and Northern Ireland. Available at: http://adlib.everysite.co.uk/resources/000/094/727/SSMatrix.pdf (Last accessed August 202).

D’Hollander, W.; Roosens, L.; Covacia, A.; Cornelis, C; Reync.```, H.; Van Campenhout, K; de Voogte, P. Bervoets, L., 2010. Brominated flame retardants and $D_{c}$ rfll ,orinated compounds in indoor dust from homes and offices in Flanders, Belgium. Chemosr.heı s1(4), 478-487.

Driffield, M.; Harmer, N.; Bradley, E.L.; Fernandes, A.; F ose, M.; Mortimer, D.; Dicks, P., 2008. The determination of brominated flame retardants in ' $v$. d by liquid chromatography with tandem mass spectrometric detection: diastereoisomer specifin 1, गxabromocyclododecane and tetrabromobisphenol A. Food Addit. Contam. 25(7), 895-903.

Ebert, J.; Bahadir, M., 2003. Formation of PBDD/F from flame-retarded plastic materials under thermal stress. Environ. Int. 29(6), 71^71し.

EC: European Commission, ¿ $100 a$. Working Document on Sludge. $3^{\text {rd }}$ draft. 27 April. Brussels, Belgium: DG Environment, Europ ’a'। Commission.

EC: European Comrı : ssi:r, 2000b. Directive 2000/76/EC of the European Parliament and of the Council of 4 December $\angle \cup 00$ on the incineration of waste. OJ L 332, 91-111.

EC: European Commission, 2003a. European Directive 2003/11/EC of 6 February 2003 Amending for the 24th Time Council Directive 76/769/ECC Relating to Restrictions on the Marketing and Use of Certain Dangerous Substances and Preparations (Pentabromodiphenyl Ether, Octabromodiphenyl Ether).

EC: European Commission, 2003b. Proposal for a Directive of the European Parliament and of the Council on Spreading of Sludge on Land. 30 April 2003. European Commission: Brussels, Belgium, 2003. 
EC: European Commission, 2008. Directive 2008/35/EC of the European Parliament and of the Council of 11 March 2008 amending Directive 2002/95/EC on the use of certain hazardous substances in electrical and electronic equipment (RoHS), as regards the implementing powers conferred on to the Commission. OJ L 81, 67-68.

EC: European Commission, 2010. Directive 2010/75/EU of the European Parliament and of the Council of 24 November 2010 on industrial emissions (integrated pollution prevention and control). OJ L 334, 17-119.

EC: European Commission, 2015. Regulation (EU) No 143/2011 of 17 February 2011 amending Annex XIV to Regulation (EC) No 1907/2006 of the European Parliâr ant and of the Council on the Registration, Evaluation, Authorisation and Restriction of Chemicá: = '‘: $\mathrm{EACH}$ '). OJ L 44.

EA: Environment Agency, 2007. Updated risk assessr enı ¿i alkanes, C14-17, chloro (mediumchain chlorinated paraffins). Environment Agency.

EA: Environment Agency, 2008. Paper sludge $10^{\prime}$ A technical report on the production and use of paper sludge ash. Environment Agency.

EA: Environment Agency, 2012. Technic . report for the production of treated ash from the incineration of poultry litter, feathers and ctrav : Environment Agency.

EFSA: European Food Safety $A_{\text {A }}$ ho.:...y, 2004. The EFSA's 1st scientific colloquium report dioxins. Methodologies and principi s for setting tolerable intake levels for dioxins, furans and dioxinlike PCBs, European Food Safel, A'jency, Parma, Italy.

EFSA: European Fou 1 _efty Authority, 2012. Update of the monitoring of dioxins and PCBs levels in food and feed. EFSA J., 10(7), 2832. doi: 10.2903/j.efsa.2012.2832

EFSA CONTAM: European Food Standards Agency Panel on Contaminants in the Food Chain, 2018a. Scientific Opinion on the risk to human health related to the presence of perfluorooctane sulfonic acid and perfluorooctanoic acid in food. EFSA Journal 16(12), 5194. doi: 10.2903/j.efsa.2018.5194

EFSA CONTAM: European Food Standards Agency Panel on Contaminants in the Food Chain, 2018b. Scientific opinion on the risk for animal and human health related to the presence of chlorinated paraffins in feed and food. EFSA Journal. Available online: 
https://www.efsa.europa.eu/sites/default/files/consultation/consultation/EFSA_CONTAM_Chlorinated_ paraffins.pdf (Last Accessed October 2019).

EFSA: European Food Standards Agency, 2020. Draft Opinion, Risk to human health related to the presence of perfluoroalkyl substances in food. EFSA Journal.

Eljarrat, E.; Barcelo, D., 2003. Priority lists for persistent organic pollutants and emerging contaminants based on their relative toxic potency in environmental samples. Trend. Anal. Chem. 22, 655-665.

Elskens, M.; Pussemier, L.; Dumortier, P.; Van Langenhove, K.; Scholl, G.; Goeyens, L.; Focant, J.F., 2013. Dioxin levels in fertilizers from Belgium: Determi, ${ }^{\text {tion }}$ and evaluation of the potential impact on soil contamination. Sci. Total Environ. 2013. 4is $366-372$.

EP: European Parliament, 2017. Commission Regula ioı, 'iتU) 2017/1000 of 13 June 2017 amending Annex XVII to Regulation (EC) No $1907 / 2006 \cdot f$ th European Parliament and of the Council concerning the Registration, Evaluation, Aut' ${ }^{\prime} u$ isation and Restriction of Chemicals (REACH) as regards perfluorooctanoic acid (PFOA), its cnlts and PFOA-related substances. OJ EU L150, 1418.

Eriksson, E.; Lundy, L.; Donner, E·S ·riki, K.; Revitt, M., 2011. Sludge Management Paradigms: Impact of Priority Substar us w. Id Priority Hazardous Substances. In: 12th International Conference on Urban . Trairrage, Porto Alegre/Brazil. 11-16 September 2011.

EU: European Union, 20น? r)irective 2003/11/EC of the European Parliament and of the Council of 6 February 200 $71_{1}$.:. .ding for the $24^{\text {th }}$ time Council Directive 76/769/EEC relating to restrictions on the marketing and use of certain dangerous substances and preparations (pentabromodiphenyl ether, octabromodiphenyl ether). OJ L42, 45-46.

Eulaers, I.; Jaspers, V.L.B.; Halley, D.J.; Lepoint, G.; Nygård, T.; Pinxten, R.; Covaci, A.; Eens, M., 2014. Brominated and phosphorus flame retardants in White-tailed Eagle Haliaeetus albicilla nestlings: Bioaccumulation and associations with dietary proxies ( $\delta 13 \mathrm{C}, \delta 15 \mathrm{~N}$ and $\delta 34 \mathrm{~S})$. Sci. Total Environ. 478, 48-57.

Eurostat, 2015. Water Statistics. Available at: http://epp.eurostat.ec.europa.eu/statistics_explained/index.php/Water_statistics (Last accessed June 2018). 
Fera, 2012. Organic Environmental Contaminants in the 2012 Total Diet Study. Report to the Food Standards Agency December 2012. Available at:

https://www.food.gov.uk/sites/default/files/media/document/research-report-total-diet-study.pdf (Last accessed June 2018).

Fera, 2017. Investigation of the Potential Transfer and Uptake of Contaminants into Food Arising from the Use of Recycled Waste in Agriculture. Final report to the Food Standards Agency FS 102009a.

Fernandes, A.; White, S.; D'Silva, K.; Rose, M., 2004. Simultaneous determination of PCDDs, PCDFs, PCBs and PBDEs in food. Talanta 63, 1147-1155.

Fernandes, A.; Dicks, P.; Mortimer, D.; Gem, M.; Smith, F : Lriff Jrd, M.; White, S.; Rose, M., 2008a. Brominated and chlorinated dioxins, PCBs and brom naıu flame retardants in Scottish shellfish: Methodology, occurrence and human dietary e; osı re. Molec. Nutr. and Food Res. 52, 238-249.

Fernandes, A.: Smith, F.; Carr, M.; Panten S. 2008b. Investigation of the Occurrence of Polychlorinated Naphthalenes and Chlorinatec Jaraffins in Food. REPORT FD 08/03 The National Archives UK. Available at:

https://webarchive.nationalarchives.gr,v.'Ih'_0141103172004/http://www.foodbase.org.uk//admintools/ reportdocuments/733-1-1245_C01i39_rCN-CP_Final_Report.pdf (Last accessed October 2019).

Fernandes, AR; Tlustos, C, Sr iith, F; Carr, M; Petch, R; Rose, M, 2009a. Polybrominated diphenylethers (PBDEs) $a_{1} 、$ レ: . . ninated dioxins (PBDD/Fs) in Irish food of animal origin. Food Addit. Contam.: Part B, 2:1, 86-94.

Fernandes, A.; Smith, F.; Petch N.; Brereton N.; Bradley E.; Panton S.; Carr, M. 2009b. Investigation into the levels of environmental contaminants in Scottish marine and freshwater fin fish and shellfish. Report to the Food Standards Agency Scotland, Fera Report 2 FD 09/01, 2009.

Fernandes, A.; Mortimer, D.; Gem, M.; Smith, F.; Rose, M.; Penton, S.; Carr, M. Polychlorinated Naphthalenes (PCNs), 2010a. Congener Specific Analysis, Occurrence in Food, and Dietary Exposure in the UK. Environ. Sci. Technol. 44, 3533-3538.

Fernandes, A.; Smith, F.; Carr, M.; Panton, S.; Mortimer, D.; Tlustos, C; Rose, M., 2010b. The Emerging BFRs Hexabromobenzene (HBB), Bis(246-tribromophenoxy)ethane (BTBPE), and 
Decabromodiphenylethane (DBDPE) in UK and Irish Foods. Proceedings of the Fifth International Workshop on BFRs, Kyoto 2010.Fernandes, A.R.; Rose, M.; Mortimer, D.; Carr, M.; Panton, S., Smith, F., 2011. Mixed brominated/chlorinated dibenzo-p-dioxins, dibenzofurans and biphenyls: Simultaneous congener-selective determination in food. J. Chromatogr. A, 1218, 9279-9287.

Fernandes, A.R.; Tlustos, C., Rose, M., Smith, F., Carr, M., Panton, S., 2011. Polychlorinated naphthalenes (PCNs) in Irish foods: Occurrence and human dietary exposure. Chemosphere 322328.

Fernandes, A.; Rose, M.; Smith, F; Holland, J. 2012. Organic environmental contaminants in the 2012 Total Diet Study samples. Food Standards Agency Report, Ava.'^ble at:

https://www.food.gov.uk/sites/default/files/media/document/resear 'h_r aport-total-diet-study.pdf (Last accessed October 2019).

Fernandes, A.R.; Mortimer, D.; Wall, R.J.; Bell, D.F. · Rc se, M.; Carr, M.; Panton, S.; Smith, F., 2014. Mixed halogenated dioxins/furans (PXDD/Fs) is biphenyls (PXBs) in food: Occurrence and toxic equivalent exposure using specific relativ^ nc'ancies. Environ. Int., 73, 104-110.

Fernandes, A.; Mortimer D.; Rose, M.; S. ith, F., Turford, Z.; Panton S., 2016. The occurrence of new or candidate Stockholm POPS in fnoc. Organohalogen Compd. 78, 508-511.

Fernandes, A.; Rose, M; Faland „л >. _., 2017. Polychlorinated naphthalenes in food and humans. Environ. Int. 104, 1-13.

Fernandes, A.; Mortimer. L. Fose, M.; Smith, F.; Steel, Z.; Panton, S., 2019a. Recently Listed Stockholm Convention PC.? $\mathrm{s}$ : .....alytical methodology, occurrence in food and dietary exposure. Sci. Tot. Environ., 678, 793-800.

Fernandes, A.R.; Lake. I.R.; Dowding, A.; Rose, M.; Jones, N.R.; Petch, R.; Smith, F., Panton, F., 2019b. The potential of recycled materials used in agriculture to contaminate food through uptake by livestock. Sci. Total. Environ. 667, 359-370.

Fernandes, A., Falandysz, J., Olivero-Verbel, J., 2020. Editorial: A new focus on legacy pollutants: Chlorinated Paraffins (CPs) and Polychlorinated Naphthalenes (PCNs). Chemosphere 238, 124580 https://doi.org/10.1016/j.chemosphere.2019.124580

Fries, G.F, 1996. Ingestion of sludge applied organic chemicals by animals. Sci. Total Environ. 185, 93-108. doi:10.1016/0048-9697(96)05045-0. 
Ganci, A.P.; Vane, C.H.; Abdallah, M.A.E.; Moehring, T.; Harrad, S., 2019. Legacy PBDEs and NBFRs in sediments of the tidal River Thames using liquid chromatography coupled to a high resolution accurate mass Orbitrap mass spectrometer. Sci. Total Environ. 658, 1355-1366.

Garcia Lopez, M.; Driffield, M.; Fernandes, A.R.; Smith, F.; Tarbin, J.; Lloyd, A.S.; Christy, J. Holland, M.; Steel, Z.; Tlustos, C., 2018. Occurrence of polybrominated diphenylethers, hexabromocyclododecanes, bromophenols and tetrabromobisphenols $\mathrm{A}$ and $\mathrm{S}$ in Irish foods. Chemosphere 197, 709-715.

Ghisi, R.; Vamerali, T.; Manzetti, S., 2019. Accumulation of perfluorinated alkyl substances (PFASs) in agricultural plants: a review. Environ. Res. 169, 326-341.

Glüge, J.; Wang, Z.; Bogdal, C.; Scheringer, M.; Hungerbïhı ^r K., 2016. Global production, use, and emission volumes of short-chain chlorinated paraffi is - ¿ minimum scenario. Sci. Total Environ. 573, 1132e1146. doi: 10.1016/j.scitotenv.2016.C3.10 J

Gong, Y.; Zhang, H.; Geng, N.; Ren, X.; Giesy u ग.; Luo, Y.; Xing, L.; Wu, P.; Yu, Z.; Chen, J., 2019. Short-chain chlorinated paraffins (SCCP^) G - rupt hepatic fatty acid T metabolism in liver of male rat via interacting with peroxisome prolife, 'tor- activated receptor a (PPARa). Ecotox. Environ. Safe. 181, 164-171.

Green Alliance, 2007. The Nutri, + ${ }^{+}$, , vle: Closing the Loop. Green Alliance, London.

Grossman, E., 2013. Nonlega v P PBBs: pigment manufacturing by-products get a second look. Environ. Health Persp. 121, A8\%.19';.

Gupta, H., 2017. PAı : x:こ, mination in effluent and sludge samples of paper industry. Env. Tech and Innov. 9, 115-121.

Hansen, N.; Schenk, M.; Moshammer, K.; Kohse-Hoinghaus, K., 2017. Investigating repetitive reaction pathways for the formation of polycyclic aromatic hydrocarbons in combustion processes. Combust. Flame, 180. 250-261.

IC Consultants, 2001. Pollutants in Urban Wastewater and Sewage Sludge. Final Report to Directorate General Environment, European Commission. http://ec.europa.eu/environment/waste/ sludge/pdf/sludge_pollutants.pdf.

Jones, V.; Gardner, M.; Ellor, B., 2014. Concentrations of trace substances in sewage sludge from 28 wastewater treatment works in the UK. Chemosphere, 111, 478-484. 
Kajiwara, N.; Desborough, J.; Harrad, S.; Takigami, H., 2013. Photolysis of brominated flame retardants in textiles exposed to natural sunlight. Environ. Sci.: Processes Impacts 15, 653-660.

Knoth, W.; Mann, W.; Meyer, R.; Nebhuth, J., 2007. Polybrominated diphenyl ether in sewage sludge in Germany. Chemosphere, 67, 1831-1837.

Kupper, T.; Brändli, R.; Bucheli, T.; Stämpfli, C.; Zennegg, M.; Berger, U.; Edder, P.; Pohl, M.; Niang, F.; lozza, S.; Müller, J.; Schaffner, C.; Schmid, P.; Huber, S.; Ortelli, D.; Becker-van Slooten, K.; Mayer, J.; Bachmann, H.; Stadelmann, F.; Tarradellas, J., 2008. Organic pollutants in compost and digestate: occurrence, fate and impacts. In: Fuchs, J.G., Kupper, T., Tamm, L., Schenk, K. (Eds.), Compost and Digestate: Sustainability, Benefits, Impacts for $\mathrm{i}^{\circ} \bullet$ Environment and for Plant Production. Proceedings of the International Congress CODIS2nc? c witzerland, 2008.

Liu G, Cai Z, Zheng M., 2014. Sources of unintentional y pizduced polychlorinated naphthalenes. Chemosphere, 94, 1-12.

Lloyd, A.S; Bailey, V.A.; Hird, S.J.; Routledge, ․ Clarke, D.B., 2009. Mass spectral studies towards more reliable measurement of perfluornx. эnesulfonic acid and other perfluorinated chemicals (PFCs) in food matrices using liquia hromatography/tandem mass spectrometry. Rapid Commun. Mass Spec. 23, 2923-2938.

Mark, F.E.; Vehlow, J.; Dresch, ' ‥ L...na, B.; Gruttner, W.; Horn, J., 2015. Destruction of the flame retardant hexabromocyclodo ecarıe in a full-scale municipal solid waste incinerator. Waste Manage. Res. 33, 165-174.

Moorthy, B.; Chu, C., Fia.:.: I, D.J., 2015. Polycyclic Aromatic Hydrocarbons: from metabolism to lung cancer. Toxicol Sci. 140(1): 5-15.

Nakao, T.; Ohta, S.; Aozasa, O.; Miya, 2002. Investigation of PCDD/Fs, PBDD/Fs, PBCDD/Fs and nitro-PAHs detected in flue gas from waste incinerators. Organohalogen Compd. 56, 349-352.

Needham, T.P.; Ghosh, U., 2019. Four decades since the ban, old urban wastewater treatment plant remains a dominant source of PCBs to the environment. Environ. Poll. 246, 390-397.

Nicholson, F.; Metcalfe, P.; Gale, P.; Taylor, M.; Tompkins, D.; Tyrrel, S.; Longhurst, P.; Weeks, J.; Hough, R., 2016. Identification and prioritisation of risks to food safety and quality associated with the use of recycled waste-derived materials in agriculture and other aspects of food production. 
FS301020, Final report to the Food Standards Agency. Available at:

https://www.food.gov.uk/print/pdf/node/352 (Last accessed August 2019).

North, K.D., 2004. Tracking polybrominated diphenyl ether releases in a wastewater treatment plant effluent, Palo Alto, California. Environ. Sci. Technol., 38, 4484-8.

Posner, S., 2013. Per and Polyfluorinated Substances in the Nordic Countries. Nordic Council of Ministers, Copenhagen, 225 pp.

Qiao, W.; Zhang, Y.; Xie, Z.; Luo, Y.; Zhang, X.; Sang, C.; Xie, S.; Huang, J., 2019. Toxicity of perfluorooctane sulfonate on Phanerochaete chrysosporium: Growth, pollutant degradation and transcriptomics. Ecotox. Environ. Safe. 174, 66-74.

Ren, M.; Peng, P., Cai, Y.; Chen, D.; Zhou, L.; Chen, P.; ' '.' ن., 2011. PBDD/F impurities in some commercial deca-BDE. Environ. Poll. 159, 1375-138C.

Rodenburg, L.A.; Dewani, Y.; Häggblom, M.M.; Keı, hof, L.J.; Fennell, D.E., 2017. Forensic Analysis of Polychlorinated Dibenzo-p-Dioxin and Fı ra.1 Fingerprints to Elucidate Dechlorination Pathways. Environ. Sci. Technol. 51, 18, 1049 ־ 'Vi93.

Rose, M.; White, S.; Macarthur, R.; Petch, Q.G.; Holland, J.; Damant, A.P., 2007. Singlelaboratory validation of a GC/MS method $: r$ tı a determination of 27 polycyclic aromatic hydrocarbons (PAHs) in oils and fats. Food Addit. Conı.? . 6, 635-651.

Rigby, H.; Dowding, A.; Fer``arı'os, A.; Humphries, D.; Petch, R.G.; Reynolds, C.K.; Rose, M.; Smith, S.R., 2015. Organic cr minnmant content and physico-chemical characteristics of waste materials recycled in agriculı re. Agriculture 5(4), 1289-1328. DOI:10.3390/agriculture5041289.

Rigby, H.; Fernandes, A.; Humphries, D.; Petch, R.G.; Rautiu, R; Reynolds, C.K.; Rose, M.; Smith, S.R., 2018. Investigation of the Potential Transfer and Uptake of Contaminants into Food Arising from the use of Recycled Waste in Agriculture. Food Standards Agency Project FS102009b.

Ryan, J.J., 1983. Higher chlorinated dioxins implicated in the mortality of young pigs kept on apentachlorophenol-treated wooden floor. Can. Vet. J. 24(3), 72-75.

Saveyn, H.; Eder, P., 2014. End-of-Waste Criteria for Biodegradable Waste Subjected to Biological Treatment (Compost \& Digestate): Technical Proposals; Publications office of the European Union, Luxembourg. 
Schowanek, D.; David, H.; Francaviglia, R.; Hall, J.; Kirchmann, H.; Krogh, P.H.; Schraepen, N.; Smith, S.; Wildemann, T., 2007. Probabilistic risk assessment for linear alkylbenzene sulfonate (LAS) in sewage sludge used on agricultural soil. Regul. Toxicol. Pharm. 49, 245-259. doi:10.1016/j.yrtph.2007.09.001.

Semple, KT; Reid, BJ; Fermor, TR, 2001. Impact of composting strategies on the treatment of soils contaminated with organic pollutants. Environ. Poll. 112, 269-283.

SEPA: Scottish Environment Protection Agency, 2015. Technical Guidance Note: Paragraph 8(2) Exemption. The Storage and Spreading of Sludge on Non-Agricultural Land. Available at: https://www.sepa.org.uk/media/105222/the-storage-and-spreading-vi cludge-technical-guidancenote-for-paragraph-8-exemptions.pdf (Last accessed September ¿11 $)$ ).

SI: Statutory Instrument, 1989. No. 1263 The Sludge (I/st ... Agriculture) Regulations 1989. HMSO, London, UK.

SI: Statutory Instrument, 1993. The Environme . .I Protection (Controls on Injurious Substances) Regulations No. 1 1993. HMSO, I nni'n, UK.

SI: Statutory Instrument, 2016. No. $114^{\circ}$ he Environmental Permitting (England and Wales) Regulations 2010. HMSO, London, UK.

Smith, S.R., 2009. Organic cont ${ }_{\mu}$ iriults in sewage sludge (biosolids) and their significance for agricultural recycling. Philos. T. Ro, э/ Suc. A 367, 3871-3872.

Smith, S.R.; Riddell-Black, ? 2007. Sources and Impacts of Past, Current and Future Contamination of Soil. App nu.:. L: Organic contaminants. Final Report to Defra. Available at: http://randd.defra.gov.uk/Document.aspx?Document=SP0547_7266_FRA.pdf (Last accessed June 2018).

Söderström, G.; Marklund, S., 2004. Formation of PBCDD and PBCDF during flue gas cooling. Environ. Sci. Technol. 38,825-830.

Stretton-Maycock, D.; Merrington, G., 2009. The Use and Application to Land of MBT Compostlike output - Review of Current European Practice in Relation to Environmental Protection. Science Report - SC030144/SR3. Environment Agency, Bristol. Available at: https://assets.publishing.service.gov.uk/government/uploads/system/uploads/attachment_data/file/29 1682/scho0109bpfn-e-e.pdf (Last accessed: August 2020). 
UKSHS: UK Soil and Herbage Pollutant Survey, 2007. Environmental Concentrations of Polychlorinated Biphenyls (PCBs) in UK Soil and Herbage. Environment Agency, Oxon, UK.

US ATSDR: Agency for Toxic Substances \& Disease Registry, 2013. ATSDR’s

Substance Priority List Available at: http://www.atsdr.cdc.gov/spl/ (Last accessed August 2019).

UN: United Nations Treaty Collection, 2001. Chapter XXVII Environment. 15 tockholm Convention on Persistent Organic Pollutants. Stockholm, 22 May 2001.

UNEP: United Nations Environment Programme, 2019. Draft risk management evaluation: perfluorohexane sulfonic acid (PFHxS), its salts and PFHxS-related compounds. Persistent Organic Pollutants Review Committee Fifteenth meeting. Rome, 1-4 Octobє1 ?019.

US ATSDR: Agency for Toxic Substances and Disease Rea, ${ }^{-t r}$, , 2015. Public Health Statement Hexachlorobenzene. Available at: https://www.atsdr.cdc.gov, Гo..-. ofiles/tp90-c1-b.pdf (Last accessed August 2019).

Van den Berg, M.; Birnbaum, L.S.; Denison, M., ᄀe Vito, M.; Farland, W.; Feeley, M.; Fiedler, H.; Hakansson, H.; Hanberg, A.; Haws, L.; Rocn I' : Safe, S.; Schrenk, D.; Tohyama, C.; Tritscher, A.; Tuomisto, J.; Tysklind, M.; Walker, N.; Pett. :on, R.E., 2006. The 2005 World Health Organization reevaluation of human and mammalian Tnxı ᄃquivalency Factors for dioxins and dioxin-like compounds. Toxicol. Sci. 93(2), 223-_:-1.

van der Drift., A.; van Doorn, ' : Vermeulen, J.W., 2001. Ten residual biomass fuels for circulating fluidized-bed gasificali n Biomass Bioenerg. 20, 45-56.

van Mourik, L.M.; Ga. '`, こ., Leonards, P.E.G.; de Boer, J., 2016. Chlorinated paraffins in the environment: a review on their production, fate, levels and trends between 2010 and 2015. Chemosphere 155, 415e428. doi: 10.1016/j.chemosphere.2016.04.037.

Venkatesan, A.K.; Halden, R.U., 2014. Contribution of polybrominated dibenzo-p-dioxins and dibenzofurans (PBDD/Fs) to the toxic equivalency of dioxin-like compounds in archived biosolids from the US EPA's 2001 National Sewage Sludge Survey. Environ. Sci. Technol. 48, 10843-10849.

Vetter, W.; Bendig, P.; Blumenstein, M.; Hägele, F.; Behnisch, P.A.; Brouwer, A., 2015. Formation of polybrominated dibenzofurans (PBDFs) after heating of a salmon sample spiked with decabromodiphenyl ether (BDE-209). Environ. Sci. Poll. Res., 22, 14530-14536. 
Wall, R., 2012. Potency and Species Specificity of Aryl Hydrocarbon Receptor Ligands. PhD thesis UK: University of Nottingham. Available at:

https://www.food.gov.uk/sites/default/files/media/document/813-1-

1487_FS201013_T01034_Final_report.pdf (Last accessed August 2019).

Wang, R.; Tanga, T.; Xie, J.; Tao, X.; Huang, K.; Zou, M.; Yin, Y.; Dang, Z.; Lu, G., 2018. Debromination of polybrominated diphenyl ethers (PBDEs) and their conversion to polybrominated dibenzofurans (PBDFs) by UV light: Mechanisms and pathways. J. Hazard. Mat. 354, 1-7.

Wang, D.; Chen, T.; Fu, Z.; Yang, L.; Li, R.; Sui, S.; Wang, Y.; Shi, Z., 2019. Occupational exposure to polybrominated diphenyl ethers or decabromodiphenyl $s$ : hane during chemical manufacturing: Occurrence and health risk assessment. Chemosı. ho' 2 231, 385-392.

WHO: World Health Organization, 1998. Polybrominatt d ü. Environmental Health Criteria 205. Available at: http://www.inchem.org/documents/ehc/ehc/ehc205.r’... (Last accessed June 2018).

Worrall, K.; Hancock, P.; Fernandes, A.; nriı. 'eld, M.; Rose, M., 2008. Application Note: Utilising the speed and resolution of UPLC to enhance. e MS/MS detection of HBCD and TBBP-A diasteromers. Available at: http://www.water - som/waters/library.htm?cid=511436\&lid=10009295 (Last accessed October 2019).

WRAP, 2012a. Poultry Litter ; sh. End of Waste Criteria for the Production and Use of Treated Ash from the Incineration of Pouiv'v' 'itter, Feathers and Straw. Environment Agency and WRAP. Available at:

https://assets.publishing.servıce.gov.uk/government/uploads/system/uploads/attachment_data/file/29 6435/geho0812bwpk-e-e.pdf (Last accessed June 2018).

WRAP, 2012b. PAS 111: 2012 Specification for the requirements and test methods for processing waste wood. Waste and Resources Action Program. Available at: http://www.organicsrecycling.org.uk/uploads/article2273/PAS111.pdf (Last accessed June 2018).

Yamashita, N.; Taniyasu,S.; Hanari, N.; Horii, Y.; Falandysz, J., 2003. Polychlorinated naphthalene contamination of some recently manufactured industrial products and commercial goods in Japan. J. Environ. Sci. Heal. A 38, 1745-1759. 
Yang, J.; Yu, H.; Xie, Z.; Yang, Y.; Zheng, X.; Zhang, J.; Huang, Q; Wen, T.; Wang, J., 2020.

Pathways and influential factors study on the formation of PBDD/Fs during co-processing BDE-209 in cement kiln simulation system. Ecotoxicol. Environ. Saf. 192, 110246.

Zacs, D.; Rjabova, J., Fernandes, A.; Bartkevics, V., 2016. Brominated, chlorinated and mixed brominated/chlorinated persistent organic pollutants in European eels (Anquilla anquilla) from Latvian lakes. Food. Addit. Contam. A. 33, 460-472.

Zennegg, M; Munoz, M.; Schmid, P.; Grecke, A.C., 2013. Temporal trends of persistent organic pollutants in digested sewage sludge (1993-2012). Environ. Int. 60, 202-208.

Zennegg, M.; Schluep, M.; Streicher-Porte, M.; Lienemann, P., '-łaag, R.; Gerecke, A.C., 2014.

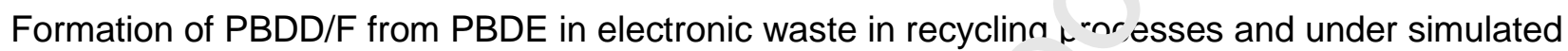
extruding conditions. Chemosphere 116, 34-39.

Zhang, K.X; Liu, J.; Wang, T.; Liu, G. Wang, Y.; Jič' 'q, (., 2014. Polychlorinated naphthalenes in sewage sludge from wastewater treatment plants '.. Thina. Sci. Total Environ. 490, 550-560.

Zhang, M.; Buekens, A.; Li, X., 2016. Dišins from biomass combustion: An overview. Waste Biomass Valor. 8(1), 1-20. doi: 10.1007/s1264` n16-9744-5 


\section{Declaration of interests}

$\square$ The authors declare that they have no known competing financial interests or personal relationships that could have appeared to influence the work reported in this paper.

$\bigotimes$ The authors declare the following financial interests/personal relationships which may be considered as potential competing interests:

Alan Dowding, co-author, is also an employee of the Food Standards Agency who funded the research. He was involved in the selection of contaminants for analysis, and in reviewing and editing the paper. 
Credit author statement - apologies I will deliver this separately as it will need to be agreed by all the authors, some of whom are currently unavailable. 


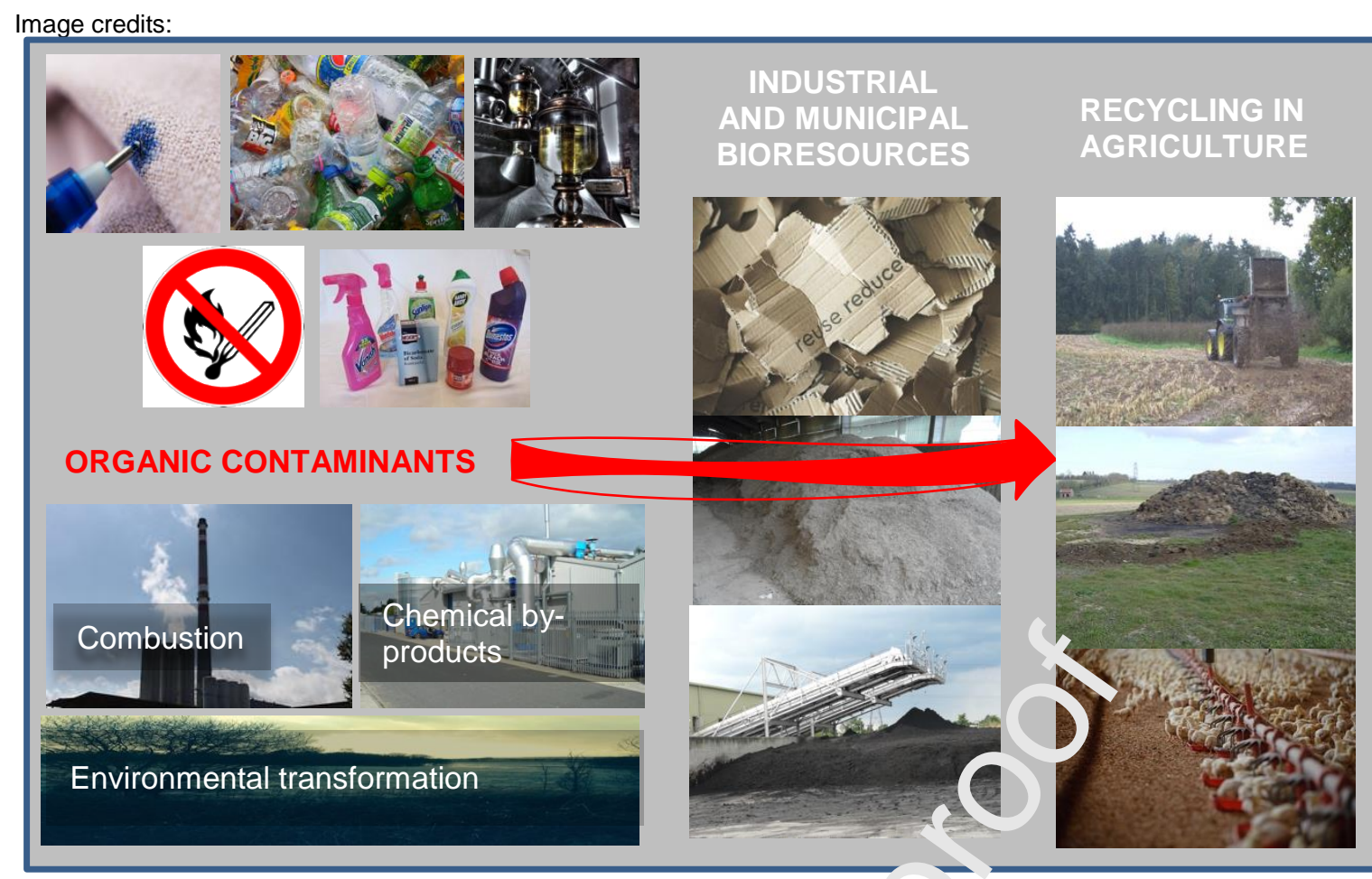

Ink stain: Image by Rajiv Kumar from Pixabay

Plastic bottles: Image by lan L from publicdomainpictures.net

Lubricating oil: Image by TheoRivierenlaan from Pixabay

No open flames: Image by Openlcons from Pixabay

Household products: Image by Meganbeckett27 (license)

Combustion: "Teplárna a spalovna Liberec; Heating and incineratior. : lant Lıberec" by Da4Sal is licensed under CC BY 2.0

Chemical by-products: Attribution-ShareAlike 2.0 Generic (CC sY- 'A ' ' . .' license (Original image was cropped)

Environmental transformation: Image by Hannah Rigby, Impc ial $C$ נllege London

Shredded cardboard: CCO public domain

Compost like output stockpile: Image by Hannah Rigby, Imperial Cu.iege London

Biosolids at treatment works: Image by Hannah Rigby, Imp rial College London

Recycling in Agriculture: Spreading biosolids: Image by $\Gamma-v i d$. 'Imphries, University of Reading

Biosolids stockpile: Image by Graham Horn (license)

Broiler chickens: This image was originally posted to Flicl $r$ r / usdanrcstexas at https://flickr.com/photos/139446213@N03/25112103855. It

was reviewed on 4 May 2018 by FlickreviewR 2 an ( Wa. sonfirmed to be licensed under the terms of the cc-by-2.0. 
- Bioresources spread on agricultural soil or used as livestock bedding were sourced

- A selection of priority organic contaminants relevant to human health were measured

- Brominated contaminants were more significant than some legacy chlorinated types

- Polychlorinated alkanes and phthalates were present in the largest amounts

- Continued vigilance is required to minimise sources of organic contaminants 